\title{
GLOBAL MENTAL HEALTH IN AN ERA OF SUSTAINABLE DEVELOPMENT: RESEARCH AND POLICY PRIORITIES
}

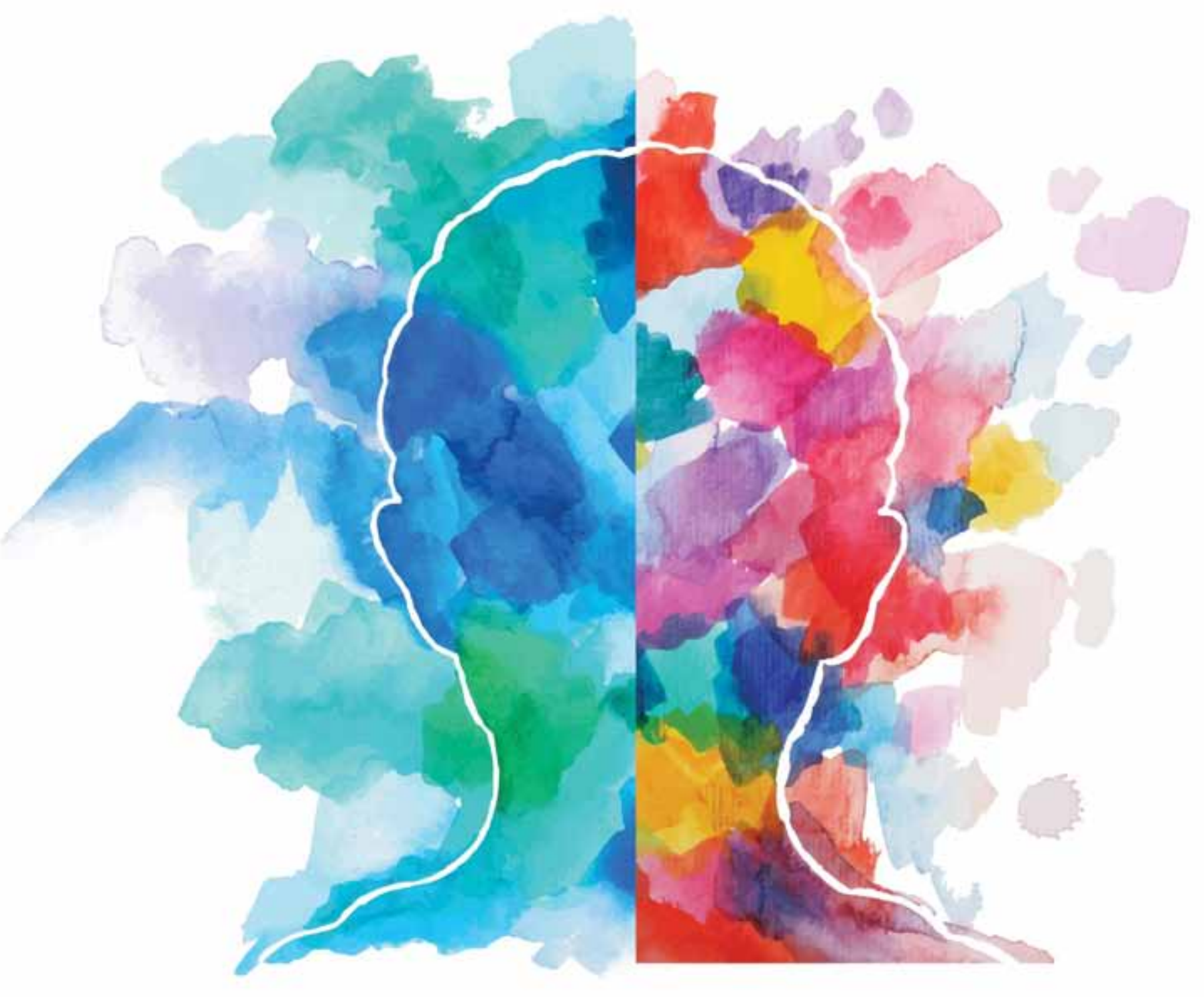

science

\& technology

Department:

Science and Technology REPUBLIC OF SOUTH AFRICA
Leopoldina

Nationale Akademie der Wissenschafter 
(c) Academy of Science of South Africa

J a nuary 2020

ISBN 978-1-928496-25-0

DOI http://dx.doi.org/10.17159/a ssaf.2019/0060

Cite:

Academy of Science of South Africa (ASSAf), (2020). G lobal Mental Health in an Era of Susta ina ble Development: Research and Polic y Prionities Symposium Proceedings

DOI http://dx.doi.org/10.17159/assaf.2019/0060

Published by:

Academy of Science of South Afric a (ASSAf)

PO Box 72135, Lynnwood Ridge, Pretoria, South Afric a, 0040

Tel: +27123496600 • Fax: +27865769520

E-mail: admin@assaf.org.za

Reproduction is permitted, provided the source and publisher are appropriately acknowledged.

The Academy of Sc ience of South Afric a (ASSAf) was inaugurated in May 1996. It was formed in response to the need for an Academy of Science consonant with the dawn of democracy in South Africa: activist in its mission of using science and scholarship for the benefit of society, with a mandate encompassing all schola rly disciplines that use an open-minded and evidence-based approach to build knowledge. ASSAf thus, adopted in its name the tem 'science' in the singularas reflecting a common way of enquiring rather than an aggregation of different disc iplines. Its Members a re elected based on a combination of two principal criteria, academic excellence and signific ant contributions to soc iety.

The Parliament of South Africa passed the Academy of Science of South Afric a Act (No 67 of 2001), which came into force on 15 May 2002. This made ASSAf the

only academy of science in South Afric a officially recognised by govemment and representing the country in the intemational community of science academies and elsewhere.

This report reflects the proceedings of G lobal Mental Health in an Era of Susta inable

Develo pment: Research and Polic y Priorities Symposium Proceedings held at St George's Hotel, Pretoria.

Views expressed are those of the individuals and not necessarily those of the Academy nor a consensus view of the Academy based on an in-depth evidence-based study. 


\section{TABIE OF CONTIENTS}

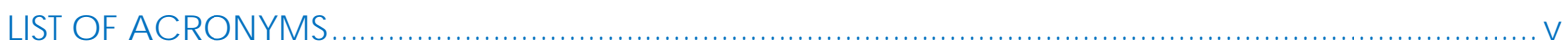

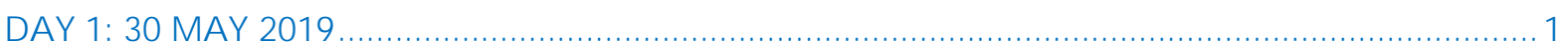

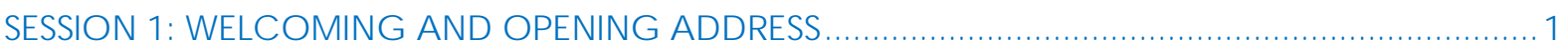

Welcome remarks (Mr Stanley Maphosa, Intemational and National Liaison Manager,

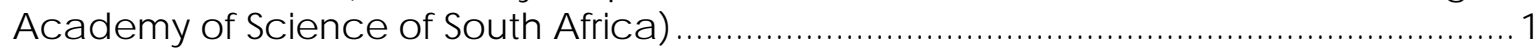

Welcome remarks (Prof Frank Rösler, Leopoldina Board Member and Senior Professor, Biologic al Psychology and Neuro psyc hology, University of Hamburg, Gemany) .......... 1

Addressing mental health disorders in the Afric an Region (Dr Steven Shongwe, Acting Director, Non-communic able Diseases, World Health Organisation Regional Office for Africa).....

Global mental health and the Susta inable Development Goals: aligning the research and policy agendas (Prof Crick Lund, Alan J Flisher Centre for Public Mental Health, Department of Psychiatry and Mental Hea Ith, University of Cape Town) .....

Keynote address (DrYogan Pillay, DDG: Health Programmes, Department of Health, South Africa)

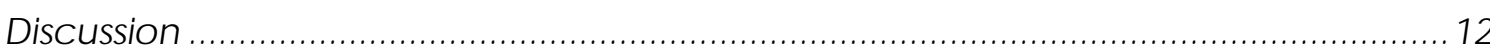

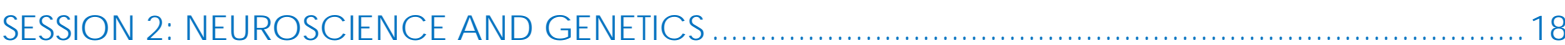

Mental health research priorities in South Afric a: Should we include neurogenetic s? (Prof Dan Stein, Head, Department of Psychiatry and Mental Health, University of Cape Town, South Afric a).

Breakthrough in understanding the molecular causes of psychiatric disorders (Prof Markus Nöthen, Director, Institute of Human Genetic s, University Ho spital of Bonn, Gemany).

China brain project and macaque models for biomedic al research (Prof Mu-ming Poo, Director, Institute of Neuroscience, Chinese Aca demy of Sciences, China).

Family studies from endogamous groups enable the eluc idation of distinct predisposing pathways in dyslexia (Prof Subrata Sinha, All India Institute of Medical Sc iences, New Delhi, India) .....

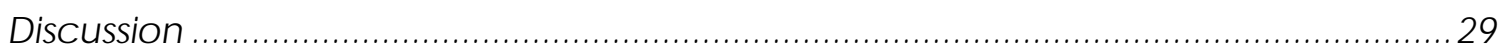

SESSIO N 3: PUBLC MENTAL HEALTH AND EPIDEMIOLOGY

Common mental disorders a mong individuals seeking HIV testing (Prof Ashraf Kagee, Co-Director, Centre for Public Mental Health, University of Stellenbosch, South Afric a)

Addressing the challenge of mental disorders: genetic approaches to nosology, a etiology, and treatment (Prof Marc ella Rietschel, Sc ientific Director, Department of Genetic Epidemiology in Psychiatry, Central Institute of Mental Health, Gemany), Faculty of Medic ine Mannheim, University of Heidelberg

Priorities of mental health public policy in Portuguese-speaking countries from Africa and South America: how to build nationwide care systems in contexts of social inequa lities, vulnerability and sc arcity (Prof Pedro Gabriel Delga do, Institute of Psyc hiatry, Federal University of Rio de J a neiro - UFRJ , Rio de J a neiro, Brazil) 
Adolescent substance abuse trends: the need for early identific ation (Prof Arvin Bhana, Chief Research Specia list, Health Systems Research Unit, South Afric an Medical

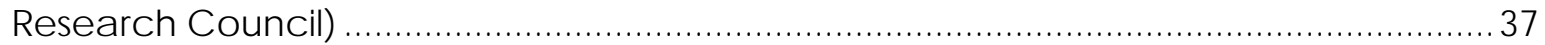

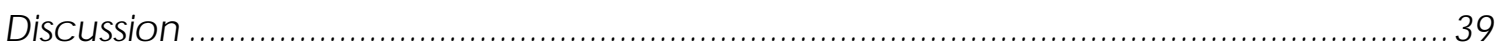

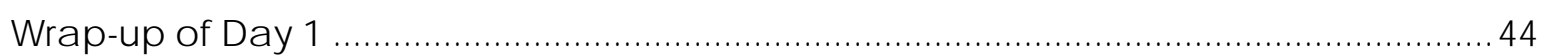

Prof Frank Rösler, Senior Professor, Biological Psychology and Neuropsychology, University of Ha mburg

Prof Crick Lund (Alan J Flisher Centre for Public Mental Health, Department of Psyc hiatry and Mental Health, University of Cape Town)............................................ 45

Provider core competencies for improved mental healthcare of the nation: a consensus study (Prof Rita Thom, University of the Witwatersrand, South Africa)

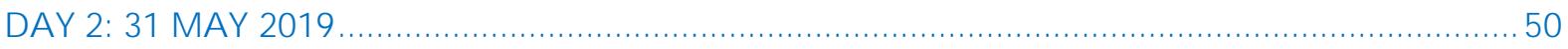

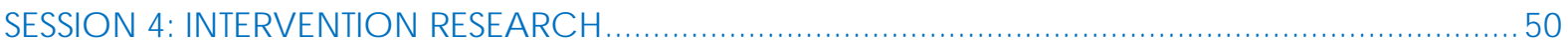

Using intervention research to drive evidence-based integration of mental hea th into primary hea lthcare settings in So uth Arica (Prof Inge Petersen, Centre for Rural Health, University of KwaZulu-Natal, South Afric a ).....

Providing sc reening, brief intervention and referral to treatment (SBIRT) for substance use disorders into South Africa's primary healthca re services: lessons from local research (Prof Bronwyn Myers, Chief Specia list Sc ientist: Alcohol, Tobacco and Other Drug Research Unit, South Afric an Medical Research Council)

Overcoming trauma and violence: from individual tra uma narratives to communitybased intervention in war-tom regions (Prof Thomas Elbert, Professor of Clinic al Psychology and Neuropsychology, University of Konstanz, Gemany) ...........................57

Disc ussion

SESSIO N 5: BREAK-AWAY: IDENTIFYING PO LCY AND RESEARCH PRIORITIES IN MENTAL HEALTH62

Group 1: Neuroscience and Genetics (Rapporteur: Prof Dan Stein, UCT)

Group 2: Public Mental Health and Epidemiology (Rapporteur. Ms Ravhengani Machaka, Sefako Makgatho University)

Group 3: Intervention Research (Rapporteur: Dr Gayle Langley, University of the Witwa tersrand)....

Disc ussion

SESSIO N 6: RESEARC H SUPPO RT: FUNDERS

NRF funding opportunities for mental health research (MsTracy Kla renbeek, Director: Knowledge Advancement and Support, National Research Foundation, South Africa)

SAMRC funding for mental health research (Prof Rachel J ewkes, Executive Sc ientist: Research Strategy, South Afric an Medic al Research Counc il).

Janssen/J \&J global public health support for mental health programmes in South Africa (Ms Abeda Williams, Senior Director Technic al and Medical Affa irs, J anssen Pha mac eutica, South Afric a)

Disc ussion

Wrap-up and closure of symposium 
Prof Crick Lund (Alan J Flisher Centre for Public Mental Health, Department of Psychiatry .....

and Mental Health, University of Cape Town)

Prof Frank Rösler (Senior Professor, Biologic al Psychology and Neuropsychology, University of Ha mburg)

Figure 1: WHO service organisation pyramid for an optimal mix of servic es for mental health. 4 Figure 2: Overlapping region between BASP1 and LOC285696. 


\section{USTOF ACRONYMS}

\begin{tabular}{|c|c|}
\hline ADHD & Attention Defic it Hyperactivity Disorder \\
\hline AIDS & Acquired Immune Defic iency Syndrome \\
\hline ART & Antiretroviral therapy \\
\hline ASSAf & Academy of Science of South Afric a \\
\hline ATTC & Addiction Technology Transfer Programme \\
\hline AUD & Alcohol Use Disorder \\
\hline AUDT & Alcohol Use Disorders Identific ation Test \\
\hline BAI & Beck Anxiety Inventory \\
\hline $\mathrm{BDI}$ & Beck Depression Inventory \\
\hline $\mathrm{BMI}$ & Body Mass Index \\
\hline BPsych & Bachelor of Psychology \\
\hline BRICS & Brazil, Russia, India, China and South Africa \\
\hline CBR & Community-based Rehabilitation \\
\hline CBT & Cognitive Behavioural Therapy \\
\hline $\mathrm{CHW}$ & Community Health Worker \\
\hline CMD & Common Mental Health Disorder \\
\hline CMSA & Colleges of Medic ine of South Afric a \\
\hline CNV & Copy Number Variation \\
\hline DDG & Deputy Director-General \\
\hline DFID & UK Department for Intemational Development \\
\hline DoH & South Afric an Department of Health \\
\hline DRD2 & D2 Dopamine Receptor \\
\hline DRC & Democratic Republic of the Congo \\
\hline DSM & Dia gnostic and Statistical Ma nual of Mental Disorders \\
\hline DST & Department of Science and Technology \\
\hline ECG & Elec trocardiography \\
\hline EMU & Extramural Unit \\
\hline GAD & Generalised Anxiety Disorder \\
\hline $\mathrm{GCl}$ & Global Community Impact \\
\hline GDP & Gross Domestic Product \\
\hline GIPD & SAMRC Grants, Innovation and Product Development Unit \\
\hline GWAS & Genome-Wide Association Study \\
\hline H3Africa & Human Heredity and Health in Africa \\
\hline HDI & Historic a lly Disa dva nta ged Institution \\
\hline HIV & Human Immunodefic iency Virus \\
\hline $\mathrm{HSCL}$ & Hopkins Symptom Checklist \\
\hline HSRC & Human Sciences Research Council \\
\hline ICD & Intemational C lassific ation of Disea ses \\
\hline ICF & Intemationa I C lassific a tion of Func tioning, Disa bility and Health \\
\hline ICT & Information and Communications Technology \\
\hline IOM & US Institute of Medic ine \\
\hline J \& & J ohnson \& J ohnson \\
\hline $\mathrm{KO}$ & Knock-out \\
\hline$K Z \mathbb{N}$ & KwaZulu-Natal \\
\hline LMIC & Low- or middle-income Country \\
\hline MAOA & Monoamine Oxidase $\mathrm{A}$ \\
\hline MDD & Major Depressive Disorder \\
\hline mhGAP & WHO Mental Health Gap Action Programme \\
\hline MNS & Mental, Neurological And Substance Use \\
\hline MoU & Memorandum of Understanding \\
\hline MRI & Magnetic Resonance Imaging \\
\hline
\end{tabular}




\begin{tabular}{|c|c|}
\hline mRNA & messenger RNA \\
\hline NeuroGAP & Neuropsychiatric Genetic s of Afric an Populations \\
\hline NGO & Non-govemment Organisation \\
\hline $\mathrm{NHI}$ & National Health Insurance \\
\hline NIDS & National Income Dynamics Study \\
\hline NIH & US National Institutes of Hea Ith \\
\hline NRF & National Research Foundation \\
\hline PET & Positron emission tomography \\
\hline PGC & Psychiatric Genomic s Consortium \\
\hline PHN & Primary Healthcare \\
\hline PRIME & Programme for Improving Mental Healthcare \\
\hline PRS & Polygenic Risk Scores \\
\hline PTSD & Post-Traumatic Stress Disorder \\
\hline$R \& D$ & Research and Development \\
\hline RE-AIM & Reach, Effectiveness, Adoption, Implementation, Ma intenance \\
\hline REM & Rapid Eye Movement \\
\hline SACENDU & South Afric an Community Epidemiology Network on Drug Use \\
\hline SADC & Southem African Development Community \\
\hline SAHRC & South Afric an Human Rights Commission \\
\hline SAMRC & South African Medical Research Council \\
\hline SARChl & South Afric an Research Cha irs Initia tive \\
\hline SBIRT & Screening, Brief Intervention and Referral to Treatment \\
\hline SCID & $\begin{array}{l}\text { Struc tured Clinical Interview for the Diagnostic and Statistic al Manual of } \\
\text { Mental Disorders }\end{array}$ \\
\hline SDG & Susta ina ble Development Goal \\
\hline S-MhINT & Southem African Research Consortium for Mental Health Integration \\
\hline SNP & Single-nucleotide Polymorphism \\
\hline SSRI & Selec tive Serotonin Reuptake Inhibitor \\
\hline SU & Stellenbosch University \\
\hline SVRI & Sexual Violence Research Initiative \\
\hline TB & Tuberculosis \\
\hline UCT & University of Cape Town \\
\hline U & University of J oha nnesb urg \\
\hline UK & United Kingdom \\
\hline UKZN & University of KwaZulu-Natal \\
\hline UN & United Nations \\
\hline UNAIDS & J oint United Nations Programme on HIV/AIDS \\
\hline UNICEF & United Nations Child ren's Fund \\
\hline US/ USA & United States of Americ a \\
\hline USAID & US Agency for Intemational Development \\
\hline WBOT & Ward-based Outreach Team \\
\hline WHO & World Health Organisation \\
\hline Wits & University of the Witwatersrand \\
\hline
\end{tabular}


SESSION 1: WELCOMING AND OPENING ADDRESS

Facilitator: Prof Rita Thom, Department of Psychiatry, University of the Witwatersrand, South Afric a

\section{Welc ome remarks (Mr Stanley Maphosa, Intemational and National Liaison Manager, Academy of Science of South Africa)}

MrMaphosa opened the meeting and welc omed everyone. The Aca demy of Science of South Africa (ASSAf) has a lmost 600 members, who a re selected on merit. ASSAf brings its members togetheras a consortium or 'think ta nk' of top sc ientists to offer evidence-ba sed science policy advice to govemment. ASSAf has realised this mandate through the many studies that it has conducted.

In August 2013, ASSAf entered into a partnership with the German National Academy of Sc iences Leopold ina by signing a bilateral memorandum of understanding (MoU), which was renewed for a further five years in April 2018. The partnership with Leopoldina has resulted in several joint a c tivities, including:

- Symposium on Tec hnologic al Innovations for Low Carbon Soc ieties (Oc tober 2012);

- Symposium on Environment and Health (J une 2015);

- Symposium on Mathematics (March 2016);

- Symposia on Infec tious Disea ses (October 2016 and April 2018);

- Science-Business-Society Dialogue Conference (December 2016 and November 2017);

- Symposium on Air Pollution and Health (J une 2019);

- ASSAf and the Leopoldina worked together with the Network of African Science Academies (NASAC) (2015-2018).

The present symposium was associated with a study on Mental, Neurological and Substance use (MNS) disorders that ASSAf would shortly be publishing aspart of its sc ience advice to govemment.

The partnership with Leopoldina had enabled both academies to partner with many sc ience ac ademies in other Afric an countriesand had opened doors to some academies in BRICS (Brazil, Russia, India, China and South Africa) and G20 countries, as well as the InterAc a demy Partnership (IAP). Together with Leopoldina, ASSAf is striving to do work that has national, regional and global impact.

\section{Welcome remarks (Prof Frank Rösler, Leopoldina Board Memberand Senior Professor, Biological Psychology and Neuropsychology, University of Hamburg, Gemany)}

Prof Rösler welcomed everyone on behalf of the Geman National Academy of Sciences Leopoldina. ASSAf and the Leopoldina are key partners in pursuing the goal of strengthening scientific cooperation between the Afric an continent and Gemany. Based on the MoU, Leopoldina and ASSAf had deepened their cooperation through joint symposia and workshops on a range of different topics. The present joint symposium was the fifth on a series of events pertaining to health issues. This symposium was not just a bilateral event between ASSAf and Leopold ina but involved other BRIC S countries a part from South Africa, namely Brazil, India and China.

Mental disorders belong to the most frequent chronic diseases. The World Health Organisation (WHO) estimates the worldwide prevalence of depression to be as high as 300 million patients, bipolar disorders 60 million, sc hizophrenia 23 million and dementia 50 
million. Mental health conditions also include developmental and substance use $\mathrm{d}$ isorders. These conditions not only result in severe suffering of patients and their families, but also camy a heavy economic burden for societies, whether high, middle or low income.

Throughout the world, the burden of mental disorders continues to grow, with signific ant impacts on health, social, ec onomic and human rights consequences. Between 1990 and 2010, the prevalence of MNSdisorders increased by 41\%; these disorders now a ccount for one in every ten lost years of hea lth globally. Mental disorders and disea ses a re a pressing problem globally, and extreme effort must be invested in research to fight this epidemic. Basic research is required to delineate the epidemiology of the various diseases, and applied research to develop and improve treatments. Strategies have to be developed to absorb the severe economic consequences. The motivation to make progress in this field is equally high in high-, middle- and low-inc ome countries.

In Gemany, for example, one in four adults is diagnosed with a mental health disorder every year. In recent years, a new group of patients have become salient in Europe: one quarter of migrants expenience post-traumatic stress disorder symptoms, because of adverse experiences in their countries of origin or on their hazardous odyssey to Europe. Low-inc ome countries a re disproportionately burdened with MNS disorders; $75 \%$ of global MNS disorders occur in low-income countries, and service users of mental health servic es in these countries a re far less likely to get access to proper treatment than in high-income countries.

The determinants of mental health and mental disorders in low-income countries include not only biological predisposition, but also social, cultural, economic, political and environmental factors which are often more salient than in high-income countries, including extreme poverty, civil wars, politic al repression, violence, and oppressive family and social struc tures.

One of the most fundamental problems in addressing mental disea ses is that there are at present no comprehensive a etiological models for the development and manifestation of any of the psychiatric disorders. Many biological, social and psychological factors that contribute to the manifestation of mental diseases, including biological factors such as genetic predisposition, transmitted deficits, psychological factors such as stressful life events and family conditions, and social factors such as stressful work conditions have been delineated. However, what is missing is a convinc ing model that integrates all these factors in a mechanistic way in order to understand the most important risk factors, how they interact, and how effic ient treatments can be developed. One reason for this is that mental disea ses are primarily defined by the psychologic al phenomenology of symptoms according to the Intemational Classification of Diseases (ICD). However, phenomenological symptomatology is not unique for any of the mental diseases, and there is considerable overlap of symptoms for different diagnostic categories. Even more problematically, a single psychological symptom may be caused by a multitude of biological defic its. This conc lusion follows from genome-wide associa tion studiesas well as brain-imaging results.

A nother important topic is how effec tive treatment can be guaranteed for patients in lowand middle-income countries (LMICS), and how public health initiatives can be established and funded. A critical question in this regard is how effectively and how soon after onset a mental disorder can be diagnosed. Mental diseases often appear as comorbidities with other severe somatic diseases (e.g. AIDS which is particula rly prevalent in sub-Saharan Africa). Patients tend to seek help initially to cure their somatic symptoms 
but not their psychic symptoms; however, where psychic symptoms exist, they also have to be treated.

A critic al question is how interventions can be improved so that many people benefit, not only in cities but a lso in rural a reas. This is not only a question of basic or applied research, but has political implic ations, as human resources and funds are required to overcome the bottlenecks in treatment supply.

These brief questions and many more will be addressed during this symposium.

Prof Rösler acknowledged and thanked the many parties that had made the event possible: the South African Department of Science and Technology for supporting the bilateral cooperation of ASSAf and the Leopoldina; the organisers (Prof Crick Lund, $\mathrm{Mr}$ Stanley Maphosa and DrSiya vuya Bula ni for ASSAf, and DrJ an Nissan and DrMarina KochKrumrei for Leopoldina); and the speakers. Prof Rösler was proud that the bilateral cooperation between ASSAf and Leopoldina had won the support of prominent researchers from South Africa, BRICS countries and Germany working in the field of psychiatry and mental illness.

\section{Addressing mental health disorders in the African Region (Dr Steven Shongwe, Acting Director, Non-communicable Diseases, World Health Organisation Regional Office for Africa)}

Mental health is an integral and essential component of health. There is no health without mental health. According to the constitution of the WHO, "Health is a state of complete physic al, mental and social well-being and not merely the absence of disea se or infimity". The deteminants of mental health include biological, socioeconomic and environmental factors. The range of mental and behavioural disorders includes depression, bipolar affective disorders, schizo phrenia, anxiety disorders, dementia, substance use disorders, intellectual disabilities and other disorders. Globally, $14 \%$ of the burden of disease is attributed to these disorders. Seventy-five percent of people with these disorders in many low-income countries do not have access to the treatment they need. The Lancet Commission on G lobal Mental Health and Susta ina ble Development estima ted that up to 1.1 billion people globally are affected by mental disorders, and human rights violations are common. Many people with mental health disorders find themselves in unfortunate and degrading positions; some are imprisoned or physically abused in care facilities. Access to treatment is often limited, or the quality of care is very poor.

The determinants of mental and substance use disorders include:

- Underlying socioeconomic challenges including poverty, unemployment and illiteracy; widespread social stigma related to mental health; and humanitarian situations due to natural or human-made disasters.

- Underlying medical conditions including HIV/AIDS, cardiovascular disease and cancer. The problemsare exacerbated by health system-related ba miers to accessing early detection, diagnosis, treatment, rehabilitation and palliative care.

- Other factors include the experience of discrimination, human rights violations, conflict, natural disa sters and humanitarian situations.

Recognising the high burden of mental health, the World Health Assembly in 2013 adopted the comprehensive Mental Health Action Plan, which has been extended until 2020 and aligned with the Sustainable Development Goals (SDGs), especially SDG 3 (Good Health and Well-being) and SDG 5 (Gender Equality). The Mental Health Action Plan is a commitment by member states to take specified actions to improve mental health and to contribute to the attainment of a greed global health targets. Targets and 
strategies have been developed for each of the objectives of the Mental Health Action Plan, namely:

- To strengthen effective leadership and govemance for mental health;

- To provide comprehensive, integrated and responsive mental health and social care servic es in community-ba sed settings;

- To implement strategies for promotion and prevention in mental health;

- To strengthen information systems, evidence and research for mental health.

The WHO policy plans and programmes for mental health are guided by the main principles of universal health access, human rights, deinstitutionalisation, integration of mental health into general healthcare (especially primary healthcare), and communitybased care. Another principle is that strategic documents should be produced in close collaboration with all relevant stakeholders.

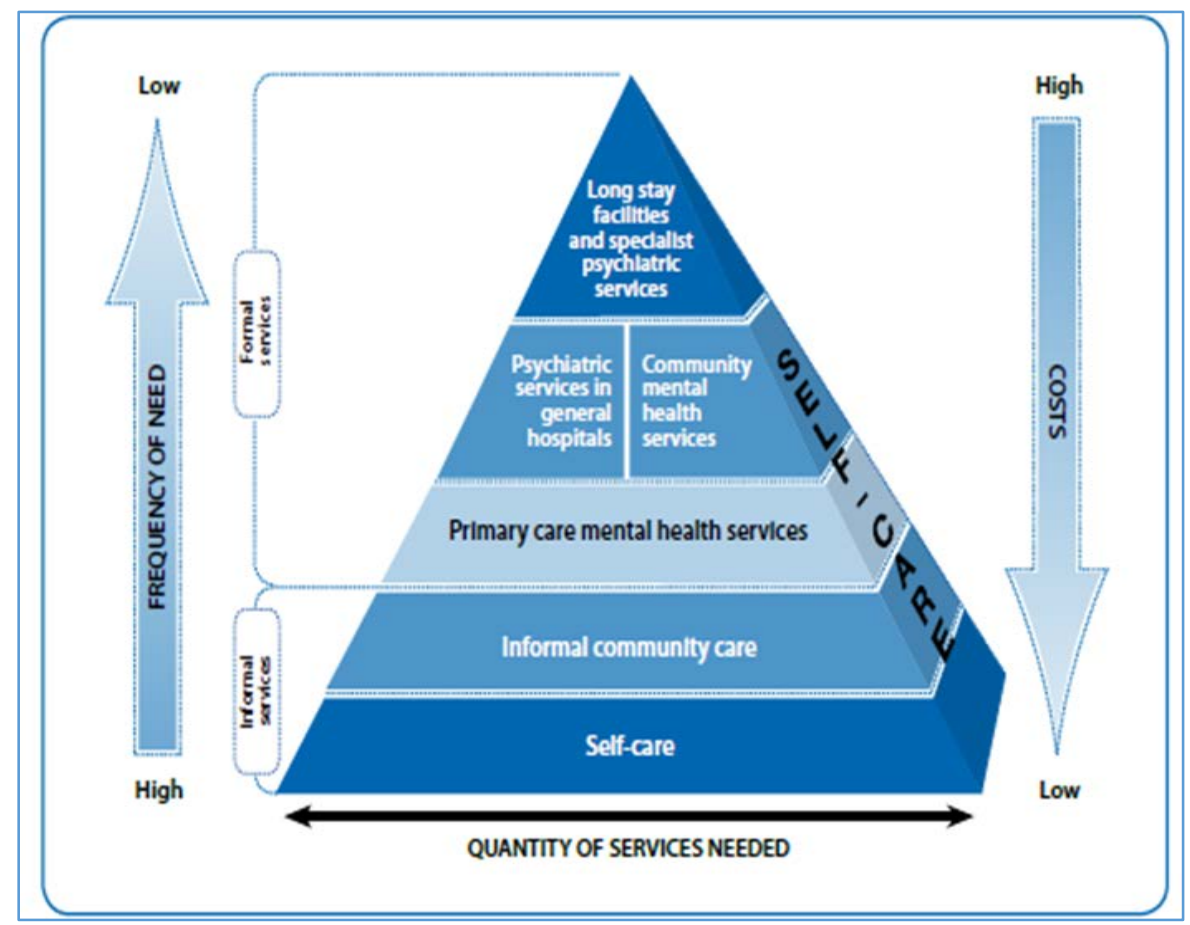

Figure 1: WHO service organisation pyramid for an optimal mix of services for mental health.

According to the WHO model for an optimal mix of services formental health (Figure 1), it is essential to integrate mental healthcare into primary healthcare, which should be supported by other levels of care including community-based and hospital services (sec ondary and tertiary levels of care). There is certa inly an important role for psychiatric hospital for specialised services, but the role of such institutions should be minimised. It is fundamental to empower people for self-care.

The WHO Mental Health Gap Action Programme (mhGAP) is a imed at scaling up services for MNS disorders, especially for LMICs. The programme entails task-shifting, capacity building at all levels, training of non-specialised health workers and mental health professionals, supportive supervision, and exploring opportunities for the review and development of curic ula.

Legislation is another important component for dealing with mental health in order to ensure that people with mental health disorders are respected. Laws should be aligned 
to international standards such as the United Nations (UN) Convention on the Rights of Persons with Disabilities as well as optional protocols.

With respect to progress in implementing the Mental Health Action Plan and other related initiatives, health systems especially for mental health are weak in most countries in the African Region. Thirty-eight of the 47 member states in Afric a have mental health polic ies and 18 have mental health legislation, but there a re challenges with implementation and enforcement. The challenges include late diagnosis, poor coordination, insufficient trained human resources, poor data, high costs and inaccessible medicines and technologies, the financial burden to individuals and systems, and low prionitisation of mental health. The number of psyc hiatrists in the Afric an Region is very low in comparison with other regions of the world and is declining even further due to the brain drain and migration. Sub-Saharan Africa has only 1823 psychiatrists for a continent of one billion people. In many countries of the Africa Region with a population of five million or more, there may be only one psychiatrist or none at all. Currently in the region, the number of psyc hia trists is 0.06 per 100,000 population, whereas in high-income countries the number of psychia trists is 6.6 per 100,000 population.

The challenges in reducing the treatment gap in the Africa Region include low prionitisation of mental health and insufficient funding, weak health systems, insufficient tra ined health workers, ina dequate mental health facilities in terms of health facilities and at community level, access to medicines, poor quality of care, and persistent stigma and disc rimination.

Some current mental health strengthening initia tives of the WHO include:

- Humanitarian emergencies: WHO and partners provide health and psychosocial support in such situations. Tools for clinical management of MNS disorders in humanita rian situations inc lude the mhGAP Humanitarian Intervention Guide.

- Programme for Improving Mental Healthcare (PRIME): This involves a consortium of research institutions and ministries of health in five countries (India, Nepal, Ethiopia, South Africa and Uganda). The goal is to generate world-class research evidence on the implementation and scale-up of treatment programmes for priority mental disorders.

- QualityRights Initiative: This is a WHO global initia tive to improve the qua lity of care of mental health services, promote human rights and address the physical, sexual and emotional abuse of those with mental health disorders. The initiative provides online training and works at multiple levels including changing mindsets and practices, transforming services, build ing civil society and reforming policy and law.

The recommendations include:

- Mobilising resources: Member states should mobilise financial, human and material resources to scale up mental health programmes, services and interventions.

- Policies, plans and legislation: Member states should accelerate the development and implementation of mental health policies, plans and legislation.

- Capacity building and training: Member states should scale up the training of mental health professionals including psychiatrists, psychologists, social workers, nurses and counsellors.

- Integration of senvices: Member states should integrate mental health, alcohol and substance use disorders into primary healthcare.

- Deinstitutionalisation: Capacity should be built for deinstitutionalisation and community-based care.

- Scaling up innovations including the use of ICT, task shifting of psychosocial interventions, and strengthening health information systems and surveillance on mental health and substance use disorders. 


\section{Global mental health and the Sustainable Development Goals: aligning the research and policy agendas (Prof Crick Lund, Alan J Fisher Centre for Public Mental Health, Department of Psychiatry and Mental Health, University of Cape Town)}

The presentation drew on the work of the Lancet Commission on Global Mental Health and Sustainable Development, in which Prof Lund had been involved for the last three years. The commission involved a number of different countries and published its report in October 2018.

The SDGs were launched by the UN in September 2015 as a big agenda with targets to be achieved by 2030. In his address at the time of the launch, the UN Secretary-General, Ban Ki-Moon, said: "We have a big bold agenda before us - now we must work to make it real in people's lives." The targets and indic ators for the SDG s have been worked out by UN agencies working in collaboration with govemments a round the world. The SDGs are shaping the policy agenda of many govemments around the world particularly in subSaharan Africa, not only for the health sector but also for other development priorities related to education, climate change, the environment, sustainable cities and communities and others.

For the first time, the importance of mental health has been acknowledged and included in an agenda of this magnitude. Mental health was not mentioned in the Millennium Development Goals (2000-2015), which preceded the SDGs. Mental health is addressed in SDG 3 (Good Health and Well-being):

- Target 3.4. “By 2030, reduce by one third prema ture morta lity from non-communic able diseases through prevention and treatment and promote mental health and wellbeing."

- Target 3.5. "Strengthen the prevention and treatment of substance abuse, including narcotic drug abuse and hamful use of alcohol."

Asc ountries move towardstrying to esta blish universa I health covera ge, it is vita I to ensure that mental health is included in the package of services. South Afric a, for example, is in the process of formulating the National Health Insurance, and it will be critical to ensure that mental health is included in the core package of services funded by universal health coverage.

Within broader global development policy, mental health has been growing as a field with a number of seminal public ations from the early 1990s onwards:

- Caracas Declaration of Mental Health and Human Rights (1990), which emphasised the need for developing psychiatric care closely linked to primary care through community-based services and advocated the need to anchor the restructuring of the services in a legal framework, and to assure proper sa feguards for the human and civil rights of patients.

- World Mental Health Report (1995), which highlighted the large and growing burden of mental disorders in low-income countries, their strong association with social deteminants (such as poverty, displacement and violence), and the pervasive lack of care and abuse of human rights.

- WHO World Health Report(2001), which focused on mental health for the first time and presented a public health perspective on mental health along with providing practical guidance to polic ymakers.

- WHO Mental Health Atlas (2001, 2005, 2011, 2014, 2018), which for the first time provided comparable data from the majority of countries on some basic indicators of mental health services and systems. 
- Lancet Global Mental Health (2007), the first in the series, which emphasised the large treatment gaps for mental disorders in LMICs and called for services for mental disorders to be scaled up, guided by the evidence of cost-effective interventions and respect for human rights.

- Movement for Global Mental Health (2007), a virtual a lliance of people affected by mental disorders and practitioners of global mental health that was formed to collec tively champion the atta inment of the call to action.

- UN Convention on the Rights of Persons with Disabilities (2007), which promotes, protects and ensures full and equal enjoyment of all human rights and fundamental freed oms by all people with disa bilities, and promotes respect for their inherent dignity. The convention was adopted, quickly signed and ratified by most countries in the world and came into force in 2008.

- WHO mhGAP (2008), which committed WHO to providing evidence-based guidance and assistance to countries for scaling-up care for MNS disorders. Over the next 10 years, the initiative assisted more than 100 countries.

- Grand Challenges in G lobal Mental Health (2011), which was the most c omp rehensive prionity-setting exercise to guide research in global mental health. It identified implementation questions as the leading priority, ushering in a wave of new funding forglobal mental health research.

- WHO Mental Health Action Plan (2013), which was adopted with the highest level of politic al commitment by all 194 ministers of health in the World Health Assembly. The global action plan hasclear objectives, actions, ind ic a tors and targets for eight years.

- SDGs (2015), which recognised the promotion of mental health, prevention of mental and substance use disorders, and universal health coverage as targets of the health goal.

- Disease Control Prionities (2016), which published recommenda tions for cost-effec tive packages of care for the prevention, treatment and care of mental disorders that are feasible for delivery through a range of platforms (from the community to the specialist) and can be prioritised as the mental health component of universal health coverage.

- Out of the Shadows meeting and declaration (2016) in which the World Bank and WHO recognised mental health not just as a global health priority, but as a global development priority.

- Lancet Commission on Global Mental Health and Sustainable Development (2018), which proposed a reframing of mental health to concurrently address the prevention and quality gaps alongside the treatment gap (for both clinical and social care interventions) in order to reduce the global burden of mental disorders.

A substantial body of evidence has grown. There are robust measures of the burden of disease (although these could be improved), the extent of service provision, and the available resources and policies. The statistics show the rising burden of mental and substance use disorders. Between 1991 and 2016, the percentage of total disabilityadjusted life years (DALY) increased globally from $6.6 \%$ to $9.4 \%$. The trend is similar for all countries, but the actual figures are higher in high-income countries. Mental health and substance use disorders are not evenly distributed across the life course. Many such disorders peak in adolescence and early adulthood, which is a critical risk period. Alzheimer's disease and other dementias peak in later life. It is nec essary to be a ware of these changes in considering prevention and promotion across the life course.

The high burden of mental and substance use conditions has major economic consequences, especially since their effect is felt more by disability than by mortality. Mental health conditions a re projected to cost the global economy US\$16.1 trillion by the year 2030, which is more than cancer, diabetes and respiratory disea sescombined. This is 
not just a problem for the ec onomies of high-inc ome countries, as the economies of LMICs are also signific antly impacted.

Despite this burden and the associated economic costs, the coverage of minimally effec tive trea tment ra tes for depression, a nxiety and substance use disorders is neg lig ible. Only about $2 \%$ of people living with an anxiety disorder, $4 \%$ with a major depressive disorder and $1 \%$ with substance use disorder in LMICs receive minimally effective treatment. The situation is somewhat better, although still inadequate, in high-income countries, where only $14 \%$ of people with an a nxiety disorder, $22 \%$ with a major depressive disorder and $10 \%$ with substance use disorder receive minimally effective care. Development assistance for mental health is pitiful and does not compa re with assistance for conditions such as HIV/AIDS, matemal and neonatal health, malaria or tuberculosis (TB).

In countries around the world, people with mental health disorders, especially those with severe mental illness, sometimes live in shocking conditions and are subjected to human rights abuses such as being chained or caged.

In the context of reframing mental health and setting research priorities, the Lancet Commission on G lobal Mental Health and Susta ina ble Development recommended three important changes that are required in the approach to the field, namely:

1. Mental health exists on a spectrum, ranging from day-to-day wellness to long-tem disabling conditions. There is a need to move away from categorical measures of mental disorders towards a more dimensional understanding of mental health. There is a continuum from diffuse non-specific mental distress, to the development of fullblown syndromes. There is a high level of comorbidity between conditions, espec ially in the early stages. Efforts should be focused on prevention and early-stage identification. Research should be directed at understanding the aetiology of mental health conditions as multiple and often overlapping deteminants, rather than trying to develop sophistic ated classific ation systems of how symptoms present themselves in a c linic al setting. The Lancet Commission developed a frameworkfor understand ing the social deteminants of mental health and categonised these across five main domains, namely demographic, economic, neighbourhood, environmental events, and social and cultural domains. A large systematic review was undertaken, and a range of distal and proximal factors were identified that influence the mental health of individuals across the life course and interact with a range of genetic risk factors. Many of these social deteminants are strongly linked to the SDGs. It was possible to identify how particular SDGs are relevant to certa in social and economic domains. The Lancet Commission's report developed a number of ind ic ators that are important to track as potential deteminants of population mental health.

2. Childhood and adolescence are key moments shaping lifelong mental health. Plasticity deteriorates over the life course. There is a period of pruning and differential maturation of neuronal cells in a dolesc ence and early adulthood. Senesc ence in later life provides high risk for dementia and other neurocognitive deterioration. Early childhood and adolescence are critical. The environment shapes neuronal development across the life course and is reflected in the incidence of mental and substance use disorders. In considering mental health strategies from the population perspective, it is important to develop interventions that target key developmental stages and try to identify problems and intervene as early as possible. The current symposium provides a n opportunity for scientists in a range of fields to meet, inc lud ing neuroscience, genetics, social epidemiology, clinical psychiatry and clinical psychology. This is encouraging, because a convergence approach is required in 
order to understand the biological and social deteminants and the ways in which they influence the presentation of phenotypes across the life course and the developmental trajectory of the human brain.

3. Mental health is a fundamental human right People living with mental ill health should be at the centre of planning servic es and challenging stigma. The Lancet Commission report goes into some detail on the UN Convention on the Rights of Persons with Disabilities and its relevance to people with mental health. The Lancet Commission emphasised youth leadership and especially the participation of young people affected by mental health conditions, resulting in the launch of the 'MyMindOurHumanity' social media campaign to fight stigmatisation.

The Lancet Commission set out a number of priority interventions, building on the approach of understanding the life course and the dimensional approach to mental health. The interventions firstly need to identify those at risk, promote mental health in those who are well, identify key risk factors and opportunities for intervention for those at risk, and provide a set of interventions for those who suffer from poor mental health, especially early in their life course. These can be delivered across a number of different platforms, from school-based to community-based and digital platforms, as well as primary care and health sector platforms. The Lancet Commission set out what the prionities should be for policy, plansand law forprimary, secondary and tertiary healthcare in low-, middle- and high-resource settings.

The key messages and recommendations emerging from the work of the Lancet Commission include:

- Mental health should be reframed using a dimensional, life-course approach that is founded on human rights and in a lignment with the SDG.

- Mental healthcare should be an essential component of universal health coverage. As countries move towards universal health coverage and national health insurance, it is important to ensure that mental health is included in specific packages of care, and scientific evidence is used to strengthen health systems and adopt task-sharing approaches to deliver mental healthca re through non-specia lists.

- Public policies should be used to protect mental health and implement the WHO action plan.

- It is important to listen to and engage people with lived experience so that they become part of the research and policy agenda.

- Mental health requires far greater investment, especially given the compelling evidence that phamacological and psychosocial mental health interventions yield economic improvements in LMICs.

- Research should be used to guide innovation and implementation. The current workshop presents an opportunity to consider the research agenda and priorities.

- Monitoring and accountability need to be strengthened.

\section{Keynote address (DrYogan Pillay, DDG: Health Programmes, Department of Health, South Africa)}

The Friendship Bench project has received considerable intemational public ity, including a bench in the exhibition area at the 2019 World Health Assembly. This is an evidencebased intervention developed in Zmbabwe to bridge the mental health treatment gap. The mission is to enhance mental well-being and improve quality of life through the use of problem-solving therapy delivered by trained lay health workers. The intervention focuses on people who are suffering from common mental disorders, such as anxiety and 
depression. This innovation is pertinent to improving mental health interventions in the context of task-shifting and involving communities.

Another intervention that could be used to mobilise communities a round mental health and mental illness is the example of a US high-school tea cher who put up a board in class with rows showing the mood of leamers, on the spectrum from 'I' $m$ happy' to 'I'm feeling sad'. Leamers were encouraged each moming to place stickers on the spectrum with their namesat the back. The teacher would then have one-to-one conversations with the leamers. This is a creative way of checking on the mood of the classroom and doing something about it.

The National Department of Health $(\mathrm{DoH})$ would like to see such innovations emerging from symposia such as the present one. Too often, meetings result only in talk without follow-up action. Dr Pillay was interested to see what would come out of the work of the Lancet Commission, how it would be ensured that the recommendations were implemented, and who would hold people accountable.

Advocates for every medic al condition all concur that there is no health without mental health. There is thus no ready answer to the question of what will distinguish mental health from conditions such as HIV, eye healthcare or oral care. Dr Pillay was hoping that this symposium would help to answer this question.

Dr Pillay's presentation would focus on the situation in South Africa. The release of the South African Human Rights Commission (SAHRC) Report of the National Hearing on the Status of Mental Healthcare in South Africa on 28 March 2019 should cause us to pause and reflect on what we have done to provide quality rights-based mental health services for the people of the country. A blog on the South African College of Applied of Psyc hology website, entitled 'The shocking state of mental health in South Africa in 2018', noted that as many as one in six South Africans suffer from anxiety, depression or substance-use problems; $40 \%$ of people living with HIV in South Afric a have a diagnosable mental disorder, $41 \%$ of pregnant women are depressed, and when crime and motorvehic le accidents a re taken into consideration, up to six million South Afric ans could suffer from post-tra umatic stress disorder. Only $27 \%$ of South Afric ans who report severe mental illness ever receive trea tment. This means that nea rly three-quarters of these sufferers are not accessing any form of mental healthcare at all. These statistic s a re poor and reflect high levels of comorbidities, and signific ant lack of integration in services.

This bleak picture is found not only in academic joumals, but also in the media. In 2014, The Sunday Timespublished a report entitled 'South Africa's sick state of mental health' in which the authors noted that one third of So uth Afric a ns suffer from mental illness, but only $25 \%$ of these rec eive treatment. These circ umstances were exacerbated by the Esidimeni tragedy. While there is an imperative to deinstitutionalise psychiatric patients and provide community-based mental health services, this clearly needs to be done with much more care and by ensuring that non-govemmental organisations to which patient care is entrusted have the capacity to provide good quality care. There are both local and global lessons to be leamt from this tragedy.

The situation around mental health in South Africa is troubling, and clearly urgent action is needed. DrPillay looked forward to this symposium to indic a te what we need to do more of, and what we should stop doing because the evidence suggests that it makes no difference to mental health or helping people with mental illness, and in the context that there are never suffic ient resources. 
The lack of access as well as the quality of mental health services is not unique to South Africa. It is a global problem and therefore needs a global movement to deal with it. The question is whether the Lancet Commission report has generated such a global movement. This was not evident from the World Health Assembly. The Lancet Commission report makes the global neglect of mental health clear, stating that "the global burden of disea se attributable to mental disorders has risen in all countries in the context of major demographic, environmental, and socio-political transitions." If the importance of these three factors is undemined, we will not succeed in having the robust interventions we need.

The Lancet Commission report notes that human rights violations and abuses of mental hea Ith patients persist, and the quality of services for mental health is routinely worse than the quality of services for physical health. Govemment investment in developing assistance remains pitifully small. Collec tive failure to respond to the global mental health crisis results in monumental loss of human c apacities and a voidable suffering.

These views reflected in the Lancet Commission report are echoed in the report of the SAHRC. The report is an indictment but sets out what needs to be done in specific timeframes. The report points to neglect, mismanagement and underfunding of mental health services in South Africa. While the report understandably locates its find ings within a human rightsc ontext, it fails to ca refully document the broadercontext of mental hea lth or illness in South Africa. If South Afric a is indeed a sick society, we need to understand the social deteminants of health, as well as the need for mental health services.

Despite a number of studies showing the poor status of mental health in South Africa, mental health and mental illness do not appear to be a priority. A four-country study in 2011 that included South Afric a suggested that there were three categories of reasonsfor under-investment in mental health, namely, not having the data to convince policymakers that mental hea th is a priority; not being able to artic ulate what needsto be done to strengthen mental health; and not being able to mobilise support for a response.

In terms of what needs to be done, the reports of both the Lancet Commission and the SAHRC include a host of recommendations. The SAHRC locates its findings and recommendations within a human rightsc ontext. We need to consider how to correct the stigma and abuse of people with mental health challenges. Using the law is clearly not suffic ient, as we have seen with HIV and TB. There is intemalised and extemalised stigma in relation to both HIV and TB. The South African National AIDS Council (SANAC) conducted a study of the stigma associated with HIV and TB using the J oint United Nations Programme on HIV and AIDS (UNAIDS) tool and found that there is still more stigma associated with TB than with HIV in South Africa, and there is more intemalised than extemalised stigma for both of these conditions.

The DoH had commissioned a team of researchers to calculate how much is spent on providing mental health services in the public sector. More than R7.8 billion was spent on in-patient and out-patient mental health senvic es in $2016 / 17$, whic h represents $4.6 \%$ of total healthcare expenditure in the public sector (excluding expenditure in the private sector). Of this total, $14 \%$ was spent on out-patient services and $86 \%$ on in-patient services. Inpatient services a re thus clearly prioritised, which means waiting for patients to become really ill before intervening, whereas the Lancet Commission urges greater focus on prevention and primary and secondary intervention. Only $8 \%$ was spent on primary mental health services, while $44 \%$ was spent on psychiatric hospital services. Psychiatric hospital servic es should not be minimised, because this might undermine the servic es that some patients would require. This issue should be approached by considering the correct number of beds in the context of the epidemiology of a particular country. 
After determining what is spent on mental health in the public sector, it is then necessary to determine what should be spent. The $\mathrm{DoH}$ is working with colleagues from the University of Cape Town (UCT) and the South African Medical Research Council (SAMRC) to develop an investment case for mental health in order to demonstrate the levels of investment required and the expected retum on the investment in tems of health. Investment cases had been developed for TB and malaria and had succeeded in securing conditional grants. In developing the case for mental health, one of the key questions is not only the size of investment but also the nature of the delivery platform (i.e. what services should be delivered and where). The DoH had also acknowledged the need for a more robust model for the provision of community-based mental health servic es. Using donor funding, the department had engaged a team from the University of KwaZulu-Natal (UKZN) to develop models for review a round community-based mental health services. In addition, the DoH had commenced the provision of refresher courses for mental health medical officers and nurses. Since the start of 2019, 383 doctors and nurses, largely from district hospitals, had been retrained to deal with acute psychiatric conditions. Many of the doctors and nurses working in district hospitals had been found to be poorly equipped to deal with acute psychiatric patients. There is nowhere else to send such patients, as the psychiatric hospitals are full, and psychiatric patients end up filling medic al wards in local hospitals. The training has an associated app with links to specia list physicians and psychiatrists, so that online consultation is available in real time. The DoH would evaluate the implementation of these measures.

The DoH acknowledges that mental health services in South Africa need radical transformation. The department is committed, together with its partners, to providing signific antly improved access and qua lity of ca re to patients and the population at large. This alliance with the global movement towards universal health coverage provides an opportunity to strengthen mental health services. This opportunity has to be seized by knowing what servic es should be provided at each level of care, at what cost, by whom, and how they will be held accountable. Practically, this meansthat as the National Health Insurance system is designed, there is a need for agreement on the package of mental health services to be provided, focusing on prevention as well as wellness. We need to ensure that this package is fully funded, with the right mix of health providers equipped to provide the best possible quality of care. Equally, as noted in the Lancet Commission report, we need to deal with the soc ial determina nts of mental illness with a n inter-sec toral focus on reducing levels of poverty and inequity, increasing gender equity, improving access to employment and educational opportunities, and decreasing levels of interpersonal violence.

There is much to be done. DrPillay hoped that the present symposium would help prionitise what has to be done, and the sequence of activities required to achieve the end result of more coverage, better quality care and greater impact on the lives of people.

\section{Disc ussion}

Ms Sc ott (Wits): Does the Lancet Commission report deal with infant mental hea lth? There is considerable research being published on infant mental health, especially on the formation of attachments and the immunity that assists with emotional regulation. Borderline personality disorder, which tends to be referred to hospitals, is often the result of complex trauma from infancy and diffic ulty in attachments. Interventions tend to start from primary school age and later, but not in infancy. Simple things such as helping a mother to connect and make eye contact with her infant, and helping her to regulate emotions and attachments, could easily be done but are generally ignored in broader polic y interventions. 
Prof Lund (UCT): This is an important area. The Lancet Commission report has a section dealing with interventionsacrossthe life course, and a section on infancy and pregnancy. There are opportunities, for example, for routine screening for antenatal and postnatal depression. The Peninatal Mental Health Project at UCTdoesa lot of work in this area.

Dr Pillay (DoH): There is a lso a need to look at what happens before conception and in utero. The in utero experience has been shown to be important for conditions such as diabetes and hypertension in later life.

Ms Scott (Wits): It is easier to put relational psychologic al interventions, such as parent infant psychotherapy, in place from birth than to intervene at the level of genetic sbefore conception or during pregnancy.

Dr Pillay (DoH): Improved matemal nutrition a lone would have very positive effects.

DrAllen (Lentegeur Psychiatric Hospital): I work on the ground as a psychia trist, providing services for two substructures in areas with the poorest and least insured group of the population in the Westem Cape. The mental health gap is well recognised, as described in the Lancet series of papers. The question is why implementation has not followed the research findings. One of the factors seems to be the assumption that those responsible for implementation a re tra ined well enough to understand systems and what needs to be done. There is a current study on the core competencies of those who are meant to implement interventions that are considered important. The Lancet Commission on Medic al Education looked at medic al education for the $21^{\text {st }}$ century and why education systems have not changed in order to implement what research shows is required. Despite the well-developed body of research on what needs to be done, universities do not have tra ining programmes that reflect what resea rch shows is required. The Lancet Commission on Medical Education found that medic al students a re not being trained to be leaders in mental health. We expect medical graduates, who have been trained largely to practice in first-world countries, to take up the challenge in LMIC sand make a difference. They are unlikely to do so, because they have not been trained to do so, do not understand the systems, and do not have the leadership skills to do what needs to be done.

Prof Lund (UCT): Agreed with these concems. There is a need to develop public mental health competency among medical health professionals, and to shift the roles from providing individual clinical care to patients, to also taking on the roles of training, supervising and supporting non-specialist health providers to deliver mental healthca re. There are fewer than one psychiatrist to two million people in sub-Saharan Africa. The treatment gap can thus not be filled by just providing care using specia lists. The curic ulum would have to be changed in order to change the core competencies of mental health professionals to understand the system within which they deliver care, and to take on additional roles of providing tra ining, supervision and support to non-specia lists.

Prof Thom (Wits): Another key issue is where people are trained. If the training platform is primarily in specialised hospitals, we will not achieve what we want.

Prof Petersen (UKZN): In considering general health issues, integration is required. It is therefore important to include public mental health in the cumicula for mental health specia list tra iners as well as the general healthc a re cadre, especially those who will be in management positions, as well as in public health master's programmes. If mental health is to be integrated into general healthcare systems, it cannot stand outside it. If we develop a district healthcare plan, the only way it will actually be implemented is if it is integrated into the district plan as a whole. We need to onentate general public 
healthcare managers with respect to the importance of mental health and how to integrate it.

Prof Thom (Wits): Infant mental health is more likely to be implemented by nurses in a postnatal clinic than by mental health specialists. Those who are implementing general healthcare therefore need to integrate the mental health component in their particular area into the work that they do.

Dr Pillay (DoH): Healthcare workers tend to think only of major mental disorders (e.g. schizophrenia or major depression) in the context of mental health. We therefore need to change the narrative related to how we talk of mental illness and mental health in order to promote these ideas, and so that they feel that these aspects are part of their job on a daily basis. The rea lity at healthc a re facilities on the ground is very different from what one would hope healthcare workers would be doing. People are working in silos at all levels of the healthcare system. Integration is important, but we need to consider how to make it happen. The DoH has been talking of integration formany years, but it is not taking place. The written words we use might mean something to us, but they do not seem to resonate with those responsible for implementation. We have to change the na rative and the way in which we think about some of the concepts.

Prof Duncan (UCT): The conceptual frameworks that inform policy, such as the ICD and the Diagnostic and Statistical Manual of Mental Disorders (DSM) have been mentioned. The Intemational Classific ation of Functioning, Disability and Health (ICF) should also be considered with respect to integrated and intersectoral mental health polic y and services. For example, the Mental Health Polic y Framework and Strategic Plan and the Framework and Strategy for Disability and Rehabilitation do not talk to each other. If they did then community-based rehabilitation including habilitation, psychosocial rehabilitation and work rehabilitation as strategies for community development would be strengthened. Making the ICF and community-based rehabilitation (CBR) part of mental health policy will go a long way towards disability prevention. The way in which the rehabilitation professions are optimally utilised has implic ations for the human resource mix at district level, and for task-shifting to and task-sharing with community workers. The district health system plansconfine rehabilitation professiona ls to c linic level. Thisisshort-sighted because they are a ready workforce that is equipped to address the functioning and disability dimensions of mental disorders through intersectoral CBR. Based on the ICF, the WHO is working on the Intemational Classification of Health Interventions. This is a significant opportunity to position disability inclusive mental health strategies and interventions at grassroots level.

Dr Pillay (DoH): In developing a new package of interventions for the National Health Insurance (NHI), the DoH is looking at the coding systems being used. At present, the public health sector uses only ICD-10. The private sector has been using other coding systems, and in primary healthcare various systems have been used. The $\mathrm{DoH}$ is trying to convene a meeting with medical schemes to consider the coding system to be used. The way in which we code illnesses and diseases is related to how we think about them and what we do about them. With the introduction of the NHI, South Africa has a unique opportunity to look at issues such as the skills mix, who does what, and how services are paid for. The key question is how to collec tively engage in this debate.

Prof Lund (UCT): In relation to the community health service model that Dr Pillay mentioned, the integrated role of community rehabilitation workers, for example, could be considered. With a primary foc us on functioning, one could considercaring for the old, for multiple comorbidities, and for loss of intellectual functioning and a range of other 
functioning. CBR workers could offera more integrated, low-cost and effective approach, using a functioning approach rather than an ICD approach.

Prof Thom (Wits): The South Afric an Association of Psychiatrists has two vocational groups, namely the private and the public sector. The private sector psychiatrists have organised themselves very well and have been able to engage with funders and get recognition for psychiatric disorders; the situation has greatly improved over the last ten years, although it is still not optimal. The society is trying to develop the public sector group to be more effec tive and to become advocatesforpatients and their families. There a re efforts to try to develop partnerships between private and public sectorpsychiatrists. O ne of the areas that private sector psychiatrists have been looking at is the concept of value-based care and different models of reimbursement, which would speak to what the NHI is looking at. It is important for people to be aware that the private sector is not just interested in ma inta ining a fee-for-service model that iscost-ineffective but is also considening different models.

Prof Kagee (SU): I agree with the speakers a bout the importance of prevention. What are your thoughts on the evaluation of prevention efforts in terms of mental health, and would these be funded?

Prof Lund (UCT): Prevention is a critic al a rea. We need to consider how we measure the effect of promotion and prevention interventions. The classical approach would be to look at the incidence of mental disorders overtime by tracing a cohort of ind ividuals. This type of design would require large numbers. It is a lso necessa ry to develop a more robust understanding of the ways in which prevention impacts on conditions such as depression, substance use or anxiety disorder, but there is much that we do not know in this regard. In considering mental health as a continuum, we need to develop more robust and culturally valid ways of measuring mental health as a positive construct, not just as a means of detecting mental illness. This is an area of research that could be usefully explored. A low-hanging fruit would be to take this approach during early life with infants, children and adolescents, as they present the best opportunity to change life-long trajec tories and potentially show an impact.

Prof Rösler (University of Hamburg): Some of these issues a re related to the problem of the strong distinction between mental health issues and other health issues. Many mental health problems are not recognised early enough because of stigmatisation in all societies. Mental health practitioners need to be sensitised that any patient that consults them might have mental health problems. In that way they could play a role in prevention. To separate mental health and somatic health issues is a n outdated way of thinking about health. As a biological psychologist, I do not see these differences, but the distinction between physical and mental health is very strongly established among the general public.

Dr Pillay (DoH): In considering the investment case for mental health, it will be necessary to determine how much should be invested at primary, secondary and tertia ry care levels, and what outcomes could be achieved. There were similar difficulties in making the investment case for HIV, for example. The focus has thus been on the question of what it would take, knowing what we know now about what works based on the best evidence we have, to (1) reduce incidence and (2) reduce morta lity. We could only find evidence for biomedical interventions to do those two things. It is easier to address this question in rela tion to HIV than mental hea lth, so it is a simplistic example. We say a lot a bout structural issues related to HIV, but the evidence of what works in dealing with structural, personal and interpersonal issues is lacking in order to justify including such aspects in the model. I 
suspect there might be similar diffic ulties with the investment case for mental health, but we should at least try.

Dr Allen (Lentegeur Psychiatric Hospital): At a conference in Durban, a speaker from the UK spoke about how to use data, especially economic data, to advocate for spending on preventative mental health programmes and why this is important from a financial perspective. Do we use health economists to help detemine where we should be spending money? How do we take decisions on cost utility and how to get the most benefit from expenditure? Decisions are often made on the basis of crude measures, for example that people tend to die from conditions such as HIV and TB but not from mental health disorders. Allocations for health are done at provincial level, but many of the provinces do not have a line item formental health, and mental health is captured within the budget for chronic diseases. Budgets a re detemined based on historical precedent (i.e. escalation of the allocation from the previous year increased by the inflation percentage). It is not possible to determine what the impact would have been if there had been expenditure on preventative programmes, because the discourse is not informed in a rational way. Economists do not consider health economics. When we devise policy and consider policy prionities, we need to look at integrating a range of different disciplines such as education and social development. We need experts to considerhow much to spend on prevention because of the benefitsof sa ving expenditure later, and we need to take this approach routinely as a matter of course.

Prof Thom (Wits): The agenda for research that will come out of this symposium is already starting to become clear.

Unidentified speaker: The science related to prevention is poor. The research is driven by agendas other than whether an approach can work in systems. Much of the research done in South Africa, largely in academic departments of psychology, tends to focus narrowly on validating a particular scale in a sample without any intention for wider applic ation. The evidence is poor on whether intervention works, which makes it diffic ult to demonstrate impact so as to motivate investment. The research agenda needs to be revisited. Research that is not related to implementation should be self-funded.

Prof Rietsc hel (Central Institute of Mental Health, Gemany): A project was conducted in Gemany in 2000 to systematically evaluate cities (Wuerzburg and Nuremberg) to establish whether arising public a wa reness for depression and implic ating practitioners in endeavours could lead to reduction in depression and suicide. The study continued over several years, and it was shown that suicide was reduced. These findings have influenced many ongoing local activities in Gemany. Such a study could be used as an example to support the need forprevention.

Prof Lund (UCT): Taking a population-level approach is an interesting idea, which would entail looking at the key levers of how a particularintervention might influence population outcomes such as preventing suicide or the onset of depression, a nxiety or substance abuse, and then considering all the system-level changes that would have to be in place to bring about those outcomes. The key challenge at population level is to have two comparable populations. If a study were conducted in two different cities, for example, they would have to be comparable, as there could be confounding factors such as labour migration and economic development that might drive the mental health outcomes. Developing a research agenda around a population approach could be informative for polic ymakers.

Prof Thom (Wits): The discussion raises the issues of how university departments decide what research they will conduct. This might require more conversation among 
polic ymakers to establish what research they need, so that universities can respond and provide useful information.

Prof Chiliza (UKZN): Would Dr Pillay elaborate on his comment that researchers need to know what to stop doing if it is not working, and what implications this has for the research agenda? Young researchers need guidance in what areas to focus on.

DrPillay (DoH): In the context of limited reso urces, it is nec essa ry to decide where to spend. The DoH has think tanks related to HIV, TB and matemal and child health, and the department recently created a think tank for mental health. The role of the think tanks is to bra instom and inform the offic ials who a re responsible for advising the Minister of Health on policy issues. Those invited to participate in the think tanks do not represent any partic ular constituency. Dr Pillay had raised the following issues for consideration by the think tank on mental health:

- Whether South Afric a's spychia tric hospitals are as effic ient as they could be (i.e. what they are doing that makes a difference, and what they should be doing differently including what they should stop doing);

- Whether South Afric a n community mental hea lth servic es a re a seffic ient asthey could be;

- How much South Africa is spending on psychiatric drugs, whether there is rational presc ription of such drugs, and whether the right drugs a re being used to treat va rious mental health conditions.

The DoH had had been addressing similar to questions related to HIV. HIV is a relatively new condition compared to mental health, but receives far more expenditure. The DoH was starting to ask in relation to HIV what things it should stop doing on the basis of the evidence. Research is required to consider what works and what does not work under certa in conditions. Anecdotally, there are many things that are not working on which expenditure should not continue. Another issue is to determine the role that district hospitals should play in managing acute psychiatric patients, in tems of whether such patients should be admitted to such hospitals, and who should do what. At present psychiatric patients are being admitted to district hospitals, but they are not receiving qua lity care. There is a need for operational research to answer some of these questions.

Dr Card (UJ): Part of my research is to understand how public healthcare workers at primary and community health centres understand mental ill health, and where patients are referred to. It was diffic ult to gain access to clinics in order to conduct this research. The study found that nurses do not have much access to mental healthca re tra ining. Only $21 \%$ of their training covers mental ill health. When they are confronted with patients experiencing trauma, they do not know how to deal with them and tend to refer them to district hospitals. There seems to be a gap between policy and implementation by people on the ground.

Dr Pillay (DoH): The nursing cumiculum is being revised, providing an opportunity to increase the focus on mental health. There have been many mistakes in the current nursing curiculum, and the integrated four-year course is not working in several areas, including mental health, obstetrics and gynaecology.

The DoH has tried to address issues of access by establishing district mental health teams. The concept is sound, but there are not enough suitable people to make them workable. The idea was that local teams of psychiatrists, psychologists and social workers would add ress the planning of services, the quality of ca re and access. The district mental health teams were modelled on the district clinic al specia list teams, which looked specific ally at matemal and child health aswell as TB and HIV. The challengesare that the mental health 
teamslack the a uthority they need; many tea mslack a full complement; not every district has such a team; and some of the teams do not have the capacity to deal with the issues (since cliniciansmay be ill equipped to address planning and issues of epidemiology). The DoH will have to rethink who is put in place in teamsand in what capacity.

Prof Lund (UCT): This is a useful conversation. We need to focus far more on operational research with the agenda set by policymakers. In the example of district mental health teams, there seem to be key gapsin theircapacity to plan servicesat the population level for mental health. A useful piece of research might entail how to support, train and supervise distric t mental health teams as they a re established in provinc ial health senvic es, and evaluate their competencies. This could have a significant public health impact in terms of access to care.

Prof Petersen (UKZN): The Southem African Research Consortium for Mental Health is evaluating the scale-up of the mental health integration project, which evolved from the model developed for the PRIME and was scaled up in KDN. The capacity-building component was driven by the National Institutes of Health (NIH) asthe funder with the a im of capacitating programme managers with implementation science. It was possible to negotiate with the provincial a uthorities in $K \mathbb{N}$, involving the mental health directorate as well as mental health coordinators from each district. An implementation science capacity development programme was co-developed for skills including developing a district mental healthcare plan and integrating it into the district plan, and using continuous qua lity improvement to integrate, implement and evaluate the plan. Between policy and ground level, there is a need to provide a tool kit and a programme to drive integration at district level.

\section{SESSION 2: NEUROSCIENCE AND GENEIICS \\ Facilitator: Prof Bongani Chiliza, Head, Department of Psychiatry, University of KwaZulu- Natal, South Africa}

\section{Mental health research prionities in South Afric a: Should we include neurogenetics? (Prof Dan Stein, Head, Department of Psychiatry and Mental Health, University of Cape Town, South Africa)}

The South African context could be summarised as follows:

- 1800s: Psychiatric a sylums were established a sea rly as the 1800s. Robben Island, where Nelson Mandela and other political prisoners were imprisoned under apartheid, had been an asylum.

- 1950s: University departments of psychiatry started to be established.

- 1960s: Researchers at the University of the Witwatersrand published papers on behavioural therapy.

- 1970s: Opposition to apartheid led to the academic boycott.

- 1990s: Academic collaboration with researchers abroad began after the end of apartheid.

- 2000s: Biologic al psychiatry began in the 2000s, inc luding the first func tional magnetic resonance imaging and neurogenetics.

- 2010s: In the last ten years, the major focus of intemational collaboration has been global mental health.

The 10/90 gap in research means that $90 \%$ of a ll research is done in places where only $10 \%$ of the world's population lives. The budget allocation by the SAMRC for mental health research is smaller than for other health conditions. 
Africa is the Cradle of Humankind. We are thus all Africans, since all Homo sapiens originated in southem Afric a. Genetic evidence shows that genetic diversity is highest in Africa and lowest in placespopulated by small isolated groups, such as lceland. Artefacts from a cave nearCape Town provide some of the oldest evidence of the creation of art dating back 125,000 years.

With respect to research prionities, the 2012 Ekurhuleni Declaration on Mental Health reached consensus on what research needed to be done in the South Afric an context. There is an ongoing debate on whether the national priorities in psychiatry and mental health research in a low- or middle-income country context such as South Africa should focus more on discovery or on implementation.

The Grand Challenges in Global Mental Health (2011) differed from prior consensus documents on research in covering the whole gamut of both discovery and implementation science. This document identified the grant challenges as follows, thus informing some of the funding for mental health:

- Identifying root causes, risk and protec tive factors;

- Advancing the prevention and implementation of early interventions;

- Improving treatments and expanding access to care;

- Raising a wa reness of the global burden;

- Building human resource capacity;

- Transforming health-system and policy responses.

The opportunities for research collaboration between Germany and South Afric a include:

- South Africa's unique plant kingdom and rich floral system, which creates various psychotropic drugs that have been used for millennia. For example, the South African endemic plant Sc eletium tortuosum has a long history of tra ditional use as a medic ine by San and Khoikhoi people and subsequently by European colonial famers as a psychotropic in tincture form, and research using MRI scans has found it to be an anxiolytic. There are many opportunities to conduct basic research on psychotropics.

- Unique animal populations in Africa include large colonies of vervet monkeys and chacma baboons. There is a long tradition of ethologists over more than 100 years understand ing primates in their local context. The naked mole rat is valuable forstudies of ageing.

- Unique societal features, including negative aspects such as high rates of genderbased violence and social inequa lity; positive a spects such a shigh rates of cell phone penetration and large antiretroviral programmes; and interesting aspects such as rapid transformation from a partheid society to liberal democracy.

- Unique clinical populations including:

- Among the highest global prevalence of HIV. Mother-to-child transmission of HIV had been stopped; however, children who had been exposed to HIV but were uninfected were still cognitively affected. This presents a major issue for the research agenda.

- The world's highest rate of foetal alcohol syndrome (possibly with the exception of Native Americans in the USA).

o High rates of methamphetamine-induced psychosis, accounting for one in four admissions to some hospitals.

o Unique African genetic signature.

Prof Stein raised the issue of whether the transition could be made in mental health from the bench to the bedside and to bundu (i.e. the community). In the USA, China and the European Union, there has been considerable research funding to give effect to this notion. Many people trained in public health are very sceptical whether this is possible and ask whether this has ever happened before or whether it is just a pipe dream. In 
response to the question of whether this has ever happened before, it can be attested that it has already been done, and in South Africa. It is not widely known that Joseph Wolpe, who developed the technique of systematic desensitisation, was a South Afric an and conducted his initial research based on cat behaviour at the University of the Witwatersrand. Amold Lazarus, one of Wolpe's young colleagues, coined the term 'behaviour therapy' for this type of intervention. Behaviour therapy has since been transformed into cognitive therapy, which is the dominant intervention in psychotherapy throughout the world.

Can cognitive behavioural therapy be taken from the bench to the clinic? Some of the ea rliest resea rch on understand ing community medic ine comesfrom South Afric a. Sydney Kark and his wife developed community health projects in KZN in the 1940s, involving taskshifting and evidence-based interaction with communities. Their protégé was Menyn Susser, who left South Africa during apartheid and established the influential Gertrude H Sergievsky Center within the Columbia Mailman School of Public Health, which integrated clinic al, epidemiologic al and genetic research.

On the issue of taking therapies from the clinic to the community, the Global Mental Health in Practice series recently published Global mental health and psychotherapy: adapting psychotherapy for middle- and low-income countries. The challenge is now to adapt and apply psychotherapy in the low-income context in which most people in the world live. Prof Stein considered this to be one of the most cutting-edge research areas in psychotherapy.

Accepting the idea that research will help development is essential for making progress in genetic research, or indeed any other kind of research. There are good data to show that development is dependent on research. The Lancet Commission on Global Mental Health and Sustainable Development showed the importance of both discovery and implementation resea rch for susta inable development.

One of the challenges to be addressed is the genetics research gap. Genomic research is failing on diversity, in that only $18 \%$ of the research is done on non-Caucasian people. The statistic sare even worse for the field of neurogenetic mental health research, where only $4 \%$ of the research is done on people of non-Caucasian ancestry.

The next challenge is to show that understanding a person's genetic make-up can lead to suc cessful treatment. Cardiologists, for example, have developed new drugs based on their understanding of new genes. The Psychiatric Genomics Consortium is working to translate the findings of genome-wide association studies into new therapeutics for psychiatry.

South Afric a hasvery few neurogenetic ists, and therefore needs to make progress through collaboration. Good collaborative models are required for neurogenetic collaboration; the sound models developed for collaboration in the field of public health could be used in this regard.

One of the problems of genetic research is that it leads to reific ation and stigmatisation of mental illness conditions(e.g. through the simplistic reduction of a complexcondition such as sc hizophrenia, and lack of ta king the social determinants into account).

Good examples of addressing the neurogenetic gap include:

- Neuropsychiatric Genetics of African Populations (NeuroGAP) study, which was launched to address global disparities in neuropsychiatric genetic research, partic ularly in Africa. The study is being conducted in Kenya, Ethiopia, South Africa and 
Uganda, and a ims to collect 10,000 samples of DNA. This is one of the largest genetic studies in Africa.

- ENIGMA Consortium, which is investigating the relationships between genetics and brain imaging through collaboration that involves Gemany and South Africa, among others.

- Drakenstein Child Health Study, which studies child development, including mental health from infant to prepubescent by integrating social deteminants, genetics, epigenetics, gene expression, poverty, food insec unity and breast feeding.

The rest of the world has something to leam from Africa. Africa, especially South Africa, presents interesting opportunities to integrate neuroscience and global mental health perspec tives.

\section{Breakthrough in understanding the molecular causes of psychiatric disorders (Prof Markus Nöthen, Director, Institute of Human Genetics, University Hospital of Bonn, Gemany)}

Genetics has grown as a bridge between research and clinical application, and the presentation will raise some arguments in favour of this.

With respect to the genetic contribution to mental disorders, psychiatric illnesses frequently occur in families, as observed overcenturies; for example, schizophrenia has a $1 \%$ incidence among the general population but 10\% among those with a first degree relative with the condition; bipolar disorder has a $2 \%$ incidence among the general population but $10-15 \%$ among those with a first degree relative with the condition; depressive disorder has a $10-15 \%$ incidence among the general population but $20-30 \%$ among those with a first degree relative with the condition. On the basis of twin studies, the genetic component (heritability) of the likelihood of developing the disea se has been estimated: sc hizo phrenia $70-80 \%$, bipolar disorder 70\% and depressive disorder $30-40 \%$. It should be bome in mind that the estimated heritability is an average value, and no statement conceming ind ividual cases is possible.

The number of genes that contribute to psychiatric disorders is determined by the two ma in dimensions of biological complexity (in that the brain is the human organ with the grea test complexity) and heterogeneity as seen in the c linical va riability of patients, since different functions of the brain can be affected leading to different symptoms in various diagnostic categories. The frequency of risk variants in the population that predispose towards a psychiatric disorder is determined ma inly by selection pressure. If the untreated disorder causes reduced reproduction, there will be a larger number of rare mutations than in the case of a disorder that does not affect the reproduction rate. It has been shown, based on a population approach, that there is a reduced reproduction rate for most psychiatric disorders, particularly for schizophrenia and to a lesser degree for some other disorders. Not only rare variants but also common variants contribute strongly to psychiatric disorders, which might be explained by subclinical manifestations with favourable effects that cause selective advantage. There may be simultaneous contrasting effects for particular disorders favouning different parts of the spectrum of mutations.

The understanding of the genetic s of multifactorial disorders has profited enomously from the general understanding of the human genome starting with the first draft of the human genome in 2001, and espec ially from the systematic understanding at a population level of the genomic variability of common and rare variants across individuals. If a genetic variant is identified, the functional consequencesorfunc tional a nnotation of that genetic va riation a re still not known. Research on this a spect is ongoing. 
The most commonly applied way of identifying the genetic risk factors for psychiatric disea se is to use a genome-wide association approach. This approach uses patient DNA and controlled DNA from a large number of individuals, which is investigated for common variants with an array-based technology that allows the characterisation of common variation across the human genome. Thistec hnique is performed at the relatively low cost of $€ 30$, having come down from the previous cost of $€ 300$ several years ago. The identification of rare variants is more expensive. The first window into rare variants was offered by applying data generated by the arraysused for the analysisand using intensity data. This allows the effic ient characterisation of genomic deletions or duplic ations if the variants have a certain size in the human genome. The future perspective is sequencing of the complete genome, the price for which is expected to come down over the next few years (currently US $\$ 1000$ for genome-wide sequencing) to the extent that it is affordable not only for major research but also for many other projects.

The understanding of the genetic contribution to a polygenic disorder, or a group of polygenic disorders such as psychiatric disorders, was only possible through large intemational collaboration, which was the key to success. The field of psychiatry is distinguished from many other fields by the extent and crucial role of intemational collaboration. The Psychiatric Genomics Consortium (PGC) was established in 2007. The consortium includes over 800 investigators from 38 countries. Data from more than 900,000 individua ls a re currently in a na lysis. This is the largest biologic al experiment in the history of psyc hiatry. The initial foc us of the project was on common single-nuc leotide polymorphism (SNP) by investigating SNP a rays and later also including the characterisation of copy number variations (CNVs) based on the array data, as well as other rare genetic variations, with the perspective of obtaining whole genome sequences from many patients in the future.

The PGC initia lly had a number of disea se-specific working groups for Alzheimer's disea se, attention defic it hyperac tivity diso rder, a nxiety, a utism spectrum diso rder, bipolar diso rder, eating disorders, major depressive disorder, obsessive-compulsive disorder and Tourette syndrome, post-tra umatic stress disorder, schizophrenia and substance use disorders. The PGC now has several cross-disorder working groups that are not bound to diagnostic categories, for example, copy numbervariation group, cross-disordergroup and pathway a na lysis group.

The Genome-Wide Association Studies (GWAS) in psychiatric disorders have been a continuing success story, for example:

- For sc hizo phrenia, the investigation of 40,675 ca ses and 64,643 c ontrols resulted in the identification of 145 genome-wide significant loci.

- For bipolar disorder, the investigation of 29,764 cases and 169,118 controls resulted in the identific ation 30 genome-wide signific ant loci,

- For dep ressive disorder, the investigation of 135,458 c a ses and 344,901 controls resulted in the identific ation of 44 genome-wide significant loci.

The Bra inSTORM Consortium looked at shared aetiologies across diagnostic categories. Data for 158,028 cases and 365,993 controls were reported for ten psychiatric diseases in a paper in Science in 2018. Widespread sharing of genetic risk a cross psychiatric disorders was found.

The GWASof psychiatric disea sesprovided insights into biology. Aswith other multifactorial diseases, almost all GWAS find ings are located in non-coding genomic regions, and not directly within a gene. It is therefore sometimes difficult to understand the functional consequences of the respective variants. The functional effects are most likely of a 
regulatory nature, and the diseases are caused by complex influences on biological networks. If pathway-based analysis of the genomic regions implic ated in the GWAS studies is conducted, some insight is gained into pathways that will most likely be involved in the disorders. The involvement of glutamatergic neurotransmission in schizophrenia, for example, has been identified. Individual rare variants have been found to make a relatively strong contribution to the development of schizophrenia in an individual, which has implic a tions for diagnostics.

Various large-scale exome and genome sequencing studies are under way, but it is diffic ult to implicate a single rare variant in the development of psychiatric disease, and requireslarge a mounts of data. So far, only one gene hasbeen implic ated in such studies, but many more are expected to follow.

It is not yet known whether common and rare risk variants explain total heritability in psychiatric diseases, but perhaps it is possible to leam from the latest results on other phenotypes. For example, pedigree heritability for height and body mass index (BMI) appear to be fully recovered from whole-genome sequence (WGS) data on 21,620 unrelated individuals of European ancestry. The contribution of rare variants to narrowsense herita bility is larger than expected undera neutral model, whic $h$ reinforc es previous observations that height and BMI have been undernegative selection.

With respect to translating genetic findings in psychiatric diseases into clinical practice, the find ings provide the rational basis for the development of new drugs through proof of principle, for example, the GWAS for schizo phrenia detects the D2 dopamine receptor (DRD2) gene, the most prominent drug target in treating psychotic disea ses in the genetic study. In recent years, it has been possible to integrate the polygenic contribution into polygenic risk scores (PRSs). In considening prevention, it is essential to think in tems of risk stratific a tion of patients or individ ua ls at risk. A typic al proxy that is used in practice isfamily information. It is now possible to base this on moleculardata and reach farmore precise estimates of risk based on PRSs. However, the use of PRSs may exacerbate health disparities when translated into clinical practice. The PRSs available today are several times more accurate in individua ls of European ancestry than other ancestries. This is an inesc a pable consequence of Eurocentric biases in genome-wide association studies. To realise the full and equitable potential of PRS, greater diversity must be prionitised in genetic studies. As a matter of urgency, data will have to be generated for every population as a prerequisite for applying these new technologies, which will require investment.

The first step in integrating genetic into diagnostic proceduresfor psychiatric disorders will be the detection of CNVs, which are rare but contribute strongly to the development of disease in an individual. CNVs are also associated with other clinical features. Patients must be seen in a multidisciplinary context and followed up over a number of years in order to ensure that they are always treated in the most appropriate way. There is general agreement that this will be the first a pplic ation of genetic diagnostic s in psychiatry. There are still a number of open issues, including indic ation criteria, detection methods, data interpretation, communication of genetic findings, the impact on clinical care in tems of precision medicine, and showing that these diagnostic procedures indeed provide advantages for patients and their families.

One of Prof Nöthen's collea gues in his department, Dr Franziska Degenhardt, is orga nising a cost action at the European level, financed by the European Commission, on developing guidelines for the genetic counselling of psychiatric patients, and guidelines for genetic testing. Researchers worldwide are invited to contribute to the programme 
and the development of standards in this field. There may be South African researchers who are interested in participating in this important field.

The future outlook for understanding the molecular causes of psychiatric disorders will include:

- Cohorts must be expanded to include ethnic groups that have been underrepresented.

- The majority of the contributory genetic factors will by systematic ally identified through GWASand in future also genome sequencing. This is a matter of biometric and systems biology interpretation to reach an understanding of the biological mechanisms that underlie the genetic contribution. In future, this should lead to the identification of aetiologic al subtypes and more therapeutic targets.

- Gene-gene and gene-environment interactions have not been extensively addressed.

- Genetic diagnosesand genetic predic ation will become more reliable.

- In tems of functional biological a na lyses, every loc us that is identified will be followed up by with many detailed.

Prof Nöthen a cknowledged the role of his colleagues, Dr Franziska Degenhardt (research group lea der for schizophrenic disorders), Dr Andreas Forstner (research group leader for affective disorders) and in particular Prof Dr Peter Propping, the previous head of the department. Prof Propping was the founder of psychiatric genetics in Gemany. The knowledge and integrity of Prof Propping overc ame Gemany's historic al burden given the abuse of genetic approaches in psychiatry during the Nazi period and allowed this field to be established in Gemany from the 1970s onwards.

\section{China brain project and macaque models for biomedical research (Prof Murming Poo, Director, Institute of Neuroscience, Chinese Academy of Sc iences, China)}

The China Brain Project is a national project following intemational brain projects in the European Union, USA, Japan and Korea and other countries. This long-tem project will extend over 15 years (2019-2035). The project is referred to as having 'one body, two wings'. The key objectives of the core programme (the body) are (1) to understand the neural basis of cognitive functions, which comprises basic neuroscience research, (2) to develop a variety of brain research technology platforms for that purpose, and (3) to develop a mesoscopic connectome project, which will entail understanding and mapping out the neural connections at cellular level in various animal models, including zebra fish, mice and monkeys. This project will be initiated through intemational collaboration. The sub-objectives of the programme (the wings) are (1) to develop an effective approach in the diagnosis and interventions of brain disorders, especially early diagnosis, and (2) to develop brain-machine intelligence technologies, including the brain-machine interface; brain-inspired computing methods, devices and systems; and new machine leaming.

The presentation will cover the diagnosis and interventions of brain disorders ' wing' of the project, which foc uses on developmental disorders, inc luding a utism, mental retardation and schizophrenia; psychiatric disorders, including depression and addiction; and neurodegenerative disea ses such as Alzheimer's and Parkinson's. In order to understand disease mechanisms, it is necessary to understand the genetic and epigenetic factors, and the pathologic al circ uit dysfunctions associated with va rious disea ses. Understanding disease mechanisms is a long-tem project, and it may be possible to develop early diagnostic tools before fully understanding the disease mechanisms through genetic, molecular, ima ging and cognitive (functional) markers for va rious disea ses. This will require longitudinal studies of cognitive functions on large cohorts of nomal human subjects as 
well as diseases subjects. Once the markers have been identified, it will be possible to develop early intervention approaches; such interventions are traditionally phamacological and physiological, but physical modulation is also believed to be an important approach. It would also be appropriate to develop new disease models using non-human primates including two types of macaque monkeys (cynomolgus and hesus) as well as ma mosets to supplement the widely used rodent models for disease.

Prof Poo introduced the research on macaque monkeys to develop disea se models. One approach several years ago was to introduce human genes into monkeys by using a lentivinus vector conta ining the human MeCP2 gene to express in the embryo. The MeCP2 gene is known to be associated with autistic disorders; for example, Rett syndrome is caused by mutation of the MeCP2 gene, for which there is a rodent model. A macaque model was developed using overexpression of the human MeCP2 gene. The lentivinus injection into the mature oocyte was followed by intra-cytoplasmic spem injection for in vitro fertilisation. The healthy developing embryo was implanted into a surrogate mother who gave birth to the transgenic monkey offspring that camy multiple copies of the human MeCP2 gene. Seven transgenic monkeys were produced several years ago. Each monkey had different copies of the transgenes in different chromosomes. The monkeys developed behavioural phenotypes that resembled the a utistic phenotype, for example, repetitive stereotype circular locomotion. Transgenic monkeys showed higher than nomal threat-related anxiety and reduced social interactions both with wild-type monkeys and with other transgenic monkeys in tems of play and grooming both in pairs and in groups. This social defic it is characteristic of autistic patients. The average scores for transgenic monkeys in cognition tests were close to those of wild-type monkeys, but their ability in various tests was highly variable. The transgenic monkeys seemed to leam tasks more slowly, but eventually reached similar levels to wild-type monkeys.

A second generation of transgenic monkeys was bred, showing that gem-line transmission of MeCP2 is possible. The gem-line produced by one of the secondgeneration male monkeys had various chromosome copies that were similar to those of the original donor. The progeny produced were variable in their expression of the transgene. They a lso showed lower social interaction than wild-type monkeys. The model resulted in a highly variable phenotype.

A more advanced approach is to produce gene-edited macaque monkeys by CRISPR/Cas9 editing of in vitro fertilised monkeys. In this c a se, in vitro fertilisation is done by spem injection. The fertilised embryo is then injected with a vector that carries out CRISPR/Cas9 editing on a specific gene (Bmal1). Ten embryos were implanted in a surrogate mother to produce the second generation. The Bmall gene that wastargeted for editing is known as the circ adian hythm gene; a defic iency of this gene is associated with many disorders, including neurodegeneration, ageing, meta bolic disea ses and even cancer. Knocking this gene out could cause a variety of downstream disease symptoms. Complete knock out of Bmall expression was achieved in five of the gene-edited monkeys. Bmall expression has a cyc lic circadian hythm variation. The Bmall knock-out (KO) monkeys moved more and did not sleep as well as wild-type monkeys; in particular, Bmall knock-out led to reduced REM and non-REM sleep during regular dark/light pattems. When the Bmal1 KO monkeys were exposed to 24 hours of light for three days, the sleep disorder was more exaggerated. The Bmall KO and particle KO monkeys also showed circadian neuroend oc rine dysregulation, with clear loss of the cyclic variation of homones in their blood, including melatonin, testosterone, dehydroepiandrosterone (DHEA) and cortisol. For all the gene-edited monkeys, cortisol levels remained high throughout the day and night and showed stress, anxiety and depression phenotypes (e.g. hiding in the comer of the cage and a voiding social contact). Bmall knock-out also 
resulted in a schizophrenia phenotype, thus produc ing psychiatric symptoms similar to humans.

Gene editing through viral expression of transgenes resulted in random insertion of multiple copies. This method thus does not result in a model that is reliable or reproducible. The results of Bmal1 knock-out showed that CRISPR/Cas9 has low efficiency, with potential offtarget effects that resea rchers cannot control as well as mosa ic expression in that not all the progeny showed the same extent of editing. The generation time of macaque monkeys is five years, unlike mice in which it is possible to breed a more uniform phenotype after only a few months by breeding successive generations. Non-uniform genetic backgrounds are the cause of variability in all the gene-editing approaches. It was therefore decided several yearsago to produce monkeysthrough cloning by somatic cell nuclear transfer. The success of the cloning method was demonstrated in 1996 through Dolly, a female domestic sheep, the first mammal cloned from an adult somatic cell, using the process of nuclear transfer. The first cloned monkeys were produced at the end of 2017. In these clones, the nuclear DNA is identic al to that of the donor fibroblast, and the mitochondrial DNA is identical to that of the oocyte donor monkey. Having conducted suc cessful cloning, the next step was the decision to clone the gene-edited monkey that clearly showed the depression and anxiety phenotype through Bmall knock-out. Using the fibroblast from a male Bmal1 KO monkey, five cloned monkeyswere produced in 2019. The nuclearDNA wasidentical to that of the fibroblast donor, and the mitochondrial DNA wasidentic al to that of the oocyte donor. Very early, while still in the incubator, one of the cloned monkeys demonstrated the same anxiety and depression phenotype as the fibroblast donor, which was already 1.5 years old (e.g. hiding in the comer, hugging the head). The work was published in two papers in 2019 in the National Science Review, a new broad-spectrum joumal from $C$ hina that publishes both reviews and research artic les.

There is debate in the field between those who believe that non-human primates could be valuable in developing models for therapies for human diseases, and those who believe that non-human primates should be used with care asopposed to using rodents, although the rodent model has proved not to be useful for the development of drugs for psychiatric disorders (e.g. the failure of the clinical trials for most drugs for Alzheimer's' disease).

Non-human primates provide useful animal models because they can be used for studying the neural basis of highercognitive functionsthat a re most prominent in or unique to primate species (e.g. empathy, consciousness, complexsocial coopera tive behaviour). The evolutionary origin of human intelligence needs to be understood. Gene-edited monkeys could serve as valuable models for human brain disorders, as demonstrated by the Bmal1 KO monkey that showed many psychiatric phenotypes that it is not possible to study in rodents.

The key issue will be to establish rigorous ethic al practices in monkey research, and to communicate the importance of non-human primate research to society. The intention within the next few years is to use non-human primate models to develop phamacological drugs or physiologic al interventions for psychia tric disorders.

\section{Family studies from endogamous groups enable the elucidation of distinct predisposing pathways in dyslexia (Prof Subrata Sinha, All India Institute of Medical Sciences, New Delhi, India)}

Dyslexia or reading disability, a form of specific leaming disability, is a neurodevelopmental d isorder and refers to diffic ulty in rea ding and writing despite nomal intelligence and adequate education. Its worldwide prevalence is estimated to be 
around $5-10 \%$. Dyslexia has recently been recognised by the govemment of India as a disability with specific characteristic s, so that sufferers of dyslexia have legislative access to benefits similar to those received by the hearing-impaired, for example. Much remains to be done to implement the legislation.

Dyslexia has definite environmental and biologic al components. Studies have been done on post-mortem brains, as well as subsequent neuro ima ging studies, but the exact nature of the abemant pathways are not clear. Like other mental health disorders, dyslexia is heterogeneous, with multifa ctorial a etiology. Dyslexia is likely to be a 'ba sket' of disorders, possibly different pathways leading to a broadly common phenotype. Research has not been able to identify a limited set of genes that play a preeminent role in susceptibility to dyslexia world wide. It is hoped that the role of genetic analysis and complex phenotyping would be useful in identifying different endophenotypes resulting from distinct molecular and cellular pathologies.

Dyslexia ischaracterised by dysregulated phonologic al processing; dyslexic patients have the basic ability to mentally manipulate and processspeech and sound correspondences but deficits in other abilities such as word reading and decoding. Psychometric assessment batteries a re used to asc erta in dyslexia in research and clinical settings.

India has a large number of reproductively isolated endogamous groups as a result of geographical, cultural (related to caste, tribes and a ranged mamages), religious and ethnic isolation, and endogamous practic es persist up to the present. In 1868, K McLeod of the Indian Medic al Service observed "a peculiar ethnologic al and pathologic al value from the circumstance that all the subjec ts examined were natives of this district. So many cases of individuals, whose life and ancestry are confined within so small an area, can only be obtained amongst a people of stationary propensities not possessing facilities or inclination to migrate. The time when such records can be easily collected is rapidly passing away. Education and enlightenment, combined with increased facilities for migrating, will eventually break down the bamier."

A paperby Nakatsuka et al., (2017) published in Nature Genetic sentitled 'The promise of discovering population-spec ific disease-associated genes in South Asia', reported on the identific ation of 81 unique groups, 14 of which had estimated census sizes of more than one million that descended from founder events more extreme than those in Ashkenazi J ews and Finns, both of which have high rates of recessive disea se due to founder events. In such groups, recessive disea sesa re a lso likely to occurat an elevated rate, even in nonconsanguineouscases, because of recent shared ancestors.

The comparative genetic simila rity helped Prof Sinha's research team to identify, with a comparatively modest research struc ture, certa in susceptibilities that it would otherwise not have been possible to identify. Seventy-six members from three generations of a family of a particular caste were assessed. This multigenerational family constituted an endogamous group from west India. There were mamiages from outside the family, but from the same group. It was found that there was an insertion present upstream of the BASP1 coding gene; this was a homozygous insertion in 12 out of 14 cases of dyslexia, whereas the heterozygous or wild type was present in 20 out of 24 cases among the controls without the dyslexic phenotype. 


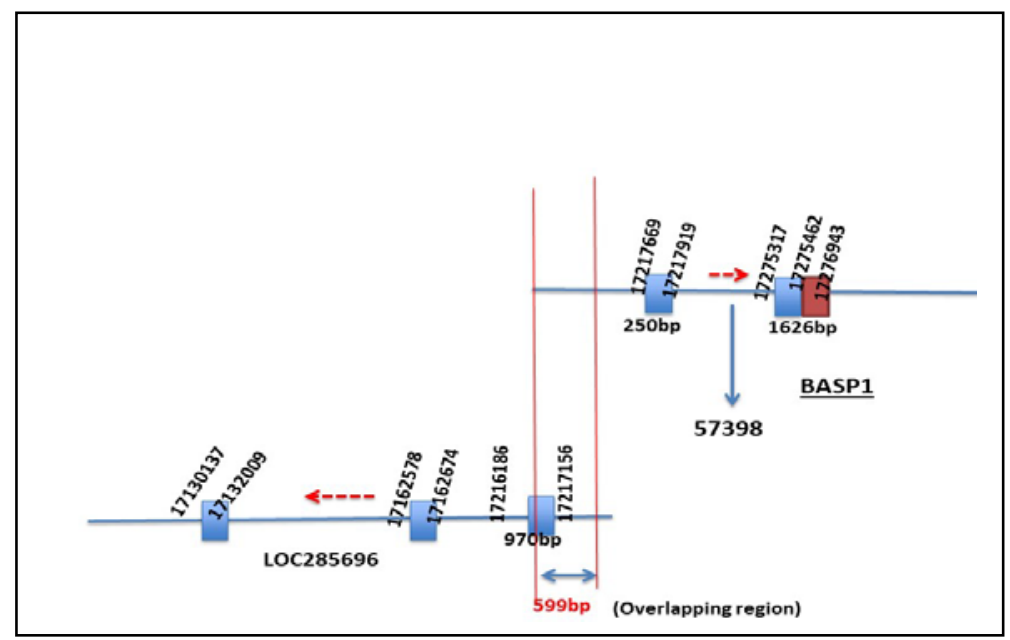

Figure 2: Overlapping region between BASP1 and LOC285696.

The overlapping region between BASP1 and LOC285696 (hitherto named BASP1-AU1) is $599 \mathrm{bp}$ long (Figure 2). Insertion is present at $350 \mathrm{bp}$ downstream from the start site of mRNA of BASP1-AU1. LOC 285696 encodes an uncharacterised long non-coding RNA in the overlapping region. This is a divergent IncRNA paining with a coding gene BASP1. Several genes are involved in neurite outgrowth and synapse formation. Co-expression of growth cone proteins GAP-43 and CAP-23 (BASP1) c an elic it long a xon extension by a dult dorsal root ganglion (DRG) neurons. BASP1 overexpression stimulated neurite outgrowth in PC 12E2 as well as in hippocampal neurons. The function of IncRNA is not yet known. Divergent IncRNA is known to regulate the corresponding coding gene. It is suspected that it helps to form a loop structure that is essential for the expression of the gene. The criteria for genomic looping are the presence of divergent CTCF sequences on looping points. CTCF protein (11-zinc finger protein or CCCTC-binding factor) binds on CTCF sequences. The Hi-C data of Rao and Huntley et al., (2014) were used forgenomic looping a nalysis and the Juicebox tool was used to visualise looping at the BASP1 genomic locus. The BASP1-AU1, BASP1 and TCF12 complex linkstwo loci associated with inherited dyslexia. The literature shows that there is a DYX1 locus on chromosome $15 q 21.2$ that is highly replic ated in dyslexia inheritance. The DYX1 loc us has two genes, namely DYX1C 1 and TCF12. The endogamousfa mily in the study a Iso had a GTinsertion in chromosome 5p15.1. There is a single common pathway critical for neuronal differentiation. It is likely that the same phenotype may result from the effects of different molecular pathways.

A second family (KA25) that was studied was a group that was geographic ally ethnic ally isolated. Whole exome sequencing and whole genome SNP array were conducted. A common set of genes was identified in both procedures. A set of 17 polymorphisms located across the $1.9 \mathrm{Mb}$ region on chromosome $5 q 31.3$ was identified, encompassing genes of the PCDHG cluster, TAF7, PCDH1 and ARHGAP26, dominantly inherited with dyslexia in this multi-inc ident fa mily. The non-risk form of 17 va riations of the PCDHG cluster are preponderant in the human lineage, while risk alleles are ancestral and conserved across Neanderthals to non-human primates. The observed association of PCDHG genes encoding neural adhesion proteins reinforces the hypothesis of aberrant neuronal connectivity in the pathophysiology of dyslexia. Additionally, the striking conservation of the identified variants indicates a role of PCDHG in the evolution of highly specialised cognitive skillsc ritic al to reading. The PCDHG haplotype wasnot present in othermembers of the community. Only four (0.1\%) of the individuals possessed both the CNTN6 and 
PCDHG haplotype together, while there was 100\% co-segregation of these haplotype within the affected individuals in fa mily KA25.

A third family was studied with respect to comorbidity between dyslexia and attention deficit hyperactivity disorder (ADHD). Variants were filtered by companing ADHD or dyslexia, or ADHD and dyslexia, with healthy individuals. Genes were prioritised on the basis of varia nts ca using protein-a ltering changes or regulatory effectson gene exp ression or structure, bra in expression, or those associated with the same or other neuropsychiatric disorders. Exome sequencing identified a $1.738 \mathrm{~kb}$ long haplotype in FAM43A (3q29) cosegregating with dyslexia and/or ADHD. FAM43A is overexpressed in whole blood of the risk genotype. The FAM43A haplotype has been shown to be present in schizophrenia, intellectual disability and lea ming diffic ulties.

Endogamous groups are a valuable genetic resource, because genetic similarity improves the possibility of identifying disease-associated variations. Better identific ation and understanding of aberrant pathways through the molecular heterogeneity of apparently similar phenotypes is well addressed by such groups. Markers for early diagnosis may be relevant to only one group, but some have large populations. Personalised or group-specific management could become possible. Novel insights into basic cellular processes can be gained, and researchers can genera te feasible research questions. Africa and Asia have endogamous groups that are a rich research resource. Some of these groups may be over a million strong.

Caution must be exercised in studying endogamousgroupsbecause the scientific findings will lack genera lisa bility, although the findings of studies of such groups contribute to the literature on aberrant pathways. There could also be negative social risks of focusing on isolated groups, including stigmatisation and exploitation, and care is required not to identify the groups that have been studied. The criterion in using endogamous groups for research is whether the community could benefit.

The laboratories that have collaborated in this work are the National Brain Research Centre/All India Institute of Medical Sciences, the Institute of Genomics and Integrative Biology, and the Regional Centre of Biotechnology.

\section{Disc ussion}

DrZawaira (AlexanderZawaira Consulting Sc ientists): Prof Nöthen's work found a negative correlation between sc hizophrenia and intelligence. If one can question one's sanity, one is probably not insane. The mathematicians J ohn Forbes Nash J r, Georg Cantor and Kurt Gödel are examples of people whose minds enlightened our understanding of the world of mathematic sand physics and were schizophrenic .

Prof Nöthen (University Hospital of Bonn): The studies can provide the first insight into phenotypes between the diseased and non-diseased population. The findings relate to correlation not causation. Expression of a particular phenotype is not responsible for the development of the other phenotype. With respect to the relationship between schizo phrenia and intelligence, there is probably a continuum of contributing genes from mental retardation to autism and schizophrenia. Some types of schizophrenia are more likely to be caused by genes representing the overlap of the different phenotypes, which is of interest in understanding aetiology. The comment was based on a level of interpretation, which is diffic ult on the basis of the available data.

Dr Zawaira (Alexander Zawaira Consulting Scientists): This response implies that the frequency of sc hizophrenia is likely to differ between major population clusters. Different 
human populations have different levels of intelligence, although this is a controversial view.

I agree with Prof Nöthen's rule of thumb, which states that a condition that seems to reduce reproductive potential is probably associated with unique genetic variations, and furthemore, I agree that this rule of thumb is useful in build ing hypothesesforexperimental work (i.e. experimentally-testable hypotheses). Have you considered building a linked chain of hypotheses from this rule of thumb to formal Darwinism? That is, have you considered formalising this rule of thumb?

Prof Lund (UCT): In terms of developing interdisciplinary research agendas, it might be valuable for neurogeneticists to introduce social epidemiological elements in order to better understand interactions between genes and the environment in longitudinal studies.

Prof Stein (UCT): One of the key messages is that phenotypes depend on the intersection of genetics and other factors. Heritability changes with environment. Any differences in intelligence are due to environment not genetic s. Reductionist emors must be avoided, such as those made in the study of genetics in Nazi Gemany and that continue to be made. GWAS shows how multiple genes are involved in multiple phenotypes.

In South Africa, pneumonia is the biggest killer of children under the age of two. The Drakenstein Child Health Study looked at the relationship between genes that code for lung development and exposure to pollutants that give rise to pneumonia. There is no gene for asthma, for example. Asthma is very complex, involving a large number of genes that intersect with pollutants in complex ways. It is likely to become possible eventually to determine a polygenic risk score for an individual, thus showing a predisposition to a partic ular condition. It can then be recommended that they avoid a particular pollutant.

Two interdisc iplinary a reas that a re very important for genetic s a re philosophy in order to address deep ethical and conceptual issues, and statistic s rela ted to risk.

Prof Nöthen (University Hospital of Bonn): I do not believe that polygenic risk a na lysis is far from implementation in clinic al care. Medical practitioners a lready stratify the population in tems of disorders (e.g. coronary heart disease, lipid levels, blood pressure or other measurements) and dispense preventive measures based on that stratification. Genetic information could be included formore precise estimates in stratific ation and clinic al care in the nearfuture. In psychiatry, risk stratific ation is not established and will take longer, as it will need to be proved that the type of risk stratific ation that has been done extensively for other disea ses makes c linic al sense.

Dr Zungu (HSRC): Is there any work in South Afric a that focuses on genetic mutation in relation to mental health disorders?

Prof Stein (UCT): The biggest study is NeuroGAP. Other work is being done at Stellenbosch University and the University of KwaZulu-Natal.

Prof Duncan (UCT): Circadian modulation was well illustrated by Prof Poo's research on cloned monkeys and could have links with social epidemiological data (as referred to by Prof Lund) and implic ations for activity and functioning. The UK National Health Service is moving towards social prescribing with respect to interventions related to how people spend their time each day in tems of func tioning and activities. In this context, play asan activity and modulation for well-being might be worth considering as a dimension, for 
exa mple in the Drakenstein Child Health Study? The introduc tion of a n a c tivity programme has been shown to reduce depression, for example, in a study by Vikram Patel).

Prof Stein (UCT): C irc a dian mythms a re interesting. It is clear that people genera lly need more sleep than they are getting and that the use of digital devices is intemupting sleep and causing a host of problems.

\section{SESSION 3: PUBUC MENTALHEALTH AND EPIDEMIOLOGY Fac ilitator: Prof Markus Nöthen, Director, Institute of Human Genetics, University Hospital of Bonn, Gemany}

\section{Common mental disorders among individua ls seeking HIV testing (Prof Ashraf Kagee, Co-Director, Centre for Public Mental Health, University of Stellenbosch, South Afric a)}

The prevalence of HIV is still high: 36.9 million people globally were living with HIV in 2017, of whom 35.1 million were adults and 1.8 million were children under the age of 15 years. HIV infection is associated with a range of mental health conditions. It has been assumed that an HIV-positive test causes people to become depressed, tra umatised, or develop other mental health conditions. In a paper in 2004, Prof Melvin Freeman referred to the HIV pandemic as a "mental health disaster".

In 2008, Freeman published a prevalence study of 900 people living with HIV using the Composite Intemational Diagnostic Interview (CIDI) and found that $43.7 \%$ had a diagnosable mental disorder major depression $11.1 \%$, mild depression $29.9 \%$, alcohol a buse $12.4 \%$, generalised anxiety disorder $0.4 \%$, post-tra umatic stress diso rder (PTSD) $0.7 \%$, PTSD (event HIV) 4.2\%, and intermittent explosive disorder 3.9\%. Mental health concems in HIV affect the quality of life, adherence to antiretroviral therapy (ART) and therefore health outcomes, family functioning and adherence to infant-feeding guidelines among new mothers.

Prof Kagee conducted a mental health and adherence study in which 101 ART users completed the Beck Depression Inventory (BDI), Beck Anxiety Inventory (BAI), PTSD scale and viral load tests. The odds of an association between high BDI scores and detectable viral load were high. Patients reporting elevated symptoms of depression on the BDI were more than three times as likely as non-depressed patients to have a detectable viral load. This ra ises several questions: whether mental health screening should be integrated during HIV testing; whether mental disorders a re present prior to an HIV test; and whether routine sc reening for common mental disorders is a good idea.

In order to try to answer these questions, participants were recruited by means of convenience sampling at five HIV testing sites in the Westem Cape, South Africa. Temporary testing centres were set up in public areas such as shopping centre parking lots and public transport centres, and community members were invited to receive a free HIV test. The Structured Clinical Interview for the Diagnostic and Statistical Manual of Mental Disorders (Research Version) (SCID) was administered, as well as a range of selfreporting measures including the BDI, BAI, Hopkins Symptom Checklist, Post-traumatic Stress Symptom Sc a le and Alcohol Use Disorders Identific ation Test (AUDIT). Five hundred people were recruited into the sample, including $49.1 \%$ males and $50.9 \%$ females, with a mean age of 36. Over a quarter of the participants had at least one form of mental disorder.

The only significant differences between men and women were related to anxiety. In a number of cases, a common mental hea lth disorder (CMD) existed prior to having a n HIV 
test. For those who later tested HIV positive, this result wasc lea rly neither the cause nor the precipitant of the mental disorder.

With respect to the question of whether routine screening is a good idea, screening measures are cost-effective, time-efficient, and easy to use, whereas diagnostic interviews such as SCID a re resource- and time-intensive, and have to be administered by a trained professional. The performance of the self-reporting measures was assessed in determining the presence of CMDs, with the following findings:

- $\quad B D I$ is effective in identifying non-cases of major depressive disorder (MDD), but less effective in identifying cases of MDD.

- BAI is effec tive in id entifying non-ca ses for genera lised a nxiety disorder (GAD), but less effective in identifying cases for GAD.

- The PTSD Symptom Scale (PSS) is effective in identifying non-cases for PTSD, but less effective in identifying cases of PTSD.

- AUDIT is well suited to identifying true non-cases of alcohol use disorder (AUD), but moderately effective in identifying true cases of AUD.

The conclusion reached with respect to the advisability of transdiagnostic screening was that it is not practic al or efficient in a public health setting to ask people to complete a lengthy battery of tests consisting of multiple sc reening instruments. It is a lso not fea sible for clinic staff to have to score and interpret multiple disorder-specific screening instruments.

The utility of a brief transdiagnostic instrument wasthen considered to identify persons who require further psychiatric assessment. The Hopkins Symptom Checklist (HSCL) was used. With respect to positive predic tive value, there was a $57 \%$ probability that ind ividuals who sc ored above 43 on the HSCL-25 would meet diagnostic criteria for a CMD. With respect to negative predic tive value, there was an $80 \%$ probability that individuals scoring below 43 would not meet the criteria for a disorder. HSCL-25 thus has some utility as a brief transdiagnostic sc reening tool to identify individuals who a re likely to have a CMD, and is modera tely accurate.

The following conclusions were reached:

- A positive screen does not nec essa rily mean ca seness for a CMD.

- Routine screening can generate a large number of false positives, with a high number of unnecessary psychiatric referrals, thereby placing a burden on the public health system.

- A two-tiered approach to screening might be effective. In such an approach, individuals who score above the cut-off point on a screening instrument should be further assessed using a diagnostic interview to detemine whether they are a true case for a CMD. This would help to avoid clinics being overloaded with false positives.

- Screening may not be a panacea.

- In using a screening approach, it is assumed that properly tra ined healthc a re workers are available to provide treatment to those who need it.

The next steps in this work a re to adapt a transdiagnostic sc reening instrument using local idioms of distress that pertain to the subjective expeniences of people in various communities. An observational cohort study of ART users would determine if screening and referral for treatment lead to the a melioration of mental health symptoms, improved mental health outcomes, improved ART adherence, retention in care and viral suppression. 


\section{Addressing the challenge of mental disorders: genetic approaches to nosology, aetiology, and treatment (Prof Marcella Rietschel, Sc ientific Director, Department of Genetic Epidemiology in Psychiatry, Central Institute of Mental Health, Gemany), Faculty of Medic ine Mannheim, University of Heidelberg}

All mental disorders are heritable, although there are differences with respect to heritability and frequency. For example, schizophrenia and bipolar disorder have a heritability of about $80 \%$ and a frequency of less than $1 \%$, while a lc ohol dependence and major depressive disorders a re the most common mental health disorders with frequency of over $10 \%$ and heritability of a bout $40 \%$. It would be useful to identify the genetic factors that underlie these disorders, because there are no objective biological markers to help guide diagnosisor predict the cause of the disorderorresponse to medic ation. Unra velling these factors at a molecular level would fosterbetter understanding of their a etiology and enable the development of better treatment.

The most straightforward approach is to compare at genome-wide level the variance between the affected and non-affected population, or people shaning or not sharing various traits. This has been done with considerable success over the last decade with GWAS, which compare differences of common variants with allele frequencies of above $1 \%$ in patients and controls. Common variants expla in $30-50 \%$ of herita bility estimated in fa milies. Increasing numbers of genome-wide signific ant variants have been identified in relation to schizo phrenia (over 40,000 patients) and bipolar disorder (over 20,000 patients), as well as in alcohol use disorder and major depressive disorder, requining larger sample sizes. The GWAS data represent ric $h$ data sets, and their a na lyses is not limited to following up the genome-wide signific ant findings. The wealth of data below the threshold can be used to gain insight into the biology and characterise gene components. Understanding the biology is done by a nalysis at the gene and pathway levels, as well as the enrichment level.

In sc hizophrenia, many variants associated with the condition have already been found, the most significant with markers in the major histocompatibility complex (MHC) region, namely expression of complement component factor C4-A. C4 proteins a re responsible for pruning in which the brain sheds weak or redundant connections between neuronsas it matures. During adolescence and early adulthood, this activity takes place primarily in the section of the brain where thinking and planning skills are centred, known as the prefrontal cortex. Given the implication of C4A in synaptic elimination duning postnatal development, this finding provides robust genetic support to the longstanding theory of excessive synaptic pruning in schizophrenia, postulated in 1982.

It was also reassuring that the DRD2 receptor, which is the target for all classical antipsychotics, was among the genome-wide significant findings. The findings support previous hypotheses with respect to dopaminergic neurotransmission, glutamatergic neurotransmission and postsynaptic density. The findings also point to hitherto unknown mechanisms in relation to histone methylation processes, acetylcholinesterase and calcium channel function. Most of the variants are enriched at enhancers active in the brain. Studies are being done to try to localise which loci are expressed in which gene regions, and when during the lifetime.

The wealth of data can be used to estimate the heritability of complex psychiatric disorders. The variance explained by the tested variants is about a $30-50 \%$ of the heritability estimated by fomal genetic studies. For alcohol use disorder, the variance explained about $9 \%, 10 \%$ for depression, $40 \%$ for schizophrenia and 30\% for bipolar disorder. These percentages would increase with sequencing data. Polygenic risk scores can be calculated. Genetic correlation can be conducted between common disorders 
and traits and Mendelian randomisation, which detects the causality of the association as well as the direction.

There is well-known comorbidity between depression and genetic a lly correlated disorders. Obesity, body fat and triglyc erides a re associated at a genetic level with depression, and the direction is from BMI to depression. The direction is opposite in relation to the correlation between smoking and depression (i.e. depression triggers smoking). Not only substance use disorders are genetic ally associated with alcohol dependence, but also depressive disorder, major depressive disorder, ADHD and PGC cross-disorder, which includes schizo phrenia. One of the major findings of the GWAS study was that psyc hiatric disorders, in contrast to neurological disorders, have large genetic commonality with substantial sharing of variant risk.

With respect to disentangling genetic commonalities and specificities, in categorical diagnosis of schizophrenia and bipolar disorder a specific number of symptoms have to be fulfilled over a predetermined time period in order to obta in a positive diagnosis, but this a pproach is somewhat arbitrary. In this process, clinic al symptoms that a re pertinent to the diagnosis of schizophrenia do not overlap with the clinical symptoms of bipolar disorder. However, all clinicians know that this is not the case; for example, $50 \%$ of schizophrenia patients show depression before the onset of the disorder, but these symptoms are not used to diagnose schizo phrenia.

In a diagnosis of schizophrenia, with a high load of manic symptoms as defined by the polygenic risk score, there will be many manic paranoia symptoms. If the polygenic risk sc ore is low, there will be many negative symptoms associated with schizophrenia. In the case of bipolar disorder with a high score for schizophrenia risk variance, there will be many psychotic symptoms. Bipolar disorder can be subdivided into bipolar 1 and bipolar 2. Until recently, it was thought that bipolar 2 was only a minor variant compared with bipolar 1 . However, while bipolar 1 and bipolar 2 share a number of genes, bipolar 1 has more commonalities with schizophrenia than bipolar 2, and bipolar 2 has more commonalities with major depressive disorder. Large multiplex families with bipolar disorderwere recently a nalysed and the same pattem wasfound. It wasfound that in the same family, bipolar 1 patients have a higher risk score for schizophrenia, and bipolar 2 patients have a higher risk score for major depressive disorder. These findings have shattered concepts that had been held formany decades. It is thus important to scrutinise not only c linic al symptoms but all other symptoms.

AUDIT is one of the most common screening measures for alcohol use disorder. It is a composite questionnaire that also measures frequency and quantity of alcohol drinking as well as binge drinking. While alcohol frequency and quantity share about $50 \%$ of the genetic underpinnings in alcohol use disorder, opposing genetic correlations have been found with disorders and traits, e.g. frequency as opposed to quality is correlated to overall better health, socio-economic factors and cognitive functioning. Animal studies show that the amount of drinking but not the frequency predicts the response to nalmefene.

Comprehensive phenotyping is recommended and should be longitudinal and respond to intervention, relapse and course among specific populations. Comprehensive phenotyping should take into account environmental factors (socio-demography, education, violence, abuse, emotional support, green space, poverty, nutrition and locomotor activity), disorder-associated symptoms (clinical symptoms, neuropsychological features, behaviour, endophenotypes [bra in imaging] and side-effects) and biological features (transcriptome, proteome, epigenome, microbiome and hair cortisol). Ecological momentary assessment can be done in real time by means of apps 
(which could measure neuropsychology, mood/emotions, cognition, volition and craving), smart watc hes (whic h could mea sure locomotion, light, tempera ture, heart rate, body posture and pressure) and smart garments (which could measure ECG and heart beat monitor, heart rate va riability, effort and fatigue assessments, QRS events, breathing rate, minute ventilation, activity intensity, peak acceleration, and track sleep). Comprehensive phenotyping would begin with prenatal monitoring and continue through birth, high risk identific ation, course of the disorder and intervention).

Phenotyping hasbeen done in population-based samples in the German national cohort of 200,000 longitudinally assessed population-based individuals with expert and selfratings. Examination modules entail the content of the face-to-face interview, selfcompletion questionna ires offered as touch-screen modules, and physical examinations.

Genetic approaches enhance the understanding of underlying biological processes and the identification of new drug targets, and help with disentangling heterogeneity and comorbidity, biologic ally guided diagnoses, individualised therapies, prediction of onset and course of the condition, as well as prevention.

\section{Prionities of mental health public policy in Portuguese-speaking countries from Afric a and South America: how to build nationwide care systems in contexts of social inequalities, vulnerability and scarcity (Prof Pedro Gabriel Delgado, Institute of Psychiatry, Federal University of Rio de J aneiro (URI ), Rio de J aneiro, Brazil)}

The presentation can be summed up by the central question 'How are developing countries facing the thomy problem of the mental health treatment gap?' This question unfolds into others, including how to set clear priorities for mental health policy, and in what way is it possible to build susta inable responses at national level. Brazil is taken as an example in answering these questions, taking into account innovations implemented in the last 35 years, and prospects for the future brought about by drastic politic al change that the country has faced since 2016. A workshop for representatives from Portuguesespeaking countries was held in Lisbon recently (J a nuary 2019) to disc uss the challenges posed by the targets of Agenda 2030. This workshop coincided with the launch of the Lancet Commission's report on mental health. The central theme of the workshop wasthe strategies developed by very populous countries such as Mozambique, Angola and Brazil with the aim of building nationwide service networks in the context of social inequality, scarcity and vulnerability. Mozambique is a successful example of innovation through task-shifting in personal mental health.

The 2030 Agenda for Sustainable Development includes mental health and well-being among its goals. The Lancet Commission report of October 2018 explic itly recommends that mental health be included in all the SDGs. Inclusive education, gender equality, sustained peace and opportunities for decent work a re all conditions for a chieving wellbeing. In that sense, the scenarios of social inequalities, violence in all its forms and vulnerability a re challenges for mental health polic $y$.

The process of psychiatric reform in Brazil will be examined in more detail, taking into account geographic and socioeconomic data. Brazil has a population of 206 million inhabitants and GDP of US\$1,960 trillion. Since 2001, Brazil has experienced significant improvement in the indicators of infant mortality (13.12\%) and life expectancy at birth (76.2 years). The human development index (2017) is 0.759 , which is the $79^{\text {th }}$ position in the world. 
The components of psychiatric reform include transformation from the hospital-centered system to community psychiatry, in a balanced care model; the radical intemalisation of mental health services to regions previously not covered by care; strong integration between community-based specialised services and primary care; the challenges of the institutionalisation of long-stay patients; the promotion of health and well-being in social contexts of inequity and vulnerability; how to build a susta inable mental health network in a large country with scarce financial resources; and the challenge of the single health system (SUS) and its goal of universal health coverage. The programme to downsize beds in psychiatric hospitals was the first challenge. Until 2001, the hospital component comprised a lmost $90 \%$ of mental health expenditure. The steady reduction of beds since 2001 was intemupted in 2017. The beds have been reduced in order to progressively transform hospitals with more than 500 beds into smaller micro hospitals, ensuning safe transition of the care model. Residential services were created in order to receive longstay patients. For the same purpose, the country has created a major innovation, namely the 'retum home' programme, which has been approved in national law and provides financial support directly to long-term patients who are discharged from hospital and treated in the community, where they can become full citizens in the society.

The second major component of the psychiatric reform process was the establishment of community-based mental health services throughout the country, called psychosocial care centres(CAPS), whic h have grown stea dily from 295 in 2001 to 2209 by 2014 , ensuring the intemalisation of mental healthcare. Facing the challenge of the mental health gap and the bamers to access to trea tment, these centres have moda lities for a dults, child ren, adolescents and youth and patients with problems associated with the consumption of alcohol and otherdrugs.

In order to ensure access to treatment, mental health has been artic ulated with primary healthcare in the form of collaborative care or inclusion of mental health teams. Community hea lth agents began to rec eive tra ining in mental health casesand situations. Unfortunately, in 2017 the expansion of this programme was intemupted by the federal govemment that took over after the removal of President Dilma Rousseff.

The coverage of family health teams has been expanded to the current figure of 39,000 teams. This is one of the ma in a chievements of the unified health system and the gateway to the whole system. The care setting has changed completely with the extension of the primary care themes throughout the country. In 2019, the new govemment extinguished the 'More Doctors' programme and made changes to the family health programme, which meansa threat to primary healthcare coverage.

The changes in funding should also be highlighted. There hasbeen a shift in the destination of financial and human reso urces from mental health so that the community component (i.e. community-based mental healthcare, residential services and primary care) has surpassed the hospital component since 2006. More than $85 \%$ of fund ing is ea marked for the community service network, with a real increase in mental health financial resources, although still insuffic ient at around $2.6 \%$ of total health expenditure compared with the WHO recommendation of at least $5 \%$. The demographic and socioeconomic characteristic s of Brazil constitute a challenge for mental health and for the promotion of well-being in accordance with the sustainable development agenda.

The main problems include:

- Extreme socioeconomic inequality, which is one of the most serious in the world, with a high concentration of income aggravated by the neoliberal agenda of the current govemment; 
- $\quad$ Decrease in overall financing for health and public polic ies since 2016;

- High unemployment of a round $13 \%$;

- Serious problems of urban violence, with temitories occupied by amed groups linked to drug traffic king or paramilitary militia groups;

- Increased mortality from homic ide (56 per 100,000 per year);

- Explosive penitentiary situation, with the third-largest prison population in the world;

- Racial and gender discrimination.

Brazil has made a safe transition from the hospital-centred psychiatric model to the community mental healthcare model of balance. There are still several challenges to overcome in the consolidation of a psychosocial care network capable of overcoming the care gap, but the existing evaluations and studies maintain that the direction is correct. However, there are two enomous challenges to be faced: firstly, the worsening of social tension, vulnerability, unemployment and inequity, especially in 2019; and secondly, the political challenge represented by the funding restrictions of the fiscal adjustment agenda of the govemments implemented in the country after 2016 . There is a real risk to the unified health system and intersectoral public policies.

Prof Delgado expressed his solidarity to all countriesthat a re pursuing the goa ls of Agenda 2030.

\section{Adolescent substance abuse trends: the need for early identific ation (Prof Arvin Bhana, Chief Research Specialist, Health Systems Research Unit, South Afric an Medical Research Council)}

The association between adolescent substance use and the emergence of future substance abuse, including mental health issues, is quite strong. Accelerated neuronal development takes place in adolescents together with advanced pruning. This group is vulnerable because of the use of substances. Due to pruning, the vulnerability to dependence has greater effects on some parts of the brain. Hamful alcohol use in early adolescence predisposes to damage in the brain in some cases. While the abuse of substancescan disnupt the potential for highercortical functioning, it should a lso be bome in mind that the shorter period of use is less likely to lead to entrenched pattems of abuse. There are some good reasons why a dolescent substance use needs to be looked at.

Repeated cross-sectional data will be presented, because the research involved respondents being surveyed at successive time points. This allows disaggregation for examining trends in some populations. The disaggregated data help provide more robust estimates of emerging or developing trends and useful information about overall pattems of abuse over time and take away the notion of a particular substance being abused more at a particular point in time forming a new trend. When the data are considered over time, the apparent trends even out, given that variations may spike over a short period of time.

The data have been collected from 78 inpatient and outpatient treatment centres by the South Afric an Community Epidemiologic al Network on Drug Use. This network has been collecting this type of data for a long time. This is currently the only data on substance use provided to the $\mathrm{DoH}$, not only among adolescents but also among adults. The data are 
facility based (i.e. from people who visit treatment centres for substance abuse issues, not data from the general population or communities). The data cover the whole of South Africa (with Mpumalanga and Limpopo combined as the Northem Region, and Free State, Northem Cape and North West combined as the Central Region). The data reflect trends in substance use among adolescents in treatment aged between 10 and 19. The data were collected every six months between 2009 and 2013.

The most populous region in tems of young people aged 10 to 19 is KwaZulu-Natal (KZN) (about two million in total), followed by the Eastem Cape and Gauteng. Over the period under investigation, Eastem Cape presented $7.7 \%$ of the data and KZN 9.4\%. Two provinces, the Westem Cape and Gauteng, have over one third of young people aged 10 to 19 in treatment, with averages far above the nom and out of proportion to the number of young people in the province.

The data bear out the perception that substance abuse is more prevalent among males. On average, four-fifths of the population in treatment is male. The Eastem Cape follows that trend, with $20 \%$ of those in treatment being girls and young women. In the Westem Cape and Northem Region by comparison, farhigherpercentages are female. Gauteng also had a substantial number of young women in treatment. The age of vulnerability peaks in mid to late adolescence, generally between 16 and 17 years of age. Every population group apart from Black Africans is overrepresented in the data in relation to the size of the respective population.

In the overall data set for the period J a nuary 2016 to December 2018, the data for the 1019 age group are predominant. Substance abuse appears to be a phenomenon of young people. A very small percentage of those treated during the five-yearperiod are retuming patients; most are new patients.

Most of the cohort in the data set were treated on an outpatient basis. This begs the question of whether this is a n effec tive approach to trea ting substance use among young people. However, this is the trea tment that is a va ilable. Most of this trea tment is provided by an NGO, not by the state.

The profile of the major substances abused has changed over time. Methamphetamine and heroine, the top drugs of use in 2009, began to decline.The most significant substances that a re currently abused are marijuana and alc ohol. Multiple substance use is often a factor (including a lso heroine, nyaope and methamphetamine). A second series of data, from 2013 to the present, might further exemplify the change in pattem. Between 2009 and 2013, there wasa stea dy inc rease in drug use a mong early and mid-a dolesc ents but not late adolescents.

Data on mental health started to be collected recently. The data are not sufficiently granular to provide details of the type of mental health issues that the patients present with. The data already show a direct relationship between mental health and substance use. Early identific ation is critic al. Given the age of greatest vulnerability, efforts to identify early abuse are possible. Substance abuse needs to be identified at school, in the community and at primary healthcare level, but the tendency is to foc us exc lusively on adults. Young people are not receiving enough attention because the problem is overlooked and they a re generally not considered to be individuals in need of help. From a prevention perspective, if young people are not targeted, the prospects of treatment for this a ge group are not good. 
Screening tools that are fit for purpose are required and may help in addressing the challenge through early identification and referral to treatment; however, there is not much treatment available.

The research gaps include the fact that most research on these issues has been done in high-income countries. The applic ability of the findings to a country such as South Africa is uncertain. It is not known whether the treatment modalities that are offered, or the relationships shown between substance use and va rious characteristic s, a re a pplicable to South Africa. There is severe underrepresentation of research in low-resource contexts. Much of the work is exploratory rather than explanatory (i.e. basic survey-oriented research that is not particularly useful in planning interventions or preventing substance use). Robust research is required, using sophistic ated methodologies and statistic s to provide better-qua lity evidence of what works, for whom, and in what context. Currently this da ta does not exist.

Systems-based research that focuses on issues of implementation is required and should form the bedrock of sustainable and effective research efforts. If interventions are implemented without considering the context in which the problems occur, the interventions a re likely to be unsusta inable, incapable of scaling up and ineffective.

Early identification is important in the interests of prevention. Research is required into adaptations, the development of valid and reliable measures, and the most appropriate type of intervention for a particular type of substance abuse problem in a given context (e.g. interventionsfor the same population group might differ between a school, a primary hea Ithc a re environment or a community). It is likely that in some provinces the issuesmight not be related to the substances that are abused, but social deteminants could play a signific ant role in some communities engaging more in substance use than others).

What systems and processes need to be in place to ensure continued care from early identific a tion to intervention? In high-inc ome countries a swell a smiddle- and low-income contexts, the evidence for effective treatment for adolescents does not inspire confidence. Early identification to prevent the problem from becoming chronic (i.e. associated with dependence) is thus even more critic al.

\section{Disc ussion}

Ms Scott (Wits): As a psychologist who sees people from both outside and inside the university, there are signs even among students of problems that will emerge more fully later, such as very high levels of anxiety, withdrawal and a voidance of reality, and low self-esteem. These are early indicators that suggest the potential for later alcohol dependence. The interventions need to foc us on anxiety.

Prof Bhana (SAMRC): Some practitioners feel uncomfortable to ask patients how much they drink, especially if the patient is a young person, but this question needs to be asked to put the patient's health into context. From a certa in cultural perspec tive in South Africa, high alcohol consumption is considered nomative, so the answer to the question could indic a te existing or potential problems and risks.

Ms Scott(Wits): Alcohol usa ge tendsto inc rease into a dulthood, and high levels of a lcohol use may be nomative among students, usually in a social context. Avoidance of reality may be seen along with alcohol use among many students. Anxiety and high levels of punitive self-talk are a nother form of a voiding facing a part of the self. These key factors a mong adult alcoholics can a lready be seen in students. High nomative social drinking among students could become alcoholism in later life. 
Prof Sinha (All India Institute of Medical Sciences): Is the approach to following the metabolome and the microbiome longitudinal? Is the microbiome expected to remain stable, and what are the components? How do you distinguish between the stable and unstable components of the microbiome?

Prof Rietschel (Central Institute of Mental Health, Gemany): Research suggests that a mic robiome pattem rema ins rela tively stable after the a ge of 3 years, a lbeit it may change thereafter due to many factors. The microbiome is only starting to be researched for psychiatric disorder. In our research the microbiome of four-year-olds was investigated. Associations were found with cognition, which have been reported before. These findings are associated with smoking by the mother duning pregnancy. The signific ance of these associations is not yet understood. Follow-up research will be required.

Dr Zungu (HSRC): Are you seeing an increase in the number of young people that present at clinics since the ruling that made dagga legal for personal use?

Prof Bhana (SAMRC): It is still too early to establish whether the change in legislative regulations for manjuana have made a difference in usage pattems. It is also diffic ult to make a direct association between people who are likely to use marijuana and whether they are now likely to use it more frequently than before. However, the changes in regulations are unlikely to improve the situation among users.

Prof Petersen (UKZN): The DoH is introducing screening into primary healthcare facilities, and also wants to introduce screening for community healthcare workers. The presentation focused on the measures. Will you also interrogate 'how' in order to provide balanced data? The question of 'how' is important from the perspective of the provider (i.e. who is doing it), what training they would need, and how best to introduce screening (e.g. in a screening room or consultation room), how it is integrated into other screening processes, as well as the patient's perspective. South Africa has a low medical literacy rate, and patients do not understand what they a re being sc reened for. Psychoeducation may thus also need to be introduced.

Prof Kagee (SU): The data raised some concems about the utility of routine screening, which needs to be borne in mind. Sc reening might seem to be an easy solution; screening is certa inly required, but we need to be more circ umspect about the potential ga ins from routine screening. Perhaps our expectations are somewhat inflated with respect to the health outcomes, including mental health outcomes, that can occur as a consequence of sc reening. In other contexts, such as the USA for example, there is mixed evidence that routine sc reening leads to optimal mental hea lth outcomes. These considerations need to be taken into account in the debate about the potential benefits of screening. We should not give up on screening, because we need to be able to identify people who require mental health services. It will be important to consider ways to integrate local idioms of distress as items on measures that perta in to people's lived subjective experience. This will probably be the next step in this line of work.

With respect to the question of where and how screening should be conducted, sc reening could not be conducted in clinic waiting rooms for example. Screening has to be done under more controlled conditions where nurses a re sc reening patients for other conditions as well. A possible approach would be to try to identify a minimum number of items on a sc reening instrument that could lead to a stepped approach in which people who endorse items in a scorable direction a re referred for additional assessment. 
Prof Domschke (University of Freiburg): Congratulations on the data showing comorbidity of HIV patients with mental disorders. There is a tendency not to look at categorical disorders any longer. There has been considerable work on transdiagnostic psychometric instruments. There are research consortia looking at genetic data that point towards a common biological trunk for several disorders. At the diagnostic level, there seem to be common intermediate phenotypes and genotypes. This mirrors efforts in treatment; Da vid Barlow's transdiagnostic unified protocol for emotional disorders, for example, pointed towards targeting intemediate phenotypes of mental disorders. This is especially interesting in the context of global mental health. If it is necessary to use resources economically, one might want to foc us on interventions that a re economic al in targeting many disorders at the same time. This also applies to therapy.

Prof Kagee (SU): There a re debates whether a mental health condition is a continuous or binary phenomenon. In a Lancet paper of which Prof Crick Lund was an author, there was a strong statement that mental health conditions should be considered as a continuum, which seems to be true. The issue is to manage this in a public health context. How do you make decisions about who to refer, who to treat, how that process should take place, and what markers to take into consideration in making such decisions? Even though mental health conditions exist on a continuum, as a heuristic approach to making quick decisions, we probably need to think about mental health conditions both in terms of a continuous variable and a binary variable for ease of decision-making.

Dr Allen (Lentegeur Psychiatric Hospital): It is not clear how to make sense of some of the data presented. The presentation emphasised that Gauteng and the Westem Cape have higher numbers of young people using substances, but it was also noted that these are the provinces with the highest numbers of facilities for treatment. The lower numbers of people presenting for treatment in other provinces could result from the fact that there are fewerfacilities. This could thus be an issue of poor case detection.

If the data show that there has been a problem of substance use among adolescents as well as older people since 2009 , should we not consider testing and sc reening pre-teens?

Prof Bhana (SAMRC): It is not clear whether the higher numbers of trea tment centres in the Westem Cape and Gauteng were established in response to the drug issues. The facilities are not operated by the state but by an NGO, which provides servic es on the basis of the demand.

Young people are usually brought into treatment by family members following a period of trying to deal with issues of substances use, or they will be referred by the school. The public health service is the least efficient channel for refering them, except in cases of overdose or attempted suicide. Even if children were identified early, the services for treating them are lacking. The young people thus enter treatment centres for adults, which are not adolescent friendly or equipped to deal with adolescent issues. Often the issues are related to the families of the adolescents who are referred for treatment also being caught up in the spiral of alcohol and drug use. There are thus social deteminants that are difficult to fix. The availability of senvices is one of the factors that detemines whether and when adolescents will receive treatment. Most of the adolescents who rec eive treatment do so asoutpatients, which calls in question the quality of the services. If an adolescent receives treatment for just a few hours and then retums to the same environment that gave rise to the problem, nothing will have changed. The success of such treatment is highly questionable. Early intervention alone would not be effective. What is required is evidence-based interventions to mitigate the issues surrounding the treatment of young people. 
Some of the evidence related to the treatment of young people from good studies conducted in high-income countries with the necessary resources is not particularly encouraging. Treatment is very expensive, time-consuming and requires specialists. The South Afric an health system cannot cope with any of these conditions.

Early intervention is required but should perhapsnot focus on substance use, but rather on wellness. South Africa needs research that does not necessa rily focus on the pathology or the negative aspects but on what would make adolescents well within the context of toxic environments.

Dr Allen (Lentegeur Psychiatric Hospital): In the Westem Cape, the management of the affairs of child ren under the age of six years is the responsibility of the Department of Social Development, while the Education Department is responsible for the management of the affairs of children aged between seven and 18; however, the mandate for substances belongsto the Department of Social Development. These factors complicate the issues of where patientsare seen, and whic $h$ party intervenes. There is a need forpolic $y$ integration in order to a void part of the system having to take responsibility for issues that they do not have the capacity to manage effectively.

Unidentified speaker: Is there any correlation between mental hea lth and soc ioeconomic conditions? One would expect a higher proportion of mental health cases in the poorer provinces.

Prof Bhana (SAMRC): The South Afric an Community Epidemiology Network on Drug Use (SACENDU) does not collect such data, and it is thus not possible to make associations between mental health and socioeconomic conditions in the data set. Other data, however, show strong and clearly established pattems of socioeconomic problems contributing directly to the extent of drug and alc ohol problems within communities, but the links between socioeconomic conditions and substance use are not exclusive.

Prof Petersen (UKZN): It would be important to take into account data on the number of trea tment centresper region. Did you record this data? It might be assumed that Ga uteng and the Westem Cape have more treatment centres because they are more affluent. The Eastem Cape is one of the poorest provinces and has among the lowest incidences of adolescents receiving treatment, but the prevalence of adolescents who need treatment for substance abuse in that province is not known.

Prof Bhana (SAMRC): The data came from 76 treatment centres overall, but the number of treatment centres per region was not explic itly singled out. The number of treatment centres per region is not related to affluence. SACENDU does not collect data on the prevalence of substance abuse. The number of treatment centres established in the various regions is probably based on a business model rather than a healthcare model.

Prof Nöthen (University Hospital of Bonn): The limitations of c linic al stud ies with respect to generalisability of the results to the general population have been mentioned. It is important for healthcare systems to establish resources for data from the general population (e.g. on prevalence) to assess the effect of certain parameters that are measured in distinct c linic al populations. Gema ny has esta blished the national c ohort for this purpose and there are endeavours in other countries worldwide. Has South Africa considered establishing such a resource?

Prof Stein (UCT): The suggestion to establish a resource for population-wide data (e.g. on prevalence of mental disorders) in order to be able to compare data from certa in clinical populations could be a recommendation of the workshop. Such initiatives a re not limited 
to high-income countries but are being done in some developing countries (e.g. Vikram Patel in India).

Prof Lund (UCT): There are several demographic surveillance sites in South Africa (e.g. in rural KwaZulu-Natal and Mpumalanga), which enumerate the entire population of a particular catchment area, capture data over time, and establish data on births, mortality, in-migration and out-migration). Many of the surveillance sites are focused specific ally on HIV. Very little work is being done on mental health in these catchment areas. South Africa does not have nationally representative data. There is one nationally representative survey in South Africa, which Prof Dan Stein conducted in 2002-2003.

Prof Stein (UCT): Other related initiatives include the Birth to Twenty study, but these are not integrated across disciplines. Some are demographic studies. An Agincourt study looked at ageing. South Afric a does not have resources such as the UK biobank or the national cohort in Gemany with a range of data that can be analysed from different perspectives and then integrated.

Prof Bhana (SAMRC): The National Income Dynamic Study collects data on mental health using a depression sc reening tool. This is perhaps a model for collecting national data on other issues. Birth to Twenty is a cohort study but does not provide data on the extent of issues in the general population.

Prof Stein (UCT): The South African National Health and Nutrition Examination Survey (SANHANES-1) collects data among other things on blood pressure.

Dr Zungu (HSRC): The HIV/AIDS national household survey also includes a measure for substance use called the Aud it and the la ter survey includes the Kessler 10 for Depression. This study has been done since 2002 and has been repeated five times.

Prof Bhana (SAMRC): These initia tives a re driven from the perspec tive of partic ula rinterests rather than being strategic. There is no emphasis on the ongoing collection of data on a national basis that covers key areas that are important for minimising or reducing the extent of health burdens.

The lack of policy integration is an issue (e.g. the Department of Social Development being responsible for young people, but not working together with the Department of Health). These issues need to be debated and approached in a sensible way.

Prof Stein (UCT): The disc ussion a lso ra ises issues of govemance. The National Drug Master Plan is driven by the Department of Social Development but is cross departmental. The plan speaks to the need for a regular survey of substance abuse in communities across the country. However, the plan is not financed. South Africa has policy that is not implemented. Due to the lack of implementation, there is a lack of data, and policy cannot be implemented because of the lack of data. The National Drug Master Plan is centrally highly regulated, but not propenly implemented.

Prof Bhana (SAMRC): Recognising substance use as part of neurological disorders and trea ting it a sd ifferent from mental hea lth placesthe cond itionsin different compa rtments. Substance use thus becomesa moral issue rather than a mental health issue.

Prof Stein (UCT): Perhapsthis is why data collection on substance use has not been funded. The USA, for example, does an annual survey of substance use in which substance use is not seen as a moral issue but as a mental health issue. 
Prof Nöthen (University Hospital of Bonn): Prof Rietschel pointed out that there are new technologies and methods of data collection to counter the impression that data collection is necessarily expensive. Much cheaper methods could be considered to obtain data that were previously costly because of the extensive examinations required at a central examination centre. New studies could make use of new technologies to collect data in more efficient and cost-effective ways. This is a matter of design and the phenotypes that researchers wish to concentrate on.

Prof Stein (UCT): Mxit was an example of a free instant messaging applic ation used by a dolescents from widely varying socioeconomic groups, which could be used to conduct surveys, for example, on their preferences. Surveys on social media would cost govemment very little.

Prof Rietschel (Central Institute of Mental Health, Gemany): Metho dolog ies developed for other studies could be repeated to collect new data in such a way that the data sets would be comparable with data that have already been collected in other surveys. For example, researchers could go back to a specified subgroup to collect biomaterial and compare this with a particular phenotype, thus producing data that would be comparable with other countries.

Cell phones are widely used among different socioeconomic groups and offer the opportunity to collect data (e.g. even beggars are using cell phones to collect money rather tha $n$ accepting cash).

\section{Wrap-up of Day 1}

\section{Prof Frank Rösler, Senior Professor, Biologic al Psychology and Neuropsychology, University of Hamburg}

It is diffic ult to sum up the broad scope in a few brief statements. The topics covered in the various presentations ranged from public health issues, to basic research and genomic psychiatry. Some of the presentationstriggered thoughts that deserve further disc ussion.

The GWAS were mentioned, and their relationship to psychiatric diseases, but there is a basic psychophysiological mapping problem. The key question is how to establish relationships between basic molecular findings on the one hand, and very broad categories of psychiatric syndromes on the other hand. In order to fill the gaps between these areas, we need more knowledge about how genes express in certa in physiological functions, and how this is mapped to behaviour, otherwise we will remain stuck with genome associations and correlations that a re not causal explanations. This area is open for research.

There are certain critical periods during the life span (e.g. some effects might work on gene expression during pregnancy). Environmental factors that might play a role in the expression of psychiatric disea ses due to existing predispositions during these critic al and sensitive periods, or that might help to strengthen resilience, a re not well understood. This research area needs more effort to be invested.

The bottom line in relation to health is raising money, which meansconvincing politicians to invest. Mental disea ses from which hundreds of millions of people suffer are a pressing problem. One of the ma in reasons why signific antly larger sums of money are spent on research on cancerand heart disea se than on mental health seems to be that politicians are more easily convinced to invest in diseases from which they could potentially suffer and that are life threatening. Mental diseases are not immediately life threatening. We 
need different ways to convince politicians, one of which might be the economic burden, which needs to be translated into terms that politic ians rea dily understand.

\section{Prof Crick Lund (Alan J Fisher Centre for Public Mental Health, Department of Psychiatry and Mental Health, University of Cape Town)}

The presentations showcased a broad range of research, from basic genetic research to applied public-health oriented research.

It was interesting to hear the prionities listed by DrYogan Pillay (DDG: Health Programmes, DoH), an influential policymaker. The prionities were heavily focused on operational research in South Africa and how to bridge the treatment gaps.

Five key points stood out from the presentations:

1. It is important to develop the field in interdisciplinary ways. Researchers tend to work in silos. In order to bridge the gaps from basic genetic science through to the way in whic $h$ symptomspresent themselves behaviourally, we need more conversations such as those at this symposium in order to consider how social epidemiologic al data could be built into genomic studies, for example.

2. Obta ining and following population representative data is important. Snippets of data from South Africa and other sub-Saharan African countries are often facility based rather than representative. There is a general lack of nationally representative data that a re adequately powered to answer the questions we need to answer. We often have cross-sectional data but are not able to follow cohorts over time. The idea of establishing a nationally representative population cohort from which biological samples could be gathered as well as a range of psychological and socioeconomic data is very compelling. Collecting such data could potentially inform the future research agenda.

3. In order to answer many of the questions in which we are interested, we need large samples. This was identified very strongly in the genomics research in particular. We cannot rely on studies with small samples from a single country. There is huge untapped potential in African populations. Most of the current genomic research is conducted on European populations. Prof Sinha made a compelling case for the potential of looking at endogenous groups in Indian and Afric an populations to take this kind of research forward.

4. We also need longer follow ups.

5. We need intemational collaboration. It is hoped that this symposium will be the start of work involving the pooling of data sets and the development of common measures despite socioeconomic and cultural diversity.

The intention on Day 2 of the symposium is to distil some of these thoughts in order to identify a set of research priorities that could be recommended to ASSAf, Leopoldina and academies in India, Brazil and China in order to start to shape the direction of fund ing for public benefit in the short and long term. 


\section{DINNER}

\section{Facilitator: Dr Khutso Phalane-Legoale, Programme Officer: Health and Related Sciences, Academy of Science of South Africa}

\section{Provider core competencies for improved mental healthc are of the nation: a consensus study (Prof Rita Thom, University of the Witwatersrand, South Africa)}

The consensus study on 'Provider core competenc ies for improved mental healthcare of the nation' is the first mental health-related project to be conducted by ASSAf. The study is still under way.

South Africa has a significant burden of MNS disorders and a large treatment gap. The National Mental Health Policy Framework and Strategic Plan (2013-2020) clearly outlines a strategy to reduce the burden of disease posed by MNS disorders. A fundamental principle and strategy in the plan is task-sharing/shifting (i.e. generalists and lay providers providing some of the interventions that might be provided by specialists in other more developed countries). There is thus a need for clanity on the core competencies for each level of provider in orderfor ta sk-shifting/sha ing to work. The US Institute of Medic ine (IOM) convened a meeting in Uganda in 2012 at which core competencies for treating MNS disorders in sub-Saharan Afric a were proposed.

ASSAf took this matter up, and convened a workshop in 2014 that considered the question 'How could these core competencies be implemented in South Africa?' The ASSAf consensus study was then commissioned in 2015 with Prof Rita Thom (Wits) as cha irperson and the following expert panel members approved by the ASSAf Council: Dr Robin Allen (DoH), Associate Prof Eve Duncan (UCT), Prof Crick Lund (UCT), Prof Bronwyn Myers (SAMRC), Prof Solomon Rata emane (Sefako Makgatho Health Sciences University), Prof Inge Petersen (UKZN), Ms Bharti Patel (South Afric an Federation for Mental Health) and Dr Gayle Langley (Wits). ASSAf was represented by Prof Roseanne Diab and Dr Khutso Phalane-Legoale, and MrRobin Hamilton was the researcher for the study.

The rationale for the study was to establish whether providers a re a dequately equipped with the necessary competencies to implement the plan. There is a need for a consensus view on the education and training needs of healthcare workers and other providers in South Africa in MNS disorders.

The a ims of the study were to:

- Interrogate core competencies developed by the IOM and ASSAf workshops, and agree on 'ideal' core competencies;

- Provide baseline data on current training programmes;

- Map these data against core competencies identified by the panel and identify gaps in current tra ining programmes;

- Consult with key stakeholders to contribute to the report;

- Make recommendations to address gaps and improve the capacity to provide comprehensive services for people with MNS disorders;

- Disseminate recommendations to the Health Professions Council of South Africa (HPCSA), the DoH and other tra ining and regulatory bodies.

The panel identified core functions and core competencies for each provider group. Baseline data were collected with respect to cumicula and existing core competencies for provider groups (although there were many gaps in the required information). A mapping exercise was done to identify appropriate training and highlight gaps. The final report is being drafted. 
It needs to be acknowledged that mental healthcare is multisectoral and multidisciplinary. The study focused mainly on public sector formal health services for a dults. The predomina nt focuswa son the distric thea lth service, taking prima ry healthca re (PHC) re-engineering and the National Health Insurance (NHI) into account. It was not possible to include other sectors (education, police, justice, correctional senvices) and informal services (traditional healers and faith-based organisations) due to resource and time constraints, although it is recognised that these sectors are important players in relation to mental healthcare.

The vision of care for MNS disorders in South Africa is that it should be a district-based, comprehensive and integrated mental health service using a task-shaning and taskshifting approach with specialist support. Such care is based on a recovery model and a disability-inclusive approach in which the human rights of all individuals a re respected. Each individual is assisted to reach their potential within the restric tions of their illness or level of disability. Services should be provided in the least restric tive setting possible, as close to home as possible. The emphasis is on ambulatory care and voluntary care. Community care needs to be defined very broadly and be inclusive of other sectors and NGOs that play a role. Admission to hospital should only be for a cute episodes of severe mental illness. Long-tem institutional care should be provided only for those who cannot be cared for in the community. There needs to be a balance between outpatient and inpatient services.

The district mental health specialist team organises services in the district. People should enter the system through primary care including PHC clinics and ward-based outreach teams (WBOT), whic $h$ visit patients in their homesand a re ideally placed for sc reening and assessment for MNS disorders. Primary care interventions include referral to providers at primary care level (counsellors, allied health professionals, doctors for medication) or referral to specia list providers (inc luding family physic ians) for consultation or for inpatient trea tment. The clinic al multid isc iplinary specia list team, for patients who cannot be dealt with by PHC practitioners, comprises a psychiatrist, psychiatric nurse, psychologist, specialised social worker and occupational therapist. Apart from the district mental healthcare specialist team, there should be clinical teams with the relevant disciplines within the district, but not hospital based. The consensus study report emphasises the importance of these clinical teams.

Inpa tient trea tment at distric thospita ls isma na ged by generalist doc tors, nursesand a llied health professionals. Seventy-two-hour assessments are conducted with appropriate facilities. Patients may be referred to secondary level care at acute psychiatric units (with specialist teams), or to tertiary level care at central academic hospitals and specialised psychiatric hospitals. Patient stays should preferably be short, and patients should be discharged back to the community, with post-discharge referral back to the clinical specia list team, and down-referral to PHC forongoing management of stabilised patients, which should include engagement with other sectors and lia ison with community-based psycho-social rehabilitation services. Specialists should provide support for PHC services.

The consensus study looked at the following service provider categories: community health workers; nurses, general medical practitioners (including emergency medical practitioners and clinical associates); the psychosocial rehabilitation team comprising psychologists, social workers, occupational therapists; and medic al specialists (inc luding family physicians, neurologists and psychiatrists).

The consensus study made several key findings with respect to the various categories of providers: 
- Community health workers (CHMs): This category developed during the HIV/AIDS epidemic prior to ARVs as a cadre employed in the public sector who form part of ward-based outreach tea ms. There is a lso a category of community caregivers. Wardbased outreach teams could play a pivotal role in screening, referral and providing adherence support for MNS disorders. Current training equips CHWs with generic competencies, but it is unclear whether there is sufficient content training in MNS disorders for them to be able to screen a ppropriately and provide a dherence support. Ongoing support, training and mentoring from professional nurses is critical. It is not clear what kind of tra ining caregivers receive. If any training is provided, it does not seem to be regulated in any way.

- Nurses: They form the backbone of the health service in South Africa and often perform an expanded role. Over the years they have taken over many roles that medical practitioners would play in other countries, including assessment and treatment of medical conditions. South Africa is facing a critical shortage of nurses, which is likely to worsen. There seems to be undenutilisa tion or lack of posts for a uxilia ry and staff nurses. The restructured nursing cumic ulum largely excludes psychiatry. The current training in the four-year degree and diploma and the Advanced Diploma in Psychiatric Nursing covers the required competencies but has been critic ised for not preparing practitioners a dequately to deal with MNS disorders. There is concem that the new curiculum contains less psychiatry and mental health than the current curric ulum. Thisneedsto be raised with the South African Nursing Council and the DoH, because primary care nurses are expected to provide primary mental healthcare. A positive aspect has been the development of the Adult Primary Care (APC) approach, which provides tra ining and resources for nurses including essential a reas of primary mental healthcare.

- Medical and associated professions:

- Emergency medical senvices are being rationalised. Generic competencies for managing emergencies are taught, but there is insufficient content on emergency presentations of mental disorders in order to manage them safely.

- Clinical associates a re a new category of professionals that were developed to support general practitioners and perform some of the roles of general practitioners. Their roles a re still quite fluid and their competencies a re not clearly defined. At present c linic al associates do not seem to be propenly utilised. Clinic al associates could play an important role in assessment, psychoeducation and monitoring of people with MNS disorders, but there is insuffic ient attention to MNS disorders in the curric ulum.

o Doctors: South Africa is relatively well-supplied with doctors compared to other SADC countries. However, there is maldistribution of doctors, with $60 \%$ of doctors working in the private sectorand a concentration in the urban areas. South Africa has instituted community service for doctors, which has gone some way towards alleviating the shortages in rural a reas. However, community service doctors are junior and need support and supervision, which a re often lacking. Doctors trained in South African medical schools generally receive sufficient training in core competencies to manage MNS disorders at primary care level, including district hospitals. Other bamiers play a significant role, including competing health priorities, lack of specialist support, time constraints, and in some situations a lack of medication.

- Psychological senvices:

o Behavioural health counsellor: This category of behavioural health counsellor has evolved from initiatives such as the PRIME and is being proposed to the DoH as a provider for struc tured counselling interventions for conditions such as depression. 
Currently there are very few posts a vailable in the public sectorfor these providers. They could play a useful role at primary care level, including supervising behavioural health counsellors.

o Psychometrists: They play an important role in assessment, especially for c hildren and adolescents.

- Registered counsellors: So uth Afric a has developed tra ining for this category in the form of the four-year BPsych. There are various categones of psychologists at master's level. The findings related to psychologists and other practitioners in this category is that there is a need for training in evidence-based psychological interventions, including psychoeducation, specific manualised and structured interventions, counselling and psychotherapy in a stepped approach, in which health counsellors provide much of the psychoeducation and manualised interventions, and psychologists provide more specialised psychotherapy. The emphasis in providing services should primarily be on ambulatory care in the district, with some servic es in inpatient settings. C linical psychologists work prima rily in specia lised settings, which a re not necessa rily hospita ls.

o There is a maldistribution of skilled professionals as for doctors, a lack of posts for registered counsellors, lack of standardisation of training and curicula across training institutions, and a need for more specialised clinicians to play a greater mentoring and training role with respect to primary care.

- Social work senvices: These include auxiliary social workers and professional social workers (as well as youth workers). Social workers are a scarce resource in the public sector, especially in health services. They are skilled in providing individual and group interventions. Current social workers have received some training in substance use disorders. Only a few institutions offer tra ining in c linic a I soc ia I work, whic h equips social workers to work in specialist mental health teams.

- Occupational therapy: This category is the most highly tra ined and skilled in functional and vocational rehabilitation and provides guidance to teams in encouraging recovery and a disability-inclusive approach. As in several other categories, there is a maldistribution of resources, with most working in private healthcare and urban settings. Related categories of providers and training programmes have developed, including community rehabilitation workers (CRWs). No tra ining is currently provided for occupational therapy assistants (OTAs) or technicians (OTTS). There is concem about the lack of recognition for occupational therapy in the PHC reengineening plans.

- Medical specialists: Family physicians lead the district health service. They are responsible for planning, organising and evaluating services in the district. General practitioners with a Diploma in Mental Health can serve as a 'specialist' resource in the district. Neurologists a re primarily hospital-based and interact very little with the district health service. Psychiatrists and sub-specialist psychiatrists a re also primarily hospital based, although some are district based. All medical specialists undergo standardised final exit examinations through the Colleges of Medic ine of South Africa (CMSA). For psychiatry, the CMSA has developed core competencies, and examinations are aligned with these. There should be greater emphasis on spec ialists providing training and mentoring to district $\mathrm{PHC}$ and other staff.

The consensus study identified a number of c ross-c utting issues and gaps:

- Substance use disorders: There is an epidemic in South Africa. The social context in which people live and the drivers of substance abuse must be taken into account in any interventions. Judgemental and punitive attitudes a re unfortunately prevalent in 
the health sector and are unhelpful. There is a lack of adequate training in interventions for people with substance use disorders across all providers. Ham reduction approachesare the most useful. Integrating some of the WHO work on brief interventions into cumicula would be important.

- Child and adolescent mental health: Thirty-four per cent of the total population in South Africa is under 18 years of age (2014). MNS disorders often begin in childhood and adolescence, and early intervention is most effective at this stage. Further research is required to focus on developing competencies for acute care in PHC for children and adolesc ents and in school health services.

- Promotion of mental health and prevention of mental disorders: It will be important to identify specific competencies in these areas and to integrate these into cumicula. Hopefully the current symposium will help to identify research priorities.

- Other sectors and altemative health practitioners: Tra ditional health practitioners a re often the first site of consultation for parallel treatment. Further research is needed on competenc ies in sc reening, identific ation and management of MNS disorders in these sectors by altema tive health practitioners.

- Ageing population: $8.1 \%$ of the population is over the age of 60 years and this percentage is increasing, with an associated high burden of non-communicable disea ses as well as an inc reasing burden of neurocognitive disorders requining specific competenc ies at all levels of providers.

- Intellectual disability: The severely and profoundly intellec tually disabled a re a highly vulnerable group. They often have associated physical disa bilities that require greater levels of supervision and physical care, and this needs to be taken into account in relation to the providers who care for this group. There is very limited tra ining across all categories of providers in caring for this group of individuals.

Other rec ommendations of the consensus study included:

- There isa need for evidence-based implementation research to test and evaluate the envisaged system of care.

- Inter-sectoral lia ison needs to occur at national, provincial and district levels.

- Posts are needed for new cadres, registered counsellors, psychiatrists and other mental health specialists in district hea lth services

- Scope of practice issues exist in rela tion to new cadres, supenvision and a c countability (e.g. if nursesa re allowed to presc ribe anti-depressant medic a tion, as suggested, who would be accountable if things go wrong, and how would appropriate supervision take place).

- With respect to training fordistrict-based services, academic platforms should be more district and community-based.

DAY 2: 31 MAY 2019

SESSION 4: INTERVENTION RESEARCH

Fac ilitator: Prof Ashraf Kagee, Co-Director, Centre for Public Mental Health, University of Stellenbosch, South Afric a)

\section{Using intervention researc $h$ to drive evidence-based integration of mental health into primary healthcare settings in South Arica (Prof Inge Petersen, Centre for Rural Health, University of KwaZulu-Natal, South Africa)}

The presentation will ta ke a systems focusto intervention research over the last eight years. The research looked at how to increase access to mental health services in the PHC system for people with common mental disorders that are comorbid with chronic conditions. Comorbidity of common mental disorders with conditions such as HIV and other non-communic able disea ses impacts negatively on treatment a dherence. This is a 
signific ant issue in South Africa due to the high burden of HIV and the size of the investment in ARV treatment.

The research began in 2012 with the PRIME. Formative and piloting work were done in North-West province at the request of the $\mathrm{DoH}$, which wasengaged in piloting NHI science as well as an integrated chronic disease model. Initial evaluation was done using an experimental approach and two trials. The work was then scaled up with additional funding and extended to districts in KwaZulu-Natal and Mpumalanga. The scale-up is currently being evaluated using implementation science methods.

The SAMRC framework for complex interventions was used. The work began with development in the Dr Kenneth Kaunda district municipality in North West province. The team engaged in a series of theory of change workshops as well as fo mative research in order to develop a collaborative package for treating common mental disorders comorbid with chronic conditions. The research team made use of what was available in the system. Primary healthcare nurses form the backbone of the healthcare system in South Africa; their capacity was strengthened to identify common mental disorders. Referral systems were also strengthened by tra ining behavioural health counsellors in the vic inity (initially these were HIV counsellors) to provide psychoeducation and depression counselling as well as adherence counselling. The capacity of doctors was strengthened to diagnose and review complex severe cases and prescribe psychotropic medication. PHC nurses in South Africa have not been able to initiate psychotropic medication. The intention was also to train psychologists to provide training supervision to counsellors as well as the referral service formore complexcases in line with the task-shaning approach.

With respect to feasibility, the research team engaged in extensive piloting, resulting in some adaptations, in particularthe need forchange management processesto orientate nurses and other providers to all the systems changes and to person-centred care that looks at the patient holistically, as opposed to the historical task-centred vertical approach. This required role clarification and training in skills to provide person-centred care. Central to this a pproach is c linic al communic a tion skills a s well as self-ma na gement for stress and bumout, since they were expected to engage in emotional labour. Other changes included the introduction of a psychoeducation talk because of the low mental health literacy in the country, existing PHC workers were used in the piloting phase, but the research team was then informed that they could not continue to use them because the requirements of the research were beyond the scope of what they were paid to do.

South Africa was one of five countries engaged in the PRIME programme, which was led by Prof Lund. The initial research was done under the auspices of PRIME, applying a method that was used across all five countries. A facility-detection survey wascaried out to establish whether there was any improvement in the detection of depression and alcohol use disorder (AUD) by the PHC providers, in this case nurses. As part of the intervention evaluation, a cohort study wasconducted to establish the impact on patients who were referred for care according to the model. A case study was used to try to understand the factors that contributed to the outcomesfound in both of the studies. This work has been published.

The findings showed a significant inc rease in identific ation by the nurses of a bout $10 \%$ for depression and $14 \%$ for AUD. Among patients referred for treatment, at the three-month follow up those receiving treatment were twice to three times more likely to have a $50 \%$ reduction in depression scores compared to the controls. There were similar findings related to remission. 
These results showed that the intervention was working. It was then tested in two pragmatic cluster randomised control trials. One trial focused on depression comorbid with hypertension, and the other on depression comorbid with HIV patients on ARTs; the latter was a CoBaIT trial responded by NIH. The PRIME trial was conducted in a single district, and the CoBaIT trial in two districts. In PRIME there were 20 clinic randomised intervention sites, and in CoBaTthere were 40. Approxima tely 1000 patients were involved in the PRIME trial and approximately 2000 in the CoBalT trial. The results are still under analysis.

With respect to implementation, funding was obtained from the US Centers for Disease Control and Prevention to assist in the scale up of the integrated model in collaboration with the University of Washington and an NGO. The scale up was done in Dr Kenneth Ka unda distric t munic ipa lity (North West province) as well as Amajuba district munic ipa lity (KwaZulu-Natal) and Ehlanzeni district municipality (Mpumalanga). There have been continual adaptations to the scale-up package.

At provincial level, project-employed counsellors were used for PRIME but it was not possible to do this during scale-up. The initia tive thus used HIV counsellors, enrolled nurses or other people that the DoH or clinic s consider to be suitable for counselling and health promotion. Continuousqua lity improvement, which is data driven, wasused as the vehicle for implementation in order to try and embed this within the services. The two key indicators for mental health at PHC level in South Africa, namely number screened and number treated, were used. The research team engaged with the $\mathrm{DoH}$ to increase the number of indic ators. Clinical communication skills tra ining was integrated into the adult PHC mental health module. The research team referred to the integrated chronic care guidelines used in the $\mathrm{DoH}$ for PHC nurses.

At facility level, the team worked with a brief mental health screening tool, which is currently being introduced. Facilities were using anything available; the tools were unstandardised and unvalidated, and sometimes healthca re providers would just look at a patient and say that the patient had been screened. The team engaged in a collaborative study with the DoH to consider how best the tool should be introduced, and developing a standard operating procedure.

The PRIME project did not have a community-level intervention. A major addition was at the community level, because of low rates of identific ation as well as evidence of the need to work on growth by improving both demand and supply. The community interventions were to improve mental health literacy and identification. The core community mental health detection tool is being adapted for the context at the request of the $\mathrm{DoH}$. The community health initiatives will be implemented by community health worker outreach, who will take a psychoeducation approach and also get people to selfidentify. The process of tracing and linking patients to care is being strengthened due to the fallout from care of about $20 \%$ of patients who a re HIV positive.

An operational manual was developed using continuous quality improvement as the vehic le forimplementation. The manuals and toolkits for integrating mental health into the PHC system for tra iners as well as those who are being tra ined can be freely accessed on the website of the Centre for Rural Health. A further initiative is a two-year capacity building programme among the $K \mathbb{N}$ provincial directorate as well as all district mental health coordinators in the province. The Centre for Rural Health co-designed the curiculum, which enta ils how to do situational a nalysis using the Mental Health Theory of Change workshops to develop the district mental health plans; how to use continuous quality improvement to drive the implementation process; monitoring and evaluation; and dissemination. 
As regards evaluation of the scale-ups, the Southem African Research Consortium for Mental Health Integration (S-MhINT) involves Mozambique, Tanza nia and South Africa. The presentation focused on uptake, implementation, effectiveness and sustainability of an existing scale-up of an integrated mental health package for chronic disorders project at prima ry hea lthc are level in two different distric ts (Amajuba in KwaZulu-Natal and Ehlanzeni in Mpumalanga) in South Africa. S-MhINT uses the RE-AIM framework to measure reach, effectiveness, adoption, implementation and maintenance.

The preliminary results included:

- Reach: The initiative started in October 2017 in a rural subdistrict with 13 facilities in Newcastle, ten in Dannhauser and two in Emadlangeni and many mobile points. The reach was only about $2 \%$, but these people would not have received any services without the intervention, since there a re only two psycholog ists in the district to service between 500,000 and 600,000 people. The psychologists reported that the referrals they were receiving were far more appropriate.

- Adoption: A PhD student linked to the project investigated adoption, looking at predictors of nurse detection and referral of chronic care patients with depressive symptoms. This work was embedded in the CoBarT study and found that nurses were identifying $50 \%$ of the patients screened by the research team as positive for depressive symptoms. This was a considerable improvement on the results for $\mathrm{Dr}$ Kenneth Kaunda district municipality. However, the nurses did not refer all of these patients, even though referral pathways were strengthened. Only $30 \%$ of those identified as having depressive symptoms were referred to treatment, resulting in an overall referral rate of $18 \%$. The nurses tended to identify patients with more severe symptoms, thus adopting a more targeted approach, but they did not necessarily refer those with more severe symptoms.

- Effectiveness: The three-month results of the cohort study show that there a re three different ams among patients: not diagnosed; diagnosed and not referred; and diagnosed and referred. Those who were diagnosed and referred showed signific antly better reduction in symptoms than those who were not dia gnosed, or were diagnosed but not referred.

Key lessons from this work included:

- Implementation science can be a useful vehicle for driving the scale-up of mental health services. Researchers should adopt and funders should support the implementation of future programmes. The NIH is forward thinking in this regard, and required the inclusion of capacity building using implementation science for implementers and managers in the health system.

- This approach allows for the development of middle-range theories of what works, for whom and under what conditions in order to inform further studies. The PRIME study, for example, found that patients have to attend five to eight sessions in order to be effective. The case studies also found that the counselling intervention was less effec tive for patients in lower soc ioeconomic groups (i.e. patients with food insecurity needed something more). The find ings need to be explored in more depth to establish why the nurses are not refeming many of the patients.

- Strong collaborative relationships built on trust are required with the $\mathrm{DoH}$ and other sectors.

- This kind of research requires long-term fund ing and flexibility to respond to DoH needs, which also helps to build trust (e.g. responding to the need of the $\mathrm{DoH}$ for validated screening tools). 


\section{Providing screening, brief intervention and refenal to treatment (SBIRT) for substance use disorders into South Africa's primary healthcare senvic es: lessons from local research (Prof Bronwyn Myers, Chief Spec ialist Sc ientist Alcohol, Tobacco and Other Drug Research Unit, South Afric an Medical Research Counc il)}

There is a considerable treatment gap for substance use disorder, as for other mental health disorders. Only $2-3 \%$ of people who meet the diagnostic criteria for substance use disorder and need trea tment a re able to access trea tment on an a nnual basis. Trea tment is reaching those with severe and chronic problems, but the vast number of people who use substances generally do so either unproblematically or at hazardous and hamful levels. There is a need to focus on reaching them as well as a way of preventing further progress to more chronic and severe problems, but services are not available to do so. The WHO has recommended that interventionsfor substance use disorders a re integrated into primary healthcare services asa means of detecting people who a re at risk for future problems and providing brief or early interventions to reduce the risk of ham.

Screening, brief intervention and referral to treatment (SBIRT) consists of several steps, starting with universal sc reening of patients as they enter healthca re service. Those who are not at risk would be congratulated on their healthy behaviour and encouraged to continue along that path. Those who are screened as being at risk would be offered a brief or extended brief intervention. Those with severe problems, or who do not respond to the brief intervention would be referred upward to more specialised services. This is a step towards namowing the treatment gap and reaching people in a window of opportunity in which their use of substancescan be discussed and they can be provided with access to services. It is a lso a strategy for reducing the hamful effects of substance use on health. For those who are using substances at hazardous and hamful levels to their hea lth but do not meet diagnostic criteria, it is an opportunity to provide brief counselling and advice to reduce their use in order to prevent chronic diseases and future health problems.

South Afric a has a National Drug Master Plan, as part of which the DoH has been tasked with implementing screening and brief interventions within primary healthcare services, particularly in emergency departments, services that reach pregnant women and in chronic diseases instances. However, the plan has not been properly implemented. In 2018, there was considerable energy in considering how to sc ale-up SBIRT and introduce it to primary healthc are facilities. There was a large meeting, a report hasbeen produced, and tra ining hastaken place forprimary care providersand NGOs working in primary care facilities.

The presentation will argue that we should not rush from training to attempted implementation without considering key sc a le-up questions such as 'What is the package of care? Who is going to deliver each component of the package? What resources do we need to support delivery of this package? What kind of environmental factors do we need to ensure are in place to support implementation?' These questions have not been a dequately addressed, but we can draw on local research findings to begin to answer these questions. This would give the opportunity for evidence for informed decisionmaking around how to start implementing these services.

The presentation draws on lessons from SBIRT intervention research in various parts of the country inc lud ing HIV servic es, emergency departments, MoUs with pregnant women and chronic disease services. Some of these projects are ongoing and others have been completed. There are some shared lessons and leamings across the projects that will be presented: 


\section{- Screening:}

- We have leamt that screening should be universal. At present, screening often involves case detection by appearance (e.g. if a patient smells of alcohol or is visibly intoxicated). A single question may be a sked about alcohol use, but if the patient says they do not drink, there is no further investigation. Participants in the studies have said that screening is a very useful process; that before screening they did not think about theira lcohol use and that it might be problematic for their health.

- Brief versions of va lidated screens that a re widely used in research studies can be very useful for detecting people who might benefit from a brief intervention (i.e. people with hazardous or harmful use, or mild to moderate symptoms, but not necessarily with severe problems). Tools that comprise three to four questions about alcohol use, such as the Alcohol Use Disorders Identific ation Test (AUDIT-C or AUDIT-PC), or even a single question on drug use in the past month can be useful for detecting people who might benefit from intervention.

- We have leamt lessons about who should do the screening. Most providers and patients themselves have said that they would like screening to be completely integrated into the history-taking process, so that it is not seen as a separate process but forms part of their entry into the health system. Nurses who work in observation rooms and take the patients' history as they present for service should thus do the screening.

- Screening should not be a once-off event. There should be multiple opportunities for screening because people who visit a clinic for the first time might not feel comfortable disclosing alcohol or other substance use and may only become more comfortable over time once they have developed a relationship with their healthcare provider. Some of the trial data show that screening results change over time, as people become more comfortable about disclosing the actual extent of their a lc ohol use.

- Patients are very open to screening and consider that it would be a valuable process. Those with other physical hea Ith comorbidities, in particular, would like to know everything about their health and how they can act appropriately and timeously to avoid future problems.

\section{- Brief and extended brief interventions:}

- A brief intervention is generally a once-off session of feedback about screening results, advice and counselling ormotivational counselling to encourage and build readiness to change. An extended brief intervention would add several more sessions to the initial session in order to help the person to build some skills for implementing changes and working towards the goals they have developed for themselves.

- Providing information is key. Participants have said that information about what a standard drink is, and how many drinks a re conta ined in conta iners is useful, as they previously did not know how much they were drinking or what a sensible or safe drinking limit was. Knowing this information made them aware of the need to change and the fact that their alcohol use was potentially ha mful.

- Aspart of this health education, goal-setting and self-monitoring were also seen as very helpful. Participants are encouraged to diarise their drinking so that they become aware, at least in the first month, about how much they actually consume. Often this is very illuminating to patients. Patients like to be able to keep track of their drinking and record progress towards their goals.

- Participants found it useful to leam strategies for coping with stress and other triggers. Stress and stressors in people's lives a re often a reason why people drink in order to avoid the problems. Having altemative strategies for coping with these issues helps them to manage the urge to use alcohol. Across all the studies, 
boredom was identified as a big risk factor for drinking. Elements of behavioural activation therapy have therefore been incorporated into the interventions so that people can consider strategies for managing boredom and positive leisure activities that a re alcohol free.

o Brief interventions a re acceptable to patients, and a re efficacious.

\section{- Intervention delivery:}

o The duration of the intervention should be flexible. The number of sessions should depend on the patient and their needs. There is a fine line between over-treating and under-treating. Some participants do very well with just one or two sessions, but others need more sessions to cement the skills that they have leamt. Optional booster sessions have been added to the interventions so that participants can receive additional sessions if they need to.

o Much has been leamt about the delivery agent. It has been demonstrated that interventions can be task-shared with facility counsellors and community health workers. We a re starting to lea $\mathrm{m}$ a bout peers. Peers a re not widely used as delivery agents in this setting, but participants are starting to say that they would like to receive the intervention from someone who has themselves struggled with substance use issues or reduced their alcohol use. Peer recovery coaches are widely used in other settings and could perhaps be considered for this setting.

o We have leamt about the competencies and qualities that are required for effec tive intervention delivery. Some of these are core competencies, while others are treatment specific. The qualities of being passionate, committed and highly ethical are important. We have also leamt about training. Initially in these interventions, we started training only those who would be responsible for screening and for the intervention delivery. We have since leamt that everybody in the healthcare setting needs to be trained so that the person delivering the intervention is supported, there is a backup, and the referral path is clear.

- Clinical supervision and debriefing are an important element of the package of care. We have started to strengthen the supervision and debriefing part of the packa ge. This is partic ula rly important in a ta sk-sharing context. Clinic al supervision goes beyond standard fidelity checking to using supervision as an opportunity for booster training to role play diffic ult cases. It is also used as an opportunity to debrief the person delivering the intervention about potentially difficult situations that have been personally challenging for the participants. Counsellors have appreciated debriefing and supervision.

\section{- Referral to treatment}

o This is a critical but often neglected part of the SBIRT process. The current way of providing refemals is often problematic for various reasons: there is a lack of awareness of where to refer people to; there are structural ba miers to accessing services; substance use treatment services are not to the person's liking; and the providerwho refers doesnot get feedback. These protocolsneed to be developed for SBIRT implementation.

\section{- Other lessons about implementation:}

- SBIRT cannot be implemented without ensuring that the environment into which it is to be implemented is conducive for implementation. We have leamt through more than 300 hours of observation at 26 primary care facilities that the core elements that need to be present for implementation preparedness are personcentred care, therapeutic environment, sufficient human resources, good leadership and infrastructural resources. 
o Stigma-reduction interventions are needed to support SBIRT implementation. Providers continue to be highly stigmatising towards people who use alcohol and drugs; patients feel judged and are wary of disclosing their substance use when a sked. To enc ourage upta ke of SBIRT when it is implemented and offered, it needs to be accompanied by interventions to reduce stigma among providers.

The resources required to support the implementation of SBIRT include training materials and resources, screening protocols, providers with appropriate competencies, intervention manuals and protocols, a referral protocol, supervision and debriefing protocols, and supervisors with appropriate competencies.

Evidence-informed implementation of SBIRT is required. Healthcare managers who are responsible for overseeing the implementation of these new services say that many new programmes that have been introduced have failed at the point of implementation because there is a rush towa rds implementation without c a reful planning or consideration of what might work in a particular setting, and what will not work. They call for careful testing and tailoring or the protocols for each facility. This should be bome in mind, but there is an opportunity to use this information to inform implementation.

\section{Overcoming trauma and violence: from individual trauma naratives to community- based intervention in war-tom regions (Prof Thomas Ebert, Professor of Clinical Psyc hology and Neuropsychology, University of Konstanz, Gemany)}

Violence, both domestic and organised, remains the major driver of mental suffering and mental disorders. The research prionity is thus how to prevent violence, and to develop and test interventions on an individual and a community or social level (i.e. in families, homes, schools and gangs, as well as violence at an orga nised level). The polic y prionity is to raise awareness about the devastating consequences of domestic violence, and to support the poor and downtrodden living on the hopeless, hungry side of town. Violence is never ending, and conflicts and organised violence can be enumerated throughout many parts of the world.

Violence operates in cycles: the victims of violence may develop a range of psychopathologic al conditions such as post-tra uma tic stress disorder, anxiety, depression or dissociation, and may in tum respond with reactive aggression. Early childhood problems create the likelihood for depression. Post-tra uma tic stress disorder is not the result of one life-threa tening event, but of ongoing repeated threats to life and fitness. Ultimately through many such experiences, a person ma y build up an asso cia tive memory of sensory information (e.g. of fire, bombs, explosions, beatings), the cognition of helplessness, negative emotions centred on anxiety and physiological defence responses. If the individual loses the realisation that a ctivation of this asso cia tive memory refers to the past and perceives it as present perceptions, threat gets triggered by many cues and becomesomnip resent. This leadsto suffering from post-traumatic stressand other traumarelated disorders. Anothercycle of violence isfuelled by a ppetitive aggression. This intrinsic enjoyment of violence, the lust to kill is so to say, "in ourblood". In peaceful times it is taboo and exists only as a latent state; though it may become apparent during hunting and killing a nimals, during war and crises it can be "easily called into play and raised to the power of a collective psychosis" as Albert Einstein has put it. The neural circuitry is quite different between reactive aggression in which people are trying to defend themselves, and appetitive aggression in which people participate to achieve a combat high and satisfy their blood lust. Appetitive aggression may thus give rise to a cycle of violence that is different but interconnec ted with the reactive cycle: in a violent environment, symptoms of psychopathy and antisocial behaviour may emerge (e.g. the stimulus of blood can become a stimulating signal for fighters in combat). 
Boys who have been exposed to severe violence during their development a re likely to fight back at some point. This reactive violence then fuels the appetitive aggression and with-it criminal behaviour. Girls who have been exposed to violence are more likely to become self-injurious.

There is evidence of massa cresgoing back asfar as the early Holocene hunter-gatherers. Pre-historic evidence of massacres comes for instance from sites at the Tukana Lake in Tanzania, and massacres continue to the present. In the Rwandan genocide in 1994, 800,000 people were hunted and killed by hundreds of thousands of perpetrators, which indicates that it is not a rare form of persona lity disorder but rather a la tent trait of humans to be able to kill and to even enjoy it. What conditions will call this tra it into play and would cause someone to kill? Of the victims of the Rwandan genocide, $40 \%$ were killed with machetes, $17 \%$ were killed with batons, $15 \%$ were shot, $9 \%$ were beaten to death, $4 \%$ were drowned and $3 \%$ were bumt. The statements of many of the perpetrators of the Rwandan genocide have been documented, for example "The more we killed, the more we got the taste to go on. If you can enjoy the craving without punishment, it will get hold of you. It was an unforeseen public enterta inment." Evidence from as far afield as Colombia, Afghanistan and Afric a shows that the more violence in which a person engages and the earlier they start, the more likely they are to become addicted to violence as a form of plea sure, without nec essa rily a ny intention to rob or to rape. Sometimes robbery becomes an excuse for engaging in killing.

In violent environments, appetitive aggression can be a resilience factor. Repeated exposure to traumatic stressors leads to tra uma-related mental disorders, while appetitive aggression may delay their development. Fighters expenience tension between the negative and positive connotations of their associative memory of live-threatening events. US combatants in the Vietnam war perceived themselves positively as heroes in the fight, but when they retumed home society at large blamed them for temible deeds. The Vietnam veterans began to suffer from PTSD and started to consume drugs. Drug prevention intervention would only succeed if the network of memories is adjusted such that cues that trigger the memory are clearly distinguished from actual threat and combat situations. Once people are caught up in the bi-cycle of reactive and appetitive aggressive, it is very difficult to stop. The best measure is to prevent this situation from a rising.

Research was conducted by sampling saliva, and differences were found in the expression of the proopiomelanocortin precursor protein and in endorphin regulation. Changes in opioids contribute to becoming addicted to violence. There is a sensitive period between the ages of 12 and 17 when appetitive aggression may become most addictive.

Research was conducted by sampling saliva, and differences were found in the expression of the proopiomelanocortin precursor protein and in endorphin regulation. Changes in opioidscontribute to becoming addicted to violence. There is a sensitive time between the ages of 16 and 17 when this can be modified.

The research undertaken among gang members in the townships of Cape Town identified tra umatic stressors in the community; $77 \%$ had witnessed killings, $90 \%$ knew someone who had been killed, and $73 \%$ had been shot at. Participants had also committed a number of criminal offences: $90 \%$ had attacked other humans, $75 \%$ had hurt someone with a weapon, and $53 \%$ had seriously injured someone. This indic ates that both the reactive and a ppetitive cycles of a ggression were in operation. Typic ally, gang members in Cape Town do not have a father present; the mother struggles to provide as a single parent; and 
around the age of 11 or 12 they start to jo in a gang and a re exposed to early experience of violence through gang fights. During a flight they become totally immersed in the hunting mechanism and do not consider that they could die. They crave to partic ipate in violence as an addiction. Drugs are essential to facilitate aggression, leading to a dual cycle of drug abuse and aggression.

Gangsters can be helped if their associative memory is properly organised during na rationsof the most a rousing past events. The sensory memory of killing someone brutally at a young age, the associated emotions, cognitions and physiological responses at the time have to be contrasted with the feelings and thoughts here and now, when the events, each at a single time are remembered. This is not an easy task for the guiding psychotherapist, as the therapist has to fully accept the emotions that the person experienced at the time, including their positive feelings of killing someone. Traumatic events can be processed in a similar way. Restructuring through narative exposure not only reduces PTSD symptoms, but also reduces appetitive aggression, whereby social inclusion rather than exc lusion is essential.

Research was also conducted in the Kivu regions of the DRC, where state authority has collapsed and there is ongoing criminal activity. Of the ex-combatants who were interviewed, $90 \%$ had been involved in armed attacks, $75 \%$ in looting, $72 \%$ in physical assaults a ga inst civilians, $25 \%$ in massacresand $12 \%$ in sexual assaults and rape, and many had even eaten human flesh. Trauma symptoms can be treated with narative exposure therapy as well as substance abuse, because survivors frequently use substances to reduce their symptoms and suffering; depression symptoms will also reside; and the likelihood of re-joining a nother a med group can be reduced. In this way, people can be extricated from the cycle of violence. Actual aggression can be reduced among both men and women. Women in civil society have very little drive for competitive aggressive actions, but if women are exposed to a violent environment at a sensitive age they bec ome highly competitively a ggressive, with little differences from men.

However, in areas such as the DRC, there are too many people to be treated on an individual basis, and other ways have to be considered. South Africa's Truth and Reconciliation processprovidesan example that can be improved upon. The process that is followed is that anonymised narratives from perpetrators and victims a re developed (including not only what was experienced but how the person felt). The community is informed a bout the facts derived from na ratives (thus breaking a voidance and reduc ing stigmatisation) and completes them. Facts from the narratives and community sessions are archived as a part of the history of the community. Individuals with severe symptoms are referred to local counsellors tra ined in na rative exposure treatment. Briefing is used as prevention in subc linic al cases.

Aggression (but not necessarily violence) is part of human nature. Violence is the major source of mental ill-health. It is driven by the failure of state monopoly of power, extreme poverty (looting and fighting for survival) in circumstances in which there are no other sourc es of well-being (insuffic ient nutrition, no healthcare, no family/erotic relationships), drug abuse (consumption to reduce trauma) and gangs (hunting in groups offers more safety and more fun). The policy priority should be to prevent violence, both domestic and organised, working at both the individual and the social or community level.

\section{Disc ussion}

Prof Stein (UCT): How could the model developed by the Centre for Rural Health be introduced in the Westem Cape without research funding? How could those responsible be persuaded to buy into a collaborative care model? 
Prof Petersen (UKZN): Eden district munic ipality in the Westem Cape has a lrea dy a dopted the model. The Centre for Rural Health has been supporting Eden district with training. They had sent a psychologist to participate in training for trainers, supervisors and mentors presented to psychologists in $K \mathbb{Z}$. Eden district had identified people to be trained in facilities. A team from the Centre for Rural Health recently visited Eden district to present a facility mana ger'straining workshop in order to orienta te facility ma na gers to the model. The district municipality had been taking this initiative with their own financial resources, but was developing a proposal for support from the provincial govemment for the model. It is possible to implement the model without large resources.

Prof Stein (UCT): The message of the presentation on SBIRT was that expert interventions do not work without implementation. The implic ation is that the Addiction Technology Transfer Programme (ATTC) of education in the Westem Cape is not effective.

Prof Myers (SAMRC): The ATTC has raised awareness of SBIRT. This was the reason for the initial meeting about scaling-up SBIRT. The ATTC has presented national training on SBIRT and associated screening tools. The way in which the ATTC has raised literacy related to issues of addiction has been very valuable, which has helped break down stigmas and bamiers to disc ussing these issues with patients. The presentation attempted to convey some caution that it cannot be assumed that implementation will take place just by tra ining people on evidence-based practice. Implementation of a new practice is unlikely to happen without the necessary support, especially given the challenges in the South Afric an healthcare system. There is an opportunity for the $\mathrm{DoH}$ to engage on the basis of what is known from substance use research, but the opportunity should not be wasted by rushing to implement without properly thinking through what is required.

Prof Stein (UCT): Perhaps we should encourage children to play rough and tumble games and participate in martial arts, thereby becoming skilled at expressing aggression in a natural way and possibly making them resilient to mental illness. However, perpetrators would still be at risk, since the South African Stress and Health (SASH) data show that perpetrating violence is a risk factor for PTSD. Is this explained in the bi-cycle theoretical model?

Prof Ebert (University of Konstanz): This is an interesting proposal which could and maybe should be tested. In addition, reasons why people use drugs have to be considered. The data show in principle that success cannot be achieved without a sound aetiological model for the causes of drug use. In South Africa, the major reasons for drug use are trauma and poverty, although these are not the only reasons. It should be a research priority to find ways of getting boys out of criminal environments. There is no universal solution, but if the causes are known it is possible to consider ways of changing them. If young people have no way to obta in social status in society, they will look for other ways of ea ming status such as in a gang. From a high-income country perspective, the solution would be to give them a job, but this is difficult in a country with high rates of unemployment. Without progress in that regard, addressing the problems is very diffic ult.

Prof Myers (SAMRC): I believe that all substance abuse treatment, especially for more severe problems, hasto be tra uma focused. We need structural interventions that address the drivers of why people are using substances. The current focus is to respond to the problem rather than preventing it, but in order to be effective, we need to address both prevention and treatment.

DrPretorius (Wits): Would it be possible to collaborate with tra ditional hea lers in developing integrated primary healthca re, especially in rural a reas? 
Prof Petersen (UKZN): The integration of tra ditional hea lers would be important not only in rural but also in urban areas. This has not yet been done because the Centre for Rural Health is working with the formal healthc are system provided by the DoH. There would be an opportunity to do so with the development of the community platform. In addition to the work on mental health, the Centre for Rural Heath is also working with the DoH to strengthen community-oriented primary healthc a re. This enta ils working with ward-based outreach teams and with community struc tures, which would include community health workers and traditional healers. The intention is to empower community members to be more in control of their own health as well as the health of the community.

Ms Lunsky (Wits): The University of the Witwatersrand is rolling out a mental wellness strategy together with several partners and as many stakeholders as possible. There are enomous challenges. Part of the initiative involves capacity building with students and staff. How did the Centre for Rural Health get the buy in of nurses? Were they voluntarily tra ined or was partic ipation mandatory?

Prof Petersen ( $\mathbf{U} \mathbf{Z N}$ ): Unless nurses a re required to report on mental health ca ses, they will generally not do so. The healthcare system runs on a series of tick boxes. We therefore have to engage all the way from provincial to district, subdistrict and primary healthcare facility ma na ger levelsto ensure that people a re involved at all levels, and that it becomes clear to primary healthcare workers that mental health issues are part of their work on which they have to report. Performance appraisal systems are important. The indicators of the numbers screened and treated formental health in primary healthca re hashelped. The indic ators and continuous quality improvement are used to get the buy in and will of primary healthca re providers to provide the service.

Prof Lund (UCT): What a re the links between endemic poverty and scarcity in relation to violence as drivers of population mental health? How is the bidirectional relationship between violence and mental health influenced by conditions of poverty and scarcity?

Prof Ebert (University of Konstanz): The presenta tion emphasised that huma ns c an get into a hunting mode in which they enjoy violence. The factors that cause someone to enter into the hunting mode, especially during development, are very complex. Prof Lund's presentation showed that plastic ity occurs when pruning takesplace during adolescence and early adulthood. It is possible to recruit child soldiers and tum them into ferocious fighters. This is one of several drivers. A prerequisite for a solution for South Afric a would appear to be creating enough jobsfor people.

Prof Lund (UCT): How do we reach men who drink, since men tend not to visit clinics?

Prof Myers (SAMRC): The health system is struggling to attract more men into the health services, especially HIV services. For alcohol-related interventions, emergency departments provide an access point within the current health services to reach to men after they have been in fights and have been injured. Ward-based outreach teams (WBOTs) provide another opportunity to identify men who are drinking and possibly intervene at a community level, and perhaps link the men with facility-based services. It will be necessary to address the configuration of WBOTs so that they are not just women run, and men feel that the services are not just for women and children. There are perceptions that health services are for women and children.

Prof Petersen (UKZN): The idea behind the community mental health detection tool is to get a household member to identify someone who might display symptoms and to ask if they want help. This would be a possible way of involving men. Another opportunity for 
community-wide interventions might be through community struc tures, led by community leaders who are often men, on which community health workers would sit and discuss problems in the community.

Prof Myers (SAMRC): The community should be seen as an extension of the health system. There might be an opportunity in this environment to use peers; for example, a man who has had a history of drinking heavily and has stopped could identify with other men who are drinking.

\section{SESSION 5: BREAK-AWAY: IDENTIFYING POUCY AND RESEARCH PRIORTIES IN MENTAL HEALTH \\ Facilitator: Dr Siyavuya Bulani, Senior Liaison Officer, Academy of Science of South Africa}

Many of the presentations included recommendations for advancing research and policy priorities in mental health. The intention of the breakaway sessions was to compile a set of recommendations for inclusion in the proceedings, which would be shared with the DoH.

\section{Group 1: Neuroscience and Genetics (Rapporteur: Prof Dan Stein, UCT)}

1. There is concem about the negative connotations of the term 'precision public health'. The tem 'potentiating public health through prevention and patient-centred care' is recommended instead. It is important to be consistent with public health principles, consistent with patient-foc used care, and consistent with prevention.

2. We need to do this because of local health inequities, because local population diversities will cause the health inequities to grow over time, and because of the need for locally based phamacogenetics. Gemany and certain other countries are already using genetic methodologies for diagnosis and treatment (e.g. in the field of intellec tual disa bility, and in using CNVsto establish preventive practices). So uth Africa is not doing this locally.

3. To do this requires capacity development, ethics, improving health literacy, decreasing stigmatisation, instituting training and equipment:

a. Capacity development South Afric a has very little capacity development. The Human Heredity and Health in Africa (H3Africa) initiative provides a good example.

b. Ethics: It must be taken into account that much of the decision-making in South Africa is communitarian.

c. Improving health literacy: The generally low health literacy in South Africa needs to be addressed, including low mental health literacy and low genetic sliteracy.

d. Training: Tra ining in genetic counselling is required. The recommendations of the ASSAf report 'Proceedings of a workshop on the implementation of core competencies for mental, neurologic al and substance use disorders' need to be extended in order to address how genetics, especially neurogenetic s, will be addressed in the future. More training is also needed in bioinformatics. Genetics should form part of all health curricula.

e. Equipment Infrastructure is required for freezers, for microchipping and for sequencing. South Africa does not have infrastructure of this nature.

4. Funding will be required. H3Africa, which is funded by the NIH and Wellcome Trust, provides an example of bringing together collaborative funding in order to advance the field. Ways of encouraging European funding for similar initiatives could be considered.

5. Consideration needs to be given to what needs to be biobanked. The suggestions ranged from whole exome sequencing of every new-bom baby, to more targeted biobanking (e.g. all clinical research should have a biobanking component). Routine 
questioning is done on factors such asgenderand age, and it was argued that routine questioning on genetic $s$ is a lso required.

6. There was a strong proposal for a population-level cohort, taking into account several key points:

a. Genetic sand environment both need to be taken into account.

b. If the aim is prevention and person-centred care, genetics should take into account the comorbidity of mental health with communicable and noncommunic able disease.

c. In the context of populations in Africa being young, a neurodevelopmental population cohort would be required.

d. Any proposal for such a cohort would need to be supported by the new professional field of health economics with specialisation in genetics. ICER (inc remental cost a na lysis ra tio) a na lysis was proposed.

\section{Group 2: Public Mental Health and Epidemiology (Rapporteur: Ms Ravhengani Machaka, Sefako Makgatho University)}

1. Epidemiological research needsto be strengthened, especially having better incident data.

2. Data collection systems should be strengthened by linking them with existing surveys and otherdata.

3. Strategies are required to look at high-risk populations such as the early childhood development phase, adolescents and young people who are affected by the high rate of unemployment and substance abuse.

4. Research is needed on how well the healthcare system is working in order to implement mental health strategies.

5. Mapping the minimum community resourcesfor mental well-being is required in order to establish how well communities a re doing with respect to social cohesion and social capital (e.g. how functional school goveming bodies are; the extent to which communities are integrated; whether there are sports groups and religious groups to foster so cial c ohesion).

6. Technology needs to be hamessed for data collection.

\section{Group 3: Intervention Research (Rapporteur: Dr Gayle Langley, University of the Witwatersrand)}

1. With respect to policy and research prionities, does the DoH have an agenda for mental health research? There does not seem to be a robust model. Gaps were identified. There wasno evidence-based model for working in South Afric a.

2. At community level, subsystems need to be strengthened to address issues of poverty and violence.

3. Prevention and promotion should start early right from pregnancy, and continue through infancy, sc hools, teenagers and ea rly adulthood.

4. In order to develop human resources in the community, it is first necessary to know what exists in the community. Very little is known in this regard, and we tend to work in silos.

5. We need to work through ward-based outreach teams, NGOs and non-profit organisations, and less formal support resources.

6. The systems, problem areas, supportive structures and social and capacity building assets inherent in communities need to be mapped, with a focus on health and wellness rather than technology.

7. The group was enthusiastic about a systems approach, using methodologies such as appreciative inquiry, and using youth desks of political parties and faith-based organisations, which would require a change in the research paradigm. 
8. Longitudinal studies are required in order to measure change, using community indicators set by communities themselves. An action research approach is recommended.

9. The DoH does not seem to have an agenda for mental health research. Interest and funding thus tend to direct and lead research, resulting in uncoordinated efforts. Power rests to a large extent with provincial authorities, which is problematic. Coord ination between universities and provincial a uthorities is recommended, which would place pressure on provincial govemments. There is also a role for the $\mathrm{DoH}$ to place pressure on provincial authorities.

10. The impediments to research include govemance issues such as ethic s committees and provincial committees. There is a need to facilitate and simplify permission issues.

11. Health is not vertical; intersectoral mapping is required.

12. The higher education space was pointed out, as there has been a burgeoning of mental health issues among student populations with respect to both incidence and severity. The need for reso urces to deal with mental health issues among students was raised, including depression, violence, substance abuse and suic idality.

13. With respect to mental health literacy, the life-span approach was suggested extending from matemal health through the trajectory of childhood, schooling, teenagers and young adults.

14. Destigmatisation is required in relation to issues of gender and sexua lity in schools and in education generally, including teachers, educators and parents. It is important to consider the whole environment. This is an issue for research attention.

15. Mentoring of students could be considered as a means to facilitate mental health.

16. Support, advocacy and referral are required.

17. Group work and group strategies could be considered.

18. There was a suggestion to start in a catchment area and develop indicators, look at promotion and track outcomes over time, and in that specific context consider children, teachers, mental health indicators and a cohort study in a bounded space in early childhood development.

19. Large amounts of data a re availa ble but are not being mined. Systematic reviews a re required of services, and meta-analysis of systems over the life course.

20. Issues that require urgent attention include substance abuse, violence, severe mental illness, chronic disea ses of lifestyle, quality of life, lifestyle follow up, and resources for mainta ining wellness after disc harge or intervention.

\section{Discussion}

Dr Siyavuya Bulani (ASSAf) invited further comments. He noted that multidisciplinary approaches had been mentioned in the discussions and asked for suggestions on how the three sets of recommendations from the three breakaway groupscould be brought together.

Prof Lund (UCT): Does the Neuroscience and Genetics group (Group 1) have any suggestions related to a population cohort, as the Intervention Research group (Group 3) had similar ideas from the intervention perspective? Would there be any possibility for or interest in developing joint proposals following a cohort over time within a given catchment a rea, collecting both biologic al and social epidemiological data, potentially nesting targeted prevention and promotional treatment interventions in the catchment a rea, and looking at longitudinal effects over time?

Prof Chiliza (UKZN): The possibility of a longitudinal catchment study was considered, but it would be very expensive. The main message from the Neuroscience and Genetics group (Group 1) was that every study that is conducted in South Africa should make use of a biobank and collect genetic data through blood and saliva. 
Prof Lund (UCT): One possibility would be to approach the organisers of the National Income Dynamics Study (NIDS) and ask them to collect blood samples duning the next wave of the study. NIDSa lrea dy has data from five waves over ten years from a nationally representative cohort.

Prof Thom (Wits): There have been recommendations for a longitudinal study in a given catchment, as well as for nationally representative samples. What exactly is being recommended: a catchment study, or a national study, or both?

Prof Lund (UCT): Some nationally representative data are already available, but if population-level interventions are considered, it would make more sense to adopt a catchment area approach.

Prof Bhana (SAMRC): The Public Mental Health and Epidemiology group (Group 2) recommended the need for better understanding of the burden of disease nationally. NIDS could be a platform for asking a variety of questions. We are not recommending a nother South Afric an Stress and Health (SASH) study related specific a lly to mental hea lth. We recommend that the understanding of mental health should be linked to social determinants. Adding a genetic component could be interesting. Perhaps what is required is a national study, with a cohort study of vulnerable populations as a subcomponent. Because of the expense of research of this nature, studies have to be ca refully designed.

Prof Stein (UCT): Most recent nationa lly representa tive epidemiologic al studies of mental health have included DNA. The presentation by the DDG of the Department of Health emphasised the need for operational research as a priority, but South Africa also needs to be a ware of the kind of research being done in otherparts of the world, including India and China.

\section{SESSION 6: RESEARCH SUPPORT: FUNDERS \\ Facilitator: Mr Stanley Maphosa, Intemational and National Manager, Academy of Science of South Africa}

\section{NRF funding opportunities for mental health research (Ms Tracy Klarenbeek, Director: Knowledge Advancement and Support, National Research Foundation, South Africa)}

The National Research Foundation (NRF) was established to facilitate the creation of knowledge, innovation and development in all fields of science and technology, including indigenous knowledge. The funding instruments of the NRF are therefore not generally discipline-specific. Most of the NRF's funding instruments are open to all disciplines. It is not easy to mine the data specifically for mental health, with some exceptions. NRF funding instruments may be developed in one of three ways: top-down, bottom-up, and bilateral or multila teral.

Top-down instrument development is informed by the policies, strategies and priorities of govemment in relation to the two ma in sourc es of income of the NRF. Approximately $80 \%$ of the NRF's income comes from contracts with government departments, primarily the Department of Science and Technology (DST), as well as the departments of Trade and Industry, and Higher Education and Training. Approximately $20 \%$ of the NRF's income comes from Parliamentary grant baseline funding to support the mandate of the organisation as outlined in the National Research Foundation Act (No. 23 of 1998), as amended. 
Bottom-up instrument development emanates from research groups and research associations in order to support vulnerable disciplines (e.g. capacity development in nursing) or emerging disc iplines. The NRF operates a lmost exclusively in higher education institutions and with science councils to facilitate strategic initiatives, infrastructure and flagship programmes.

A host of different players operate in the space of bilateral or multinational instrument development, including:

- Government departments, including the Department of Intemational Relations and Cooperation;

- Intemational partners through formal country-to-country, or funding agency-tofund ing agency bilateral agreements;

- NRF through intemational partnerships (e.g. Belmont Forum for environmental susta ina bility;)

- Individual researchers;

- Research groups and research associations;

- Higher education institutions and science councils.

The NRF supports the range of phases of a research career, with several instruments that are not disc ipline spec ific for the next-generation, emerging and established researchers, namely:

- Thuthuka: PhD, Post-PhD and NRF Rating Tracks;

- Competitive Support for Rated and Unrated Researchers;

- Incentive Funding for Rated Researchers;

- Knowledge Interchange and Collaboration;

- Infrastructure or Equipment Funds;

- Freestanding Bursaries and Fellowships.

When the NRF dataset was filtered for support for mental health, psychology and psychiatry between 2013 and 2017, 30,538 awards were identified (excluding student bursa ries) a mounting to R720 million, which represented $32 \%$ of the NRF budget over this period. Forty-seven percent of these a wards were for inventive funding, and almost $10 \%$ for intemational engagements, including travel.

NRF contract funding currently supports 198 research chairs through the South African Resea rch Cha irs Initiative (SARC hl), 40 of which a re in hea lth (representing $20 \%$ of the total) including:

- Post-tra umatic Stress Disorder

- Enabled Environments for Assisted Living

- Clinic al Neurosciences Research

- Brain Imaging

- Health and Wealth in South Africa

- Health Systems, Complexity and Social Change.

NRF contract fund ing a Iso currently supports 15 Centres of Exc ellence, three of which a re in health, namely Epidemiological Modelling and Analysis, HIV Prevention, and Biomedical Tuberculosis Research.

NRF funding can be accessed via university research offices or online submission. There are opportunities to shape the research agenda at various levels by partnering with the NRF and/or other potential stakeholders to shape funding instruments, identifying intemational initiatives and lobbying for South African inclusion and/or funding. 


\section{SAMRC funding for mental health research (Prof Rachel J ewkes, Exec utive Scientist Research Strategy, South Afric an Medical Research Council)}

The SAMRC is a complic ated funder. Funding for the field of mental health is available from the SAMRC in both formal and less obvious ways. There are four key avenues for SAMRC funding:

- Intramural units and departments, four of which work on mental health, na mely:

o Alcohol Tobacco and Other Drugs Unit (ATODRU), which deals with substance abuse and other mental health issues as they overlap with the substance abuse agenda.

- Genderand Health Research Unit, which doesc onsiderable work in mental hea lth because the its core area is gender-based violence, a large part of which is to study the medical health impact of gender-based violence, and the ways in which mental health and substance abuse may impact on the risk of genderbased violence. Mental health interventions for preventing gender-based violence a re considered aswell as the implic a tionsforhealth services. The Gender and Health Research Unit houses the Sexual Violence Research Initiative (SVRI), which is a small-scale grant maker. The SVRI/World Bank mechanism extends oneyear grants of about US\$10,000 a nnually. Work at the interface of mental health and gender-based violence is potentially fundable through this mechanism. The call is advertised each year. Anyone interested in this field is advised to become a member of the SVRI, whic $h$ send sout a bimonthly mailing, including funding and conference opportunities and new public ations. The SVRI convenes an annual conference. The Genderand Health Research Unit hasalso been managing large DFID funds and supporting large grants for intervention evaluations, including interventions at the interface of mental health and violence. The work from the first funding mechanism is being completed, and it is not known if there will be a nother opportunity.

- Health Systems Research Unit, which has a long history of collaboration with the Division of Child and Adolescent Psyc hiatry at UCT.

o Violence and Injury Prevention Research Unit, which is embedded in the community psychology work with the aim of developing data-driven prevention initiatives and transferable solutions for issues of injury and violence, including the promotion of safety and peace.

- Biostatistics Unit which has a cross-cutting mandate and provides a source of biostatistic sexpertise and support to the SAMRC's network of medic al and health researchers as well as govemment departments and national and intemational research bodies. It is an interdisciplinary unit with expertise in biostatistics, geographic information science, data management and food science.

- Cochrane South Africa, which is part of the global, independent Cochrane network of researchers, professionals, patients, carers and people interested in health. Cochrane is a non-profit organisation that prepares and disseminates information in the form of systematic reviews on what works and what does not in healthcare. These reviews enable policymakers, health service providers and the public to make informed decisions about healthcare. The Cochrane Centre hasa variety of training mechanisms in the systematic review field ranging from workshops over several hours to programmes over several days. Webinars are posted on the website as a resource for researchers and students. Cochrane provides support in response to queries on how to conduct meta-analysis.

- Research Capacity Development The SAMRC funds PhDs, master's degrees and postdoctoral fellowships, and hosts the Bongani Mayosi National Health Scholars Programme. 
- Extramural units (EMUs) located in universities orresearc $h$ institutions, only one of which is in the field of mental health, namely the Risk and Resilience in Mental Disorders Unit at UCT. The SAMRC usually advertises a call once a year for new extramural research units. Since mental health is underrepresented, the SAMRC would welcome strong applications for mental health units. EMUs are built around the scientific excellence and leadership of the unit director. The goals of EMUsare to genera te knowledge using SAMRC seed funding, develop nodes of research excellence, and develop the next generation of research leaders. EMUs are supported for up to 15 years. Continued funding is based on progress measured by peer review every five years. The baseline funding is R1 million. Incentivised fund ing is based on the previous year's public ations. The unit's total budget may not exc eed R2.5 million.

- Self-initiated grants which a re advertised each year. The grants a re for R200,000 per year for three years. Early career researchers are funded, as well as mid-career and established researchers in a different category with capacity development as one of the criteria. The grants are moved to different prionity areas year. Mental health was not a prionity area in 2018, and it is not yet known if it will be in 2019. Prionity is given to quality proposals from women researchers, and researchers from historically disadvantaged groups or historic ally disadvantaged institutions (HDIs). Researchers from other institutions could consider collaborating with HDIs. Advantages in EMU applications include being based in an HDI or collaborating with an $\mathrm{HDI}$, the gender and race of the unit director, and geographical location outside the Westem Cape (where most of the EMUs have historic ally been located).

- Ad hoc mechanisms, whic h a re nomally but not exc lusively a dvertised a nd managed through the SAMRC's Grants, Innovation and Product Development Unit (GIPD). The SAMRC occasionally funds large studies with big budgets in important areas; for example, in response to a particularneed. The SAMRC isplanning to fund the National Survey of Mental Health and Suicide in Higher Education Institutions. GIPD manages joint funding mechanisms between the SAMRC and other funds, which are usually intemational, including the Swedish Research Council for Health, Working Life and Welfare (Forte), UK Medical Research Council, Wellcome Trust, and Bill and Melinda Gates Foundation.

A co-funded SAMRC/NIH call forproposa Is isout for colla borative research between South Afric $n$ and US institutions involving HIV as a component of the work. Work on the interface between mental health and HIV would fall within the remit of the call.

\section{Janssen/J \& global public health support for mental health programmes in South Africa (Ms Abeda Williams, Senior Director Technical and Medical Affairs, Janssen Pharmac eutica, South Africa)}

The approach of J anssen/J \& is commerc ial, philanthropic and self-susta ining:

- Commercial model: Janssen/J\&J's core business is profit-driven through Janssen Pharmaceutica, J\&J Medical Devices and J\&J Consumer Healthcare. The first responsibility is to doctors, nurses, patients, mothers and fathers, and everyone who uses the products. Every day, the products touch over a billion people worldwide.

- Philanthropic approach: Global Community Impact (GCI) is the social responsibility group, which seeks to strengthen frontline health workers and sustain healthy communities. GCI has a strong presence in Africa. GCI partners include bilateral and UN agencies (including USAID, UNICEF and WHO), intemational NGOs, professional asso ciations, Ministries of Health, global collaboratives, youth and innova tors.

- Self-sustainable approach: Global Public Health provides cross-sector product- and solution-centric innovations that improve patient and social outcomes in resource- 
limited settings via susta inable access models and partnerships. The intention is to be in a position to deliver healthcare to the entire spectrum of patients. The four core foc us a reas are TB, HIV, mental health and so il-transmitted helminths. Other a reas of interest and supporting platforms include vector-bome diseases (dengue, malaria), vaccines (an Ebola virus has been developed and will be delivered to the DRC), essential surgery and trauma, and myopia. The cross-cutting approach to the four foc us a rrears or pillars entails:

- Build ing R\&D capacity in Afric a, inc luding c linical trial sites and fellowships

o Strengthening health systems and enabling frontline healthca re workers

o Private sector round table leadership on global health security

Some examples of J \& g global public health support for mental health include:

- In Rwanda, determining the prevalence and burden of disease to inform policy decision-making; increasing access to mental healthcare within communities; and accelerating access to innovative, life-saving and transformational schizophrenia medic ines. The accomplishments include undertaking the first nationwide mental health survey in the country; providing remote training to 65,000 healthcare workers on mental health counselling and support; leveraging digital technology; and dosing the first patients with long-acting injectablesas part of a pragmatic study.

- In South Africa:

o A consensus study has been funded on provider core competencies for the improvement of mental healthcare.

o The DoH hasapproached J \&J to develop an investment case for mental health to determine the costs and retums of a prionitised package of system and servicelevel interventions to reach important targets related to South African mental health services.

o The current community-based mental health servic es model has been reviewed to detemine the input costs for implementation of the model and develop guidelines to guide provinces in the development and provision of community-based mental health services.

o Tra ining is provided with a focus on public sector nurses in Gauteng. The capacity of registered nurses at peripheral sites has been developed to diagnose, treat and where required refer patients who present with a range of commonly occuming mental health conditions.

- Patient-level support is provided through the Spring Foundation Lentegeur market garden. This is a flagship programme of the Spring Foundation with the aim of providing rehabilitation, food security, mentoring and training opportunities for patients at the hospital and in the surrounding community.

\section{Discussion}

Prof Lund (UCT): To what extent can this ASSAf symposium on mental health influence the priority-setting processes of the NRF and the SAMRC? How are potential research priorities for mental health established? Do the NRF and SAMRC have a strategic vision formental health funding?

Prof J ewkes (SAMRC): The SAMRC does not have a stra tegic vision spec ific a lly for mental health funding, but the SAMRC will be embarking on strategic planning over the next six monthsand focusing the vision for va rious research a rea sshould form part of that process. The SAMRC is inviting comments and input from a wide range of stakeholders. The outcome of this symposium should help inform the SAMRC's strategic planning. The SAMRC recently decided to prioritise selected areasfor self-initiated grantseach year. The SAMRC should perhapsinvite suggestions to influence the selection of these a reas. A case could be made for prionitising mental health in a future round of self-initiated funding or 
establishment of extramural research units. The SAMRC wants to be positioned as an organisation that listens to advice and demands for fund ing to move to particular a reas.

Ms Karenbeek (NRF): The NRF and the SAMRC work quite similarly. Many NRF initiatives come from the bottom-up. It is encouraging that this symposium has started to identify prionity a reas for research and policy. Some of the suggestions would meet the criteria for NRF funding instruments. Before applying to large funding instruments such as SARChl or the Centres of Excellence, engagement with the $\mathrm{DoH}$ is recommended in order to get political buy in. Important considerations in awarding grants include innovation (in line with the DSTs recent White Paper on Science, Technology and Innovation), societal benefit, multidisciplinarity and transdisciplinarity, and community engagement that involves the development of research questions and the co-creation of knowledge. One of the priorities identified by this symposium, namely hamessing technology for data collection, would have enomous societal impact.

Ms Williams ( $\mathbf{J}$ anssen/J $\boldsymbol{\&} \mathbf{J}):$ Mental health is a key priority among the focus areas of J \& J . The company is committed not only to supporting drugs and medicines, but also strengthening health systems and addressing the research required for that purpose.

Prof J ewkes (SAMRC): Researchers a re encouraged to put their id ea sforwa rd. The SAMRC responds to the demands of stakeholders and invites quality grant proposals.

Ms Karenbeek (NRF): The NRF offers opportunities outside of research grants, including freestanding student bursaries and early career development funding tracks, which strongly address the transformation agenda. The NRF partners with the Department of Higher Education and Training for capacity development initiatives (e.g. successful training in mathematics and statistics in 2018). The NRF National Equipment Programme funds research infrastructure. Researchers need to advocate for support in order to suc cessfully win research grants.

\section{Wrap-up and closure of symposium}

\section{Prof Crick Lund (Alan J Fisher Centre for Public Mental Health, Department of Psychiatry and Mental Health, University of Cape Town)}

Prof Lund thanked ASSAf for their work and support in convening the symposium. It was encouraging that an institution with the stature of ASSAf within South Africa was focusing on mental health. He also thanked Leopold ina for their role in planning and organising the symposium and the opportunity to meet colleagues from Gemany. A basis has been established for ongoing collaboration and exchange of ideas. He thanked the partic ipants for sharing their thoughts, expertise and wisdom so freely, and contributing to interesting and stimulating disc ussions.

ASSAf would compile a report of the symposium documenting not only the presentations, but also the recommendations with respect to research and policy prionities. The report would be sent to the South African Department of Health, which was interested in identifying research prionities. Research often takesplace on a failly ad hoc basis around researchers' individual interests and on the basis of a va ila ble fund ing. The symposium had identified the need for national leadership to identify research prionities for mental health.

The intention was to develop an agenda for mental health research in the national interest, especially in order to cater for the needs of those who are most disadvantaged in society. South Africa is a classic example of the inverse care law, in that people who have the least access to care have the most mental health needs. Historically, South 
Africa's services have focused on psychiatric hospitals which continue to dominate the budgeting landscape but are not necessarily the most conducive space formental care. Research is especially needed a round prevention and promotion for mental health. It is important to take a life course perspective, including early interventions, from pregnancy through to old age.

It was encouraging to hear from the SAMRC and the NRF about the potential for national priority-setting processes to inform funding.

\section{Prof Frank Rösler (Senior Professor, Biological Psychology and Neuropsychology, University of Hamburg)}

The symposium covered a broad range of topics, from basic to applied research. Research effort is required for integration of the various initiatives in this wide-ranging field. Many of the problems of South Afric a were presented in some form during the symposium, and provided valuable insights that could be used to promote mental health research in low- and middle-income countries.

The symposium provides further evidence of the success of the cooperation between Leopoldina and ASSAf. Prof Rösler thanked colleagues from both organisations and looked forward to the next symposium. 


\title{
Addressing Mental Health Disorders in the Afric an Region
}

Steven Shongwe, Non-communicable Diseases, Wold Health Organisation (WHO) Regional Office for Africa.

Email: shongwes@who.int

\begin{abstract}
Mental disorders include a range of mental and behavioural disorders such as depression, bipolar affective disorders, schizophrenia, anxiety disorders, dementia, substance use disorders, intellectual disabilities, and other disorders. Globally, $14 \%$ of the global burden of disease is attributed to these disorders. Seventy-five percent of the people with these disorders in many low-income countries do not have access to the treatment they need. Deteminants of mental health and mental disorders include social, cultural, economic, political and environmental factors. Certa in individuals may be at higher risk of mental disorders - those with chronic conditions such as human immunodeficiency virus (HIV)/acquired immunodeficiency syndrome (AIDS), cardiovascular diseases, cancer, people exposed to substance use, people experiencing discrimination and human rights violations, and those in conflict, natural disasters and humanitarian situations. The overall goal of the WHO Mental Health Action Plan 2013 - 2020 is to promote mental well-being, prevent mental disorders, provide care, enhance recovery, promote human rights and reduce morta lity, morbid ity and disability for persons with mental disorders. In line with this global action plan, WHO has advocated for prioritisation of mental health in countries, provided technical support for the development and implementation of mental health policies, plans and legislation. WHO has also provided technical support towards the implementation of the WHO Mental Health Gap Action Programme (mhGAP), and the provision of psychosocial support and care during disasters and humanitarian emergencies. Progress in implementing the WHO global action plan has been slow due to several challenges including inadequate funding for mental health, insufficient numbers of trained health workers, inadequate mental health facilities, stigma and discrimination aga inst people with mental disorders. This presentation recommends that countries in the Afric an region should mobilise financial, human and material resourc es to scale up mental health programmes, services and interventions and accelerate the development and implementation of mental health polic ies, plans and legislation. It also recommends scaling up the training of mental health workers and promoting task shifting and sharing among health workers and integrating mental health, alc ohol and substance use disorders into primary health care.
\end{abstract}




\title{
Global Mental Health and the Sustainable Development Goals: Aligning the Research and Policy Agendas
}

Crick Lund, Alan J Flisher Centre for Public Mental Health, Department of Psychiatry, University of Cape Town.

Email: crick.lund@uct.ac.za

\begin{abstract}
The past 20 years have seen an unprecedented growth in the field of global mental health. Beginning with early research efforts in the 1990s, we have seen key policy commitments from the WHO, national govemments and the United Nations Susta inable Development Goals (SDGs). There have also been large new investments in research funding, generating substantial evidence regarding the global burden of mental illness, and cost-effective interventions. Yet the SDG era challenges us, as mental health researchers and practitioners, to think differently about mental health: to understand mental health from a life-course perspective, to develop a more dimensional approach to the construct of mental illness in diverse cultures, and to protect and promote the human rights of people living with mental illness. This talk will present a framework for the social deteminants of mental health and the SDGs and propose an agenda for future research and policy priorities in the SDG era.
\end{abstract}

\section{Mental Health Research Prionities in South Africa: Should We Include Neurogenetics?}

Dan Stein, Department of Psychiatry and Mental Health, University of Cape Town, South Africa.

Email: dan.stein@uct.ac.za

\begin{abstract}
Several mental health research prionty exercises have taken place, both locally and globally. Epidemiological and implementation research has been viewed as particularly important for low and middle-income countries. More recently, attention has been paid to the relevance of discovery research in these contexts. Given advances in neurogenetics and possible clinical implications, there are good reasons for including genetics research as part of such discovery efforts. Still, to maximise potential, an integration of neurosc ience with global mental health research is needed.
\end{abstract}




\title{
Breakthrough in Understanding the MolecularCauses of Psychiatric Disorders
}

Markus Nöthen, Institute of Human Genetic s, University Hospital of Bonn, Gemany.

Email: markus.noethen@ukbonn.de

\begin{abstract}
A long-established hypothesis is that genetic factors contribute to the development of psychiatric diseases, including common illnesses such as schizophrenia and the affective disorders. However, reliable molecular identific ation of these factors representsa farmore recent innovation. This has been rendered possible by technological advances in the individual characterisation of the human genome, and the combining of large genetic data sets at the intemational level. For the first time, the results of genome-wide analyses provide researchers with systematic insights into disease-relevant biologic al mechanisms. Here, the integrated a nalysis of different omics-level data genera tes important insights in terms of the interpretation of the genetic findings (e.g. the national IntegraMent consortium). The results of genetic studies also demonstrate the degree of etiological overlap between differing psychiatric disorders, with the greatest commonality having been observed to date between schizophrenia and bipolar affective disorder. Although the translation of genetic findings into routine clinical practice is being pursued at various levels, elaborate follow-up studies are typic ally necessary. The diagnostic investigation of rare genomic deletions/duplications (so-called copy number variants) in patients with schizo phrenia is likely to represent one of the first examples of routine clinical a pplic ation. The necessary prerequisites for this are currently being defined, for example at the European level within the COSTaction EnGagE.
\end{abstract}

\section{China Brain Projectand Macaque Models for Biomedical Research}

Mu-ming Poo, Institute of Neuroscience, Chinese Aca demy of Sciences.

Email: guyixi@ion.ac.cn

\begin{abstract}
After years of discussion and planning, China Brain Project (on Bra in Science and Braininspired Technology) is officially initiated this year. This project consists of basic research on the neural circuit basis of cognition, as well as the development of new diagnostic and therapeutic approaches in treating brain disorders and brain-inspired machine leaming methods and computing devices. Non-human primates will play a prominent role as the a nimal model forboth basic and applied research in the China Bra in Project. In particular, the project proposes the mapping of mesosc opic connectome of the macaque monkey, a long-tem project that requires extensive intemational collaboration. The project also calls for the generation of macaque models of brain disorders and the development of intervention and therapeutic approaches using these models. For preclinical animal studies, it is desirable to have monkeys with a relatively uniform genetic background. I will summarize our recent efforts in cloning macaque monkeys using somatic cell nuclear transfer (SCNT) and showed that this approach could be used in generating macaque monkey clones camying identical gene-editing. As an example, we first performed CRISPR/Cas9 editing on in vitro fertilised macaque embryos to knockout Bmal1, gene encoding a core transcription factor for circadian rhythm, and obtained a group of moneys with either complete or mosa ic knockout of BMAL1 expression. To varying extent,
\end{abstract}


these monkeys showed circadian disorders in locomotive activity, sleep pattem and circulating homones, as well as anxiety/depression and schizophrenia-like psychosis phenotypes. We then took the skin fibroblasts of one young male monkey that showed a complete BMALI knockout and most severe circ a dian disorder phenotypes for SCNT and generated five monkey clones with identical BMAL1 knockout genotype. Thus, geneedited macaque monkeys with uniform genetic background will soon be available for studying primate neurobiology and for developing therapeutic sfor human diseases.

\title{
Family Studies from Endogamous Groups Enable the Eucidation of Distinct Predisposing Pathways in Dyslexia
}

Subrata Sinha, All India Institute of Medic al Sciences, New Delhi, India.

E-mail: sub_sinha@hotmail.com

\begin{abstract}
Dyslexia is a specific leaming disability that manifests as diffic ulty in reading despite adequate intelligence oropportunity. It is a complexdisorder, which hasa strong herita ble component. While these are several genes that have been implicated in the pathogenesis of dyslexia, none of these account for a significant proportion of the disa bility a cross populations.

We have studied three extended families with from distinct endogamous groups who had a high proportion of dyslexia. All these fa milies had distinct pattems of inheritance. One of these had an autosomal dominant pattem of inheritance. A set of 17 polymorphisms on Chromosome 5p31.3 that encompassed a $1.9 \mathrm{Mb}$ region comprising mainly the Protocadherin G (PCDHG) cluster, was strongly associated with dyslexia in this family. Seven of the risk-associated variants are ancestral variants preponderant Neanderthal and Denisovan sequences, while the non-risk associated variants are preponderant in modem humans. The otherfamilieshad different inheritance pattems; one wasautosomal recessive, while the third had an association with Attention Defic it Hyperactive Disorder (ADHD), a known co-morbidity condition of dyslexia.
\end{abstract}

Endogamous groups are common in the developing world and are of great help in identifying disease pathogenesis and the molecular sub-classification of disease phenotypes. Because of genetic similarities, especially during family studies, they provide a better opportunity to identify pre-disposing mutations and pathways. While the exact pathways thusidentified may not be generalised to the population at large, they provide vital clues for endophenotyping and pathogenesis. However, it is important that such studies have to be pursued with sensitivity and within clear ethic al guidelines, so that they do not increase the vulnerability of the populations being studied. An important component of this work was done at the National Brain Research Centre, Manesar, India. 


\title{
Common Mental Disorders Among Individuals Seeking HIV Testing
}

Ashraf Kagee, Centre for Public Mental Health, University of Stellenbosch, South Afric a.

Email: skagee@sun.ac.za

\begin{abstract}
The presentation will have two parts. In the first part, the prevalence of mental health conditions among persons seeking an HIV test will be disc ussed. In the second part, the utility of screening for common mental health disorders will be examined. Much of the literature assumes that the receipt of an HIV-positive test results precipitates a mental hea Ith condition, such as depression, anxiety or posttra uma tic stress. I will present data on the prevalence of common mental disorders a mong persons seeking an HIV test, i.e. prior to receipt of their test results. Using the Structured Clinical Interview for the DSM (SCID) among 500 persons seeking HIV testing, my studies found the following prevalence of $14.2 \%$ for major depressive disorder; $5.0 \%$ for generalised anxiety disorder, $4.9 \%$ for posttraumatic stress disorder, and $19.8 \%$ for alcohol use disorder. These findings imply the need to integrate mental health assessment and referral trajectories in the context of voluntary HIV counselling and testing.
\end{abstract}

Considerable literature has also indic ated that screening for common mental disorders will assist in case detection and consequent trea tment. We administered a battery of selfreport screening instruments to test their accuracy in determining caseness for the disorders mentioned above. Receiver operating characteristic c une a na lysis was used to determine the ability of these measures to discriminate between caseness and noncaseness as detemined by the SCID. We found the ability of screening instruments to predict ca seness for common mental disorders was limited. Persons sc reening positive for a common mental disorder may still require evaluation with a clinical interview by a trained professional to be diagnosed with a common mental disorder, which raises questions about the resource utilisation in the public health system.

\section{Addressing the Challenge of Mental Disorders: Genetic Approaches to Nosology, Etiology, and Treatment}

Marcella Rietschel, Department of Genetic Epidemiology in Psyc hiatry, Central Institute of Mental Health, Gemany.

Email: Marcella.Rietschel@zi-mannheim.de

\begin{abstract}
Genetic factors are implic ated in the etiology of all mental disorders. Unravelling these factors on the molecular level will generate insights into biologic al mechanisms and the interplay between genetic sand environment. This in tum will guide future intervention and prevention strategies on both the individual and population level. An ever-increasing number of genetic variants are being identified via high-throughput genome-wide association analyses (GWAS). The majority of these variants a re common and make only a limited contribution to the respective mental disorders. However, such va riants c an shed light on genes and pathways of etiological significance. Furthemore, joint analyses generate insights into the genetic architecture of mental diso rders, as well as overlap with (co-morbid) diseases and traits. GWAS data on different mental and somatic disorders
\end{abstract}


can be compared using approaches such as polygenic risk score and linkagedisequilibrium score regression analyses. To date, important findings from such analyses include a wide-spread cross-disorder sharing of common risk variants. Future steps in mental disorder research will include a disentangling of the communalities and spec ific ities of the different mental disorders, elucidation of the impact of environmental factors on mental disorder risk, and the establishment of biologic ally guided diagnoses. This is a challenging undertaking, since no objective measure or biological marker comparable to blood pressure monitoring in hypertension, or glucose measurement in diabetes - is yet available to assist the diagnostic process or predict the course of mental disorder and disease risk. This endeavour will require new approaches, including novel methods of phenotyping. Use of new cost-efficient devices, such as smartphones and actigraphs, will allow active and passive real-time assessment of many phenotypes of interest. These phenotypes will include: psychological parameters (e.g. emotion, cognition, volition, craving); physiological parameters (e.g. heart rate variability, locomotor activity, breathing rate); behaviour (e.g. fluid intake, social interaction); and environmental conditions (e.g. geolocation, surroundings). Longitudinal monitoring of these phenotypes can be performed over extended time periods in both patients and subjects from the general population. Combining these data with the results of parallel neuroimaging and multi-omics analyses will generate infomation conceming the biological mechanisms of traits underlying the development and course of the various mental disorders. The clinic al utility of these ecologic al assessments in tems of predicting and preventing mental disorder relapse has already been demonstrated.

\title{
Prionities of Mental Health Public Policy in Portuguese-speaking Countries of Africa and South America: How to Build Nationwide Care Systems in Contexts of Social Inequalities, Vulnerability and Scarcity
}

Pedro Gabriel Delgado, Institute of Psychiatry, Federal University of Rio de J a neiro, Rio de Janeiro, Brazil.

Email: p.g.godinhodelgado@gmail.com

\begin{abstract}
The sustainable development agenda (United Nations (UN) 20/30) recommends that middle and low-income countries face bamiers to access to mental health care in order to a chieve a dequate health care coverage by 2030. In a ddition to the general guidelines and measures, such countries should develop innovations that address and include local peculiarities, especially in contexts of socioeconomic inequity, vulnerability and scarcity of resources. The present study a na lyses the experience of expanding accessto treatment in Brazil, in the period of 2001 - 2015, and presents and discusses the strategy developed, i.e, replacing hospital-centred care for the intemalisation of community-based services and mental health actions in the primary care level. We describe the model change, and the results obtained in the expansion of access. In order to dialogue with the recommendations of Agenda 20/30, the strategies for expanding coverage in mental health of two Portuguese-speaking African countries, equally marked by inequity, vulnerability and scarcity, in very diverse socio-cultural and economic contexts, are summarily disc ussed. The a im is to identify strategies that constitute local innovations and can be effective ways to address the mental health gap in countries of an intemational community, the Community of Portuguese Speaking Countries (CPLP).
\end{abstract}




\title{
Adolescent Substance Abuse Trends: The Need for Early Identification
}

Arvin Bhana, Health Systems Research Unit, South African Medical Research Council, South Afric a

Email: Arvin.Bhana@mrc.ac.za

\begin{abstract}
The presentation focuses on adolescent substance abuse trends using data collected over a five-year period from treatment facilities in South Afric a through the South African Community Epidemiology Network (SACENDU). The spotlight is falls on a number of individuals in treatment in the country, key demographic characteristics and the major substances abused by adolescents. Implications of these trends a re discussed in relation to mental health in general and in relation to neurobiologic al vulnerabilities. Suggestions for future research are discussed in advocating for early identification and treatment.
\end{abstract}

\section{Epigenetics in Psychiatry and Psychotherapy - At the Crossroads between Risk and Resilience}

Katharina Domschke, Department of Psyc hia try and Psychotherapy, University of Freiburg, Gemany.

Email: katharina.domschke@uniklinik-freiburg.de

\begin{abstract}
After identific a tion of the genetic arc hitecture of complex genetic mental disorders, there is burgeoning evidence for epigenetic mechanisms such as DNA methylation or histone modifications to crucially shape risk and resilience towards mental disorders at the crossroads between the genetic and the environmental level. Epigenetic pattems might furthemore govem treatment response and/orconstitute temporally dynamic biological correlates of treatment success. Finally, phamacological targeting of epigenetic mechanisms camies promising potential to augment treatment efficacy in mental disorders. The present talk will focus on recent advance in epigenetic research from basic mechanisms to treatment options exemplarily for anxiety, affective and stress-related disorders and will provide a forum to disc uss future developments as well as limitations in the field. Despite some pitfalls, such as a variety of confounders, the difficulty to translate peripheral findings to central processes in humans and open questions relating to stability and transgenerational transmissibility of epigenetic marks, progress and perspectives in the field of epigenetics camy great promise to take us closer to clinical application comprising resilience-inc reasing indicated preventive mea sures in high-risk groups, as well as more targeted, personalised and innovative trea tment options for mental disorders.
\end{abstract}




\title{
Using Intervention Research to Drive Evidence-based Integration of Mental Health into Primary Health Care Settings in South Arica
}

Inge Petersen, Centre for Rural Hea Ith, University of KwaZulu-Natal, So uth Africa.

\author{
Email: PEIERSENI@ukzn.ac.za
}

\begin{abstract}
While there is research evidence on the effectiveness of integrating mental health into primary health care using task sharing in low and middle-income countries; there is a paucity of knowledge of how to scale up such models in real-world settings. Using the Medic al Research Counc il fra mework forc omplex interventions, this presentation will track the development, implementation, evaluation and scale up of a collaborative care model for the integration of care for common mental disorders into the chronic primary health care platform in South Africa in real-world settings. Through the Programme for Improving Mental Health Care (PRIME), an initial programme theory for integrated mental health care for adults with common mental disorders was co-developed with local stakeholders in one district in the North West province, using Theory of Change workshops. The resulting collaborative care model was piloted, refined and then initially evaluated using a quasi-experimental design comprising a repeat facility detection survey to assess changes in detection, a cohort study to assess ind ividual-level changes in symptoms and functioning, and a case study to examine the process of implementing the plans. This implementation study was followed by a pragmatic cluster randomised control trial of patients with comorbid hypertension depression and hypertension. Process indicators, collected alongside the trial, were analysed using qualitative comparative analysis to understand the configurational effects of these indicators on trial outcomes across the casc a de of care. Through the Mental Health Integration (MhINT) project, this collaborative model has been scaled up in the KwaZulu-Natal province starting with the Amajuba district using continuous qua lity improvement as the vehic le of implementation, resulting in differentiated refined scale-up packagesfordifferent contexts. This sc aled-up package is being evaluated using implementation science methods by the Southem African research consortium for Mental Health IntegraTion (SMhINT). Findings from these various studies will be reported.
\end{abstract}

\section{Providing Screening, Brief Interventions and Refenral to Treatment (SBIRT) for Substance Use Disorders into South Africa's Primary Health Care Senvices: Lessons from Local Research}

Bronwyn Myers, Alc ohol, Tobacco and Other Drug Research Unit, So uth Afric an Medical Research Council, South Afric a

Email: Bronwyn.Myers@mrc.ac.za

\begin{abstract}
In recent years, the South African Department of Health has expressed commitment to scaling up the provision of screening, brief intervention, and referral to more intensive trea tment (SBIRT) for ha mful substance use within primary health care servic es. To ensure that the provision of SBIRT for hamful substance use moves from a service plan to successful implementation requires evidence-based tools for SBIRT to be identified and questions related to the process of delivering SBIRT within current health services to be addressed. This presentation will describe findings from studies of SBIRT for hamful
\end{abstract}


substance use conducted within emergency departments, HIV, and chronic disease services. First, we will present findings related to screening tools and brief intervention materials. Next, patient, health system, and contextual bamiers to SBIRT implementation that require consideration when developing a national implementation strategy will be reviewed. Finally, provider and patient recommendations for how to enhance the acceptability of SBIRT, fea sibility of implementation, SBIRT adoption, and the fidelity with which SBIRT is implemented will be presented. If used, lessons from these loc al studiesc ould support the successful implementation of SBIRT within primary health ca re servic es.

\title{
Overcoming Trauma and Violence - From Individual Trauma Nanatives to Community- based Intervention in War-tom Regions
}

Thomas Ebert Sabine Sc hmitt, Katy Robjant, Maggie Sc hauer, \& Anke Köbach, University of Konstanz, Gemany.

Email: Thomas.Elbert@uni-konstanz.de

\begin{abstract}
Expeniences of a dversities and stressors a re stored in an asso cia tive memory. With regards to social and physic al threa ts for life and integrity, this tra uma network becomes enlarged, with ever more cues being able to trigger alam or dissociative responses. Ultimately this will lead to forms of trauma-related suffering, including post-traumatic stress disorder (PTSD) and depression. Narrative Exposure Therapy (NET), an evidence-based psychotherapy, assists survivors to reorganise their memory and thus initiates a healing process. In NET, the c lient, with the assistance of the counsellor, constructsa chronological namative of her/his life story with a focus on the traumatic experiences. Within a predefined number, usually about $4-12$, of 90 - 120 min sessions, the fragmented reports of the traumatic experiences will be transfomed into a coherent narrative. Empathic understanding, active listening, congruency, and unconditional positive regard are key components of the therapist's behavior and attitude. For tra umatic stress experiences the therapist explores sensory information, resulting cognitions, affective and physiological responding in detail and probes for respective observations. The patient is encouraged to relive these experiences while narrating, while consciously contrasting them to the "here and now". Using pemanent reminders that the feelings and physiologic al responses result from activation of (hot) memories, the therapist links these mnemonic representations to episodic facts, that is, time and place (cold memory). For survivors of violence, the testimony can be recorded and used for documentary purposes.
\end{abstract}

While this treatment hashelped thousandsof survivors in warand crisis regionsto find ways back to a life with social relations and occupational functioning, individual therapy can only be one component for hea ling. Anotherone isacceptance and support by the social group. Therefore, we have developed NElfacts, a feasible intervention on the community level. NElfacts combines ongoing provision of trauma therapy with delivery of a 3 to 4week trauma-infomed community intervention. It includes the development of a community lifeline symbolising shared highly affective experiences. It is constructed in a meeting with community members followed by a 2-week period in which tra umatic events of traumatised individuals (with subclinical symptom severity) are recorded in single exposure sessionsaccording to the NET logic. The narratives of tra umatic experiences that are found critical for the continuation of violence will be presented to community members during the next two session. In the fourth and last community session, an anti- 
violent action schemes is developed by the community. All members of a community/village are encouraged to actively participate.

We have first tested the feasibility and then demonstrated the efficacy of NET facts in villages of the war-stricken Kivu regions of Eastem Democratic Republic of the Congo (DRC). An example of a community lifeline is presented in Figure 1. It is our hope that this approach can be scaled up to support larger numbers of survivors of war and violence, and even contribute to a susta inable peace-building process. 


\begin{tabular}{|c|c|c|c|}
\hline Allen & Robin & $\mathrm{Dr}$ & $\begin{array}{l}\text { Lentegeur Psychiatric Hospital, } \\
\text { DoH }\end{array}$ \\
\hline Amold & Robyn & Ms & Write Connection \\
\hline Bhana & Arvin & Prof & $\begin{array}{l}\text { South African Medical } \\
\text { Research Council }\end{array}$ \\
\hline Bulani & Siya vuya & $\mathrm{Dr}$ & $\begin{array}{l}\text { Academy of Science of South } \\
\text { Africa }\end{array}$ \\
\hline Card & Melissa & $\mathrm{Dr}$ & University of J oha nnesb urg \\
\hline Chi & Venessa & Ms & $\begin{array}{l}\text { Gold Yard Intemational } \\
\text { Exchange Service }\end{array}$ \\
\hline Chiliza & Bongani & Prof & University of KwaZulu-Natal \\
\hline Domschke & Katha rina & Prof & University of Freiburg \\
\hline Duncan & Eve & $\begin{array}{l}\text { A/Pr } \\
\text { of }\end{array}$ & University of Cape Town \\
\hline Elbert & Thomas & Prof & $\begin{array}{l}\text { University of Konstanz, } \\
\text { Germany }\end{array}$ \\
\hline Erasmas & Fourie & $\mathrm{Mr}$ & Janssen Pha maceutica \\
\hline Fick & Linda & $\mathrm{Dr}$ & $\begin{array}{l}\text { Academy of Science of South } \\
\text { Africa }\end{array}$ \\
\hline J ewkes & Rachel & Prof & $\begin{array}{l}\text { South Afric an Medical } \\
\text { Research Council }\end{array}$ \\
\hline Kagee & Ashraf & Prof & University of Stellenbosch \\
\hline Kebogile & Mokwena & Prof & Sefako Makgatho University \\
\hline Klarenbeek & Tracy & Ms & National Research Council \\
\hline Koch-Krumrei & Marina & $\mathrm{Dr}$ & Leopoldina \\
\hline Langley & Gayle & $\mathrm{Dr}$ & University of the Witwatersrand \\
\hline Lund & Crick & Prof & University of Cape Town \\
\hline Lunsky & Anne & $\mathrm{Ms}$ & University of the Witwa tersrand \\
\hline Mabotha & Tebogo & $\mathrm{Dr}$ & $\begin{array}{l}\text { Academy of Science of South } \\
\text { Africa }\end{array}$ \\
\hline Majake & Tsepo & $\mathrm{Mr}$ & $\begin{array}{l}\text { Academy of Science of South } \\
\text { Africa }\end{array}$ \\
\hline Mandiwana & Marvin & Ms & $\begin{array}{l}\text { Academy of Science of South } \\
\text { Africa }\end{array}$ \\
\hline Maphosa & Stanley & $\mathrm{Mr}$ & $\begin{array}{l}\text { Academy of Science of South } \\
\text { Africa }\end{array}$ \\
\hline Masemola & Floyd & $\mathrm{Mr}$ & $\begin{array}{l}\text { Academy of Science of South } \\
\text { Africa }\end{array}$ \\
\hline Matlhabi & & Ms & Pretoria News \\
\hline Mngadi & Phaka mile & Ms & $\begin{array}{l}\text { Academy of Science of South } \\
\text { Africa }\end{array}$ \\
\hline Mpondo & Feziwe & $\mathrm{Dr}$ & $\begin{array}{l}\text { South Afric an Medical } \\
\text { Research Council }\end{array}$ \\
\hline Muchemwa & Marifa & Ms & University of the Witwa tersrand \\
\hline Muhati-Nya kundi & Linet Imbosa & $\mathrm{Dr}$ & University of J oha nnesburg \\
\hline Muhlanga & Ntsa kisi & Ms & University of the Witwatersrand \\
\hline Myers & Bronwyn & Prof & $\begin{array}{l}\text { South African Medical } \\
\text { Research Council }\end{array}$ \\
\hline Nissen & Jan & $\mathrm{Dr}$ & Leopoldina \\
\hline Nöthen & Markus & Prof & University Hospital of Bonn \\
\hline
\end{tabular}




\begin{tabular}{|c|c|c|c|}
\hline Padayachi & Raja & $\mathrm{Dr}$ & Sefako Makgatho University \\
\hline Petersen & Inge & Prof & University of KwaZulu-Natal \\
\hline Phalane-Legoale & Khutso & $\mathrm{Dr}$ & $\begin{array}{l}\text { Academy of Science of South } \\
\text { Africa }\end{array}$ \\
\hline Pillay & Yogan & $\mathrm{Dr}$ & Department of Health \\
\hline Pretorius & Edmarie & $\mathrm{Dr}$ & University of the Witwa tersrand \\
\hline Machaka & Ravhengani & Ms & Sefako Makgatho University \\
\hline Rawatlal & Nishola & $\mathrm{Dr}$ & $\begin{array}{l}\text { Psychologic al Soc iety of South } \\
\text { Africa }\end{array}$ \\
\hline Rietsc hel & Marcella & Prof & $\begin{array}{l}\text { Central Institute of Mental } \\
\text { Health }\end{array}$ \\
\hline Rösler & Frank & Prof & University of Hamburg \\
\hline Scholtz & Patsy & Ms & $\begin{array}{l}\text { Academy of Science of South } \\
\text { Africa }\end{array}$ \\
\hline Scott & Michelle & Ms & University of the Witwa tersrand \\
\hline Sefora & Moratabatho & $\mathrm{Mr}$ & $\begin{array}{l}\text { Department of Science and } \\
\text { Technology }\end{array}$ \\
\hline Sesoko & Oabile & $\mathrm{Mr}$ & $\begin{array}{l}\text { Department of Science and } \\
\text { Technology }\end{array}$ \\
\hline Shongwe & Steven & $\mathrm{Dr}$ & $\begin{array}{l}\text { WHO Regional Office for } \\
\text { Africa }\end{array}$ \\
\hline Sigida & Salome & Ms & $\begin{array}{l}\text { Human Sciences Research } \\
\text { Council }\end{array}$ \\
\hline Sinha & Subrata & Prof & $\begin{array}{l}\text { India Institute of Medical } \\
\text { Sc iences }\end{array}$ \\
\hline Stein & Dan & Prof & University of Cape Town \\
\hline Temane & Annie & $\mathrm{Dr}$ & University of J oha nnesburg \\
\hline Thom & Rita & Prof & University of the Witwa tersrand \\
\hline Van Rooyen & Niki & Ms & Kaimara \\
\hline Venier & Renate & Ms & $\begin{array}{l}\text { Academy of Science of South } \\
\text { Africa }\end{array}$ \\
\hline Williams & Abeda & Ms & J anssen Pha mac eutica \\
\hline Zawaira & Alexander & $\mathrm{Dr}$ & $\begin{array}{l}\text { Alexa nder Za wa ira Consulting } \\
\text { Sc ientists (Pty) Ltd }\end{array}$ \\
\hline Zungu & Nompumelelo & $\mathrm{Dr}$ & $\begin{array}{l}\text { Human Sciences Research } \\
\text { Council }\end{array}$ \\
\hline
\end{tabular}


2020

\section{Global Mental Health in an Era of \\ Sustainable Development: Research and Policy Priorities}

\section{Academy of Science of South Africa (ASSAf)}

Academy of Science of South Africa (ASSAf)

Academy of Science of South Africa (ASSAf), (2020). 'Global Mental Health in an Era of

Sustainable Development: Research and Policy Priorities. Symposium Proceedings'. DOI http://dx.doi.org/10.17159/ http://hdl.handle.net/20.500.11911/138

Downloaded from ASSAf Research Repository, Academy of Science of South Africa (ASSAf) 